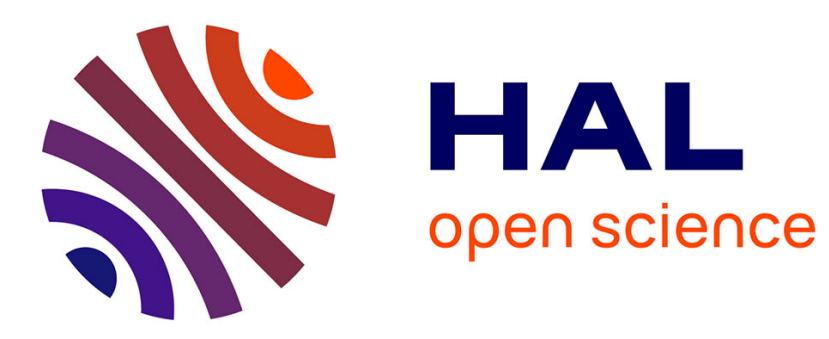

\title{
Transition metal oxides for combustion and depollution processes
}

\author{
Nicolas Bion, Fabien Can, Xavier Courtois, Daniel Duprez
}

\section{To cite this version:}

Nicolas Bion, Fabien Can, Xavier Courtois, Daniel Duprez. Transition metal oxides for combustion and depollution processes. Jacques C. Védrine. Metal Oxides in Heterogeneous Catalysis, Elsevier, pp.287-353, 2018, Metal oxides series, 978-0-12-811631-9. 10.1016/B978-0-12-811631-9.00006-5 . hal03110594

\section{HAL Id: hal-03110594 \\ https://hal.science/hal-03110594}

Submitted on 14 Jan 2021

HAL is a multi-disciplinary open access archive for the deposit and dissemination of scientific research documents, whether they are published or not. The documents may come from teaching and research institutions in France or abroad, or from public or private research centers.
L'archive ouverte pluridisciplinaire HAL, est destinée au dépôt et à la diffusion de documents scientifiques de niveau recherche, publiés ou non, émanant des établissements d'enseignement et de recherche français ou étrangers, des laboratoires publics ou privés. 
In "Metal Oxides in Heterogeneous Catalysis"

Ed. JC Vedrine (Elsevier Publ.), Chapter 6, p. 287-353 (2018)

DOI: 10.1016/B978-0-12-811631-9.00006-5

ISBN: 978-0-12-811631-9

\title{
Chapter 6
}

\section{Transition metal oxides for combustion and depollution processes}

\author{
N. Bion, F. Can, X. Courtois, D. Duprez* \\ IC2MP, Université de Poitiers, CNRS UMR 7285, 4 Rue Michel Brunet, TSA 51106, 86073 Poitiers Cedex, France
}

\section{Keywords}

Total oxidation on oxides, carbon monoxide oxidation, methane combustion, COV oxidation, NO decomposition, $\mathrm{NO}$ oxidation, $\mathrm{NH}_{3}$ oxidation, wet air oxidation.

\begin{abstract}
Transition metal oxides $(\mathrm{M}=\mathrm{Mn}, \mathrm{Co}, \mathrm{Fe}, \mathrm{Ni}, \ldots)$ are potential catalysts for application in combustion and depollution processes. Owing to huge improvements in their preparation, perovskites, spinels, hexaaaluminates and some other oxide structures can replace noble metals in a number of processes. In this chapter, the most recent advances in the use of oxides for total oxidation ( $\mathrm{CO}$, methane, COV, wet air oxidation) and for the treatment of nitrogen compounds ( $\mathrm{NOx}, \mathrm{NH}_{3}$, urea) will be reviewed. In every case, the most probable mechanism (Langmuir-Hinshelwood, Eley-Rideal, Mars-van Krevelen, ...) and the nature of active sites $\left(\mathrm{M}^{\mathrm{n+}} / \mathrm{M}^{\mathrm{n+1}}\right.$ ion pairs, acid-base sites,...) as well as the role of reactive oxygen species will be examined in the light of recent results and up-to-date concepts. Finally the outstanding progresses in the oxide synthesis allow to apply these concepts to the development of extremely active and more stable catalysts.
\end{abstract}




\subsection{Introduction}

In 1815, H. Davy invented the safety lamp for miners consisting in a mesh screen enrolled around the flame, thus protected from methane and dusts of the gallery. Some years later, Davy improved his invention by adding a Pt filament close to the flame [1]. This filament continued to burn the oil even though the flame was blown out allowing the gallery to remain brightly lit for a while. It was the first clear demonstration of the action of Pt for hydrocarbon combustion, the beginnings of the Catalysis Science [2]. Given the high prize of platinum and other noble metals, many efforts have been made in the $19^{\text {th }}$ century to replace these metals by oxide catalysts for catalyzing hydrocarbon combustion. But it was rapidly established that oxides showed a high tendency to form oxygenated intermediates during combustion. And in fact, during the second part of the $19^{\text {th }}$ century, the objective of many researchers has been to make these oxides highly selective. All these studies led to an extraordinary development of new processes for Chemical Industry $[3,4,5]$. A turning point in history of Catalysis by oxides was the First World War. Chemical war with poison gases (chlorine, phosgene, yperite,...) led to equip soldiers with protecting masks containing absorbent filters. These filters were improved by adding a catalyst favoring adsorption and elimination of decomposition products at ambient temperature (CO and other VOC), especially for use in confined spaces. One of the best catalysts was hopcalite, a mixture of Mn and Cu oxides (improved by addition of Co or Ag oxides). Hopcalite was discovered by scientists of the John Hopkins University (hop) associated with the University of California (cal) in the last years of the war and described in 1920 [6] and in more detail in 1941 [7]. Nearly a century later, hopcalite and more generally copper-manganese mixed oxides continue to attract intensive researches for improving their synthesis [8,9], their stability [10] and for various applications in VOC oxidation $[11,12,13]$.

Activity of single oxides for total oxidation is generally linked to the presence of $\mathrm{M}^{\mathrm{n}} / \mathrm{M}^{(\mathrm{n+1})+}$ ion pairs associated to oxygen vacancies, essential for the adsorption or the heterolytic splitting of the molecule (CO, hydrocarbons, ...) and for $\mathrm{O}_{2}$ activation. It is the reason why oxides such as $\mathrm{CO}_{3} \mathrm{O}_{4}, \mathrm{Fe}_{3} \mathrm{O}_{4}, \ldots$ which intrinsically possess two valences of the metal in their structure, are taken as good candidates for oxidation reactions $[14,15,16]$, even in absence of noble metal [17]. The density of active sites depending on the crystal face (mainly 111, 110), the oxide shape (nanorods, nanosheets, nanocubes, ...) plays a major role in oxidation reactions [18].

However, mixed oxides $\mathrm{M}_{1} \mathrm{M}_{2} \mathrm{O}$ x have generally superior performances owing to the presence of very active $\mathrm{M}_{1}{ }^{\mathrm{n}} / \mathrm{M}_{2}{ }^{(\mathrm{n}+1)+}$ ion pairs. Hopcalites $\mathrm{CuMnO}_{2}$ (see above) or CoFeOx $[19,20,21]$ are good examples of such catalytic materials. In these materials, $M_{1}$ and $M_{2}$ may initially have the same charge but they adapt the right valence under the reaction conditions: the reductant-to-oxygen ratio is then a critical parameter for a good activity. In certain mixed oxides, the metal $M_{1}$, not reducible and inactive per se, is able to induce a partial reduction of $M_{2}$ : the active site is a $\mathrm{M}_{2}{ }^{\mathrm{n}} / \mathrm{M}_{2}{ }^{(\mathrm{n}+1)+}$ ion pair stabilized by the presence of $\mathrm{M}_{1}$. $\mathrm{LaMnO}_{3}$ and $\mathrm{LaCoO}_{3}$ perovskites are remarkable examples of this category of materials $[22,23,24]$. There is coexistence of $\mathrm{Mn}^{4^{+}}$and $\mathrm{Mn}^{3+}$ ions in $\mathrm{LaMnO}_{3}$ while $\mathrm{CO}^{3+}$ and $\mathrm{Co}^{2+}$ ions are present together in $\mathrm{LaCoO}_{3}$. It is the reason why the conventional nomenclature of these perovskites is $\mathrm{LaMnO}_{3+\delta}$ and $\mathrm{LaCoO}_{3-\delta}$ respectively, with $\delta=0.15$ for the manganite and $\delta=0.1-0.3$ for the cobaltite. Substitution of one or two cations of the binary oxides by other elements is a classical way to improve activity of the oxide catalysts widely used in oxidation reactions (perovskites, 
hexaaluminates, spinels, ...). Some indication will be given about this strategy but it is not possible to be exhaustive because of the huge number of studies dealing with ternary and quaternary oxides, particularly in the vast world of perovskite-based materials. In parallel with oxides and mixed oxides prepared by sophisticated methods, waste derived materials were developed as active oxidation catalysts. A number of industrial wastes (for instance, red muds from aluminum industry) contain several oxides (iron, manganese, ...) which are currently used in oxidation. Bennett et al. have recently reviewed these applications [25].

Carbon-Hydrogen bond activation is a crucial step of the reactivity of noble metals for alkane oxidation $[26,27]$. On these metals, adsorbed O species can diffuse rapidly at the catalyst surface to reach the site where the reactant $(\mathrm{CO}$, hydrocarbons, $\mathrm{VOC}, \ldots)$ is adsorbed [28]. Oxygen mobility over oxides is generally much slower and may become a determining step in the catalytic reaction. As this will be seen in section 6.2, the so-called Mars and Van Krevelen mechanism, adapted for total oxidation, requires a significant mobility at the surface or inside the solid [29]. It is the reason why O mobility was investigated, mainly by ${ }^{16} \mathrm{O} /{ }^{18} \mathrm{O}$ exchange, on single oxides [30], perovskites [31], hexaaluminates [32,33] or Yttrium-Stabilized Zirconia (YSZ) [34,35].

After a short overview of the mechanisms of reaction with $\mathrm{CH}_{4}$ and $\mathrm{CO}$ as model reactant (section 6.2), the complete oxidation reactions will be reviewed by class of compound: carbon monoxide (section 6.3), methane (section 6.4), other hydrocarbons and oxygenates (section 6.5), other VOC (Cl- and S-containing compounds, section 6.6), automotive soots (section 6.7), nitrogen compounds within their implication in DeNOx catalysis (section 6.8). All these oxidation reactions are carried out in gas phase. An interesting application of oxide catalysts concerns their use in aqueous phase for the so-called wet-air oxidation, which will be reviewed in section 6.9. For evident reason of space in this chapter and because several reviews were already published on the same topics, priority will be given to the most recent investigations, in the 2012-2016 period.

\subsection{Overview on the mechanisms of total oxidation reactions over metal oxides}

\subsubsection{Different types of mechanisms for total oxidation}

Recently, Liang and Fang have reviewed the different types of mechanisms that can predict the oxidation kinetics of various organic compounds, mainly hydrocarbons [36 ]. In the Langmuir-Hinshelwood (LH) mechanism, both hydrocarbon and oxygen are chemisorbed on the catalysts surface and react according to a bimolecular reaction. If the hydrocarbon and oxygen compete for the same sites, the kinetic derivation of the LH mechanism leads to the classical rate equation:

$$
r_{L H}=k_{C} \frac{K_{C} P_{C} \cdot K_{O} P_{O}}{\left(1+K_{C} P_{C}+K_{O} P_{O}\right)^{2}}
$$

where $r$ is the rate of $\mathrm{HC}$ consumption, $k_{c}$, the kinetic constant, $P_{C}$ and $P_{O}$, the partial pressure of $\mathrm{HC}$ and oxygen, $K_{c}$ and $K_{0}$ their respective adsorption constants. Depending on the relative adsorption strength of $\mathrm{HC}_{\mathrm{C}}$ or $\mathrm{O}_{2}$, kinetic orders may vary from -1 for the most strongly adsorbed reactant to +1 for the reactant that is weakly adsorbed. If the hydrocarbon and oxygen are adsorbed on distinct sites, the equation becomes:

$$
r_{L H}=k_{C} \frac{K_{C} P_{C} \cdot K_{O} P_{O}}{\left(1+K_{C} P_{C}\right)\left(1+K_{O} P_{O}\right)}
$$

Positive orders are then observed for all the reactants. 
In the Eley-Rideal (ER) mechanism, $\mathrm{O}_{2}$ is too weakly adsorbed so that it reacts directly from the gas phase with the adsorbed hydrocarbon molecule. The kinetic derivation of this mechanism leads to the following rate equation:

$$
r_{E R}=k_{C} \frac{K_{C} P_{C} \cdot P_{O}}{\left(1+K_{C} P_{C}\right)}
$$

The kinetic order is +1 with respect to oxygen and comprised between zero $(H C$ strongly adsorbed) and $+1(H C$ weakly adsorbed) for the hydrocarbon.

But, in fact, the reverse (gas phase $\mathrm{HC}$ or CO reacts with adsorbed O) can occur. Eq. 6.3a becomes:

$$
r_{E R}=k_{O} \frac{K_{O} P_{O} \cdot P_{C}}{\left(1+K_{O} P_{O}\right)}
$$

The Mars and van Krevelen (MvK) mechanism was initially proposed to explain the kinetic of selective oxidation reactions over vanadium oxide catalysts [29]. In this mechanism, the hydrocarbon is oxidized by the metal cation with concomitant insertion of the oxygen of the surface leading to $\mathrm{CO}_{2}, \mathrm{H}_{2} \mathrm{O}$ and an oxygen vacancy (rate of this step: $r_{c}$; kinetic constant: $k_{c}$ ) while the oxygen vacancy is refilled by gaseous $\mathrm{O}_{2}$ (rate $r_{0}$; kinetic constant: $\left.k_{0}\right)$. The steady state is reached for $r c=r o$, which leads to rate equation:

$$
r_{M k V}=\frac{k_{C} P_{C} \cdot k_{O} P_{O}}{v k_{C} P_{C}+k_{O} P_{O}}
$$

where $v$ is the overall stoichiometry of the reaction (one molecule of $\mathrm{HC}$ requires $v$ moles of $\mathrm{O}_{2}$ ). As discussed by Vannice [37], this mechanism implies that (i) both oxidation step and reoxidation of the surface are of first order with respect to $\mathrm{HC}$ and $\mathrm{O}_{2}$, respectively, (ii) $\mathrm{O}$ surface sites are free of carbon intermediates.

In the literature specific of perovskite-based catalysts, oxidation mechanisms are often presented as "suprafacial" or "intrafacial" mechanisms [23,38,39,40]. Suprafacial mechanisms mean that only surface oxygens are involved in the catalytic reaction: they correspond to LH or ER classical mechanisms, but also to the MvK mechanism in which the steps of $\mathrm{O}$ abstraction and $\mathrm{O}$ vacancy refilling are restricted to surface atoms. In intrafacial mechanisms, bulk oxygens are involved in the oxidation reaction. This is typically the case of MvK mechanisms with participation of all the oxygens of the oxide network.

\subsubsection{Mechanisms of carbon monoxide oxidation}

Kinetics and mechanisms of CO oxidation over transition metal oxides was reviewed by Royer and Duprez in 2011 [16]. Reaction kinetics depend very much on the nature of oxide, its exposed facet, its pretreatment (reducing or oxidizing, in wet or dry atmospheres, etc...). Figure 6.1 illustrates the effect of oxide pretreatment on the activity of several oxides for CO oxidation. This figure shows that the most active oxides (with the lowest $\mathrm{T}_{1} / 2$ ) are also the most sensitive catalysts to moisture in the gases (representative points above the diagonal). 


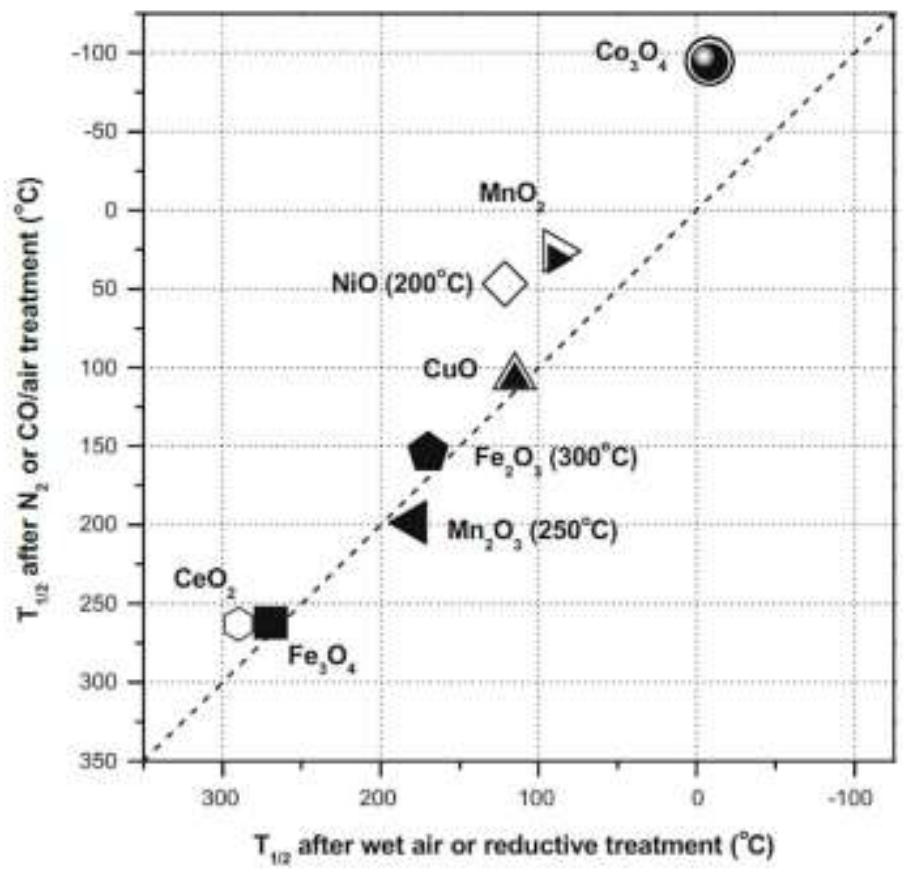

Figure 6.1. Activity of various oxides in $\mathrm{CO}$ oxidation. Temperature $\mathrm{T}_{1} / 2$ for a $50 \%$ conversion after pretreatment in dry $\mathrm{N}_{2}$ or in a $1 \% \mathrm{CO} /$ air mixture as a function of $\mathrm{T}_{1} / 2$ after pretreatment in wet air or in reducing atmosphere. The pretreatments were carried out at $150^{\circ} \mathrm{C}$ or at the temperature noted in parentheses. Reaction conditions: $0.15 \mathrm{~g}$ catalyst sample, $1.0 \mathrm{vol} \% \mathrm{CO}$ in air, $50 \mathrm{~mL} / \mathrm{min}$. From ref. 41

All the mechanisms depicted in 6.2.1 were proposed for CO oxidation. However, LH and ER mechanisms seem to represent, at the best, kinetics, spectroscopic and ${ }^{18} \mathrm{O}$ labeled experiments carried out at low temperature.

For instance, $\mathrm{Yu}$ et al. have proposed the following reaction scheme for $\mathrm{CO}$ oxidation over $\mathrm{Co}_{3} \mathrm{O}_{4}$ at $-80^{\circ} \mathrm{C}[41]$ :

$$
\begin{aligned}
& \mathrm{CO}+\mathrm{Co}^{3+} \rightarrow \mathrm{CO}-\mathrm{Co}^{3+} \\
& \mathrm{O}_{2}+\mathrm{Co}^{3+}-\mathrm{VO}_{\mathrm{O}}-\mathrm{CO}^{3+} \rightarrow \mathrm{CO}^{3+}-\mathrm{O}_{2}^{-}-\mathrm{CO}^{2+} \\
& \mathrm{CO}-\mathrm{Co}^{3+}+\mathrm{Co}^{3+}-\mathrm{O}_{2}^{-}-\mathrm{Co}^{2+} \rightarrow \mathrm{CO}_{2}(\mathrm{~g})+\mathrm{Co}^{3+}+\mathrm{Co}^{3+}-\mathrm{O}^{-}-\mathrm{Co}^{2+} \\
& \mathrm{CO}-\mathrm{CO}^{3+}+\mathrm{Co}^{3+}-\mathrm{O}-\mathrm{CO}^{2+} \rightarrow \mathrm{CO}_{2}+\mathrm{Co}^{3+}-\mathrm{VO}-\mathrm{CO}^{3+}
\end{aligned}
$$

This sequence of elementary steps corresponds to a L-H mechanism with adsorption of $\mathrm{CO}$ and $\mathrm{O}_{2}$ on different sites ( $\mathrm{Co}^{3+}$ for $\mathrm{CO}$ and an oxygen vacancy between two adjacent $\mathrm{Co}$ ions), which explains why relatively close positive orders with respect to $\mathrm{O}_{2}$ and $\mathrm{CO}$ were obtained (between 0.2 and 0.5 ). This mechanism is coherent with the model of surface structure of $\mathrm{CO}_{3} \mathrm{O}_{4}$ developed by Broqvist et al. for their DFT study [42]. However, in the Broqvist's model, there are two types of surface oxygens (denoted $\mathrm{O} w$ and $\mathrm{O}$ s) whose abstraction requires different energies. A MvK mechanism cannot thus be discarded in which each of these oxygens plays an inequivalent role in adsorption and surface reaction. Yu et al. have also noticed that the high activity of $\mathrm{Co}_{3} \mathrm{O}_{4}$ can be linked to a metal-oxygen bond energy much lower in this oxide than in inactive $\left(\mathrm{TiO}_{2}\right)$ or less active oxides ( $\mathrm{MnO}_{2}$ for instance). 
Mechanisms of CO oxidation over oxide catalysts may depend on the exposed face. Therefore, mechanistic studies with polycrystalline solids can lead to erroneous interpretations. For instance, CO oxidation over the (100) face of $\alpha-\mathrm{Fe}_{2} \mathrm{O}_{3}$ seems to follow an E-R mechanism with gaseous CO reacting on $\mathrm{O}_{\text {ads }}$ while a $\mathrm{LH}$ mechanism would be favored on the oxygen terminated (0o01) surface $[43,44]$. The postulated E-R mechanism on the (100) face of $\mathrm{Fe}_{2} \mathrm{O}_{3}$ was proven on the basis of FTIR and ${ }^{18} \mathrm{O}$ labeling studies. Iron oxide surface is essentially covered by adsorbed oxygen and $\mathrm{CO}_{2}$. Intermediates such as monodentate carbonates are detected by DRIFT but there is no evidence of adsorbed CO in the course of the reaction [44]. However, the mechanism on $\mathrm{Fe}_{2} \mathrm{O}_{3}(100)$ would be more complex than a classical E-R mechanism. DFT studies reveal that a first molecule of $\mathrm{CO}$ is strongly bound to some Fe ions of the surface, which destabilizes the other O-Fe bonds [43]. A second molecule of $\mathrm{CO}$ could then approach the surface and react with the $\mathrm{O}$ atoms weakly bound to Fe. The E-R mechanism corresponds to this last step of the overall process as depicted in eq. 6.6.

$$
\begin{aligned}
& \mathrm{Fe}_{2} \mathrm{O}_{3}+\mathrm{CO}_{\mathrm{g}} \rightarrow \mathrm{Fe}_{2} \mathrm{O}_{3}(\mathrm{CO}) \\
& \mathrm{Fe}_{2} \mathrm{O}_{3}(\mathrm{CO}) \rightarrow \mathrm{Fe}_{2} \mathrm{O}_{2}(\mathrm{CO})+\mathrm{CO}_{2} \mathrm{~g} \\
& \mathrm{Fe}_{2} \mathrm{O}_{2}(\mathrm{CO})+\mathrm{O}_{2} \rightarrow\left[\mathrm{Fe}_{2} \mathrm{O}_{2}(\mathrm{CO})\right]_{2} \\
& {\left[\mathrm{Fe}_{2} \mathrm{O}_{2}(\mathrm{CO})\right] \mathrm{O}_{2}+\mathrm{CO}_{\mathrm{g}} \rightarrow \mathrm{Fe}_{2} \mathrm{O}_{3}(\mathrm{CO})+\mathrm{CO}_{2 \mathrm{~g}}}
\end{aligned}
$$

\subsubsection{Mechanisms of methane oxidation}

Methane is an hydrocarbon extremely refractory to oxidation. Palladium-based materials are the most active catalysts for methane combustion $[45,46]$. Oxidation generally starts at $300-350^{\circ} \mathrm{C}$. Even though they operate at higher temperatures, oxide catalysts and especially perovskites can be good alternatives to the use of noble metals [23], particularly for heat production [47]. As for CO oxidation, the reaction can obey different mechanisms depending on the oxide used as catalyst. The simplest model is the $L-H$ mechanism with coadsorption of $\mathrm{CH}_{4}$ and $\mathrm{O}_{2}$ on the same sites formed by a Metal-Oxygen pair of the oxide surface. In the study of Pengpanich et al. [48], this mechanism leads to the best fitting for the kinetics of $\mathrm{CH}_{4}$ oxidation over $\mathrm{CeO}_{2}-\mathrm{ZrO}_{2}$ mixed oxides. The resulting rate expression is analogous to that of Eq. 6.1 with terms of $\mathrm{O}_{2}$ adsorption in $\mathrm{Po}^{1 / 2}$ instead of $\mathrm{P}_{\mathrm{O}}$. Penganich et al. found that oxygen was more strongly adsorbed than $\mathrm{CH}_{4}$, adsorption energy of $\mathrm{O}_{2}$ on $\mathrm{Ce}_{0.75} \mathrm{Zr}_{0.25} \mathrm{O}_{2}$ being 2.4 times higher than that of methane in the $400-600^{\circ} \mathrm{C}$ temperature range of reaction. A close examination of the data of Penganich et al. shows that the $\mathrm{L}-\mathrm{H}$ model was ascertained on the basis of the coefficient of correlation $\left(\mathrm{R}^{2}=0.994\right)$ better than that of an $\mathrm{E}-\mathrm{R}$ model with $\mathrm{CH}_{4}$ reacting on adsorbed oxygen ( $\mathrm{R}_{2}=0.929$ for Eq. 6.3b with a term in $\mathrm{Po}^{1 / 2}$ instead of $\left.\mathrm{PO}_{\mathrm{O}}\right)$.

Contrasting with the previous study, Belessi et al. showed that the $\mathrm{CH}_{4}$ oxidation reaction on ferrite-like perovskite catalysts obeyed an E-R mechanism, rather than a L-H model [49]. They also demonstrated that the E-R rate equation could be assimilated to power-law kinetics with apparent orders close to the experimental values (Eq. 6.7). 


$$
r_{E R}=k_{O} \frac{\left(K_{O} P_{O}\right)^{1 / 2} \cdot P_{C H_{4}}}{1+\left(K_{O} P_{O}\right)^{1 / 2}} \approx k_{O}^{\prime}\left(K_{O} P_{O}\right)^{0.5-a} P_{C H_{4}}^{b}
$$

Experimental orders, measured in the $420-620^{\circ} \mathrm{C}$ temperature range, are comprised between 0 and 0.5 for $\mathrm{O}_{2}$ and close to 1 for methane, which is in full agreement with Eq. 6.7.

Methane oxidation requires high temperature of reaction, above $400^{\circ} \mathrm{C}$ for most oxides. Oxygen mobility can thus be very high, which allows MvK mechanisms to occur. For instance, Zavada et al. showed that $\mathrm{CH}_{4}$ oxidation over $\mathrm{CO}_{3} \mathrm{O}_{4}$ shifted gradually from a suprafacial mechanism of the $\mathrm{E}-\mathrm{R}$ type at $400^{\circ} \mathrm{C}$ to a $\mathrm{MvK}$ mechanism implying cobalt-oxo species above $600^{\circ} \mathrm{C}$ [50]. Changes of mechanisms may also occur depending on the catalyst composition. By studying $\mathrm{CH}_{4}$ oxidation over a series of $\mathrm{Ce}_{x} \mathrm{Sn}_{(1-x)} \mathrm{O}_{2}$ catalysts, Liu et al. concluded that the MvK model was preferred over the Sn-rich catalysts [51]. Figure 6.2 illustrates the reaction scheme proposed by Liv et al.

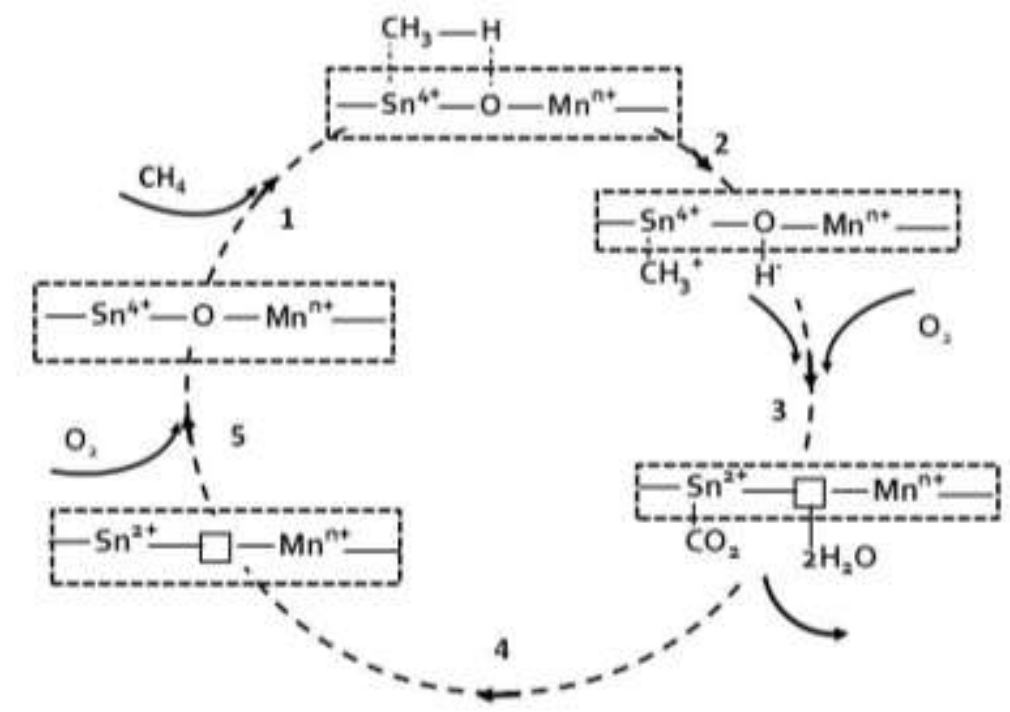

Figure 6.2. Mars and van Krevelen (MvK) mechanism of methane oxidation over $\mathrm{Ce}_{x} \mathrm{Sn}_{(1-x)} \mathrm{O}_{2}$ catalysts. From ref. [51].

Similarly, by coupling in situ electrical conductivity and $\mathrm{CH}_{4}$ oxidation measurements over a series of $\mathrm{LaCO}_{x} \mathrm{Fe}_{(1-}$ x) $\mathrm{O}_{3}$ perovskites, Popescu et al. established that the reaction obeyed a MvK mechanism on $\mathrm{LaFeO}_{3}$ while a suprafacial mechanism was preferred on $\mathrm{LaCoO}_{3}\left[5^{2}\right]$. Both mechanisms can occur on $\mathrm{LaCo}_{x} \mathrm{Fe}_{(1-x)} \mathrm{O}_{3}$ perovskites. To clearly demonstrate the role of oxygen mobility in MvK mechanisms, it is necessary to add a component to the oxide catalyst allowing a fast $\mathrm{CH}_{4}$ activation. A dual bed catalyst constituted of $\mathrm{LaMnO}_{3}$ and YSZ (yttrium-stabilized zirconia) showed exceptional performance for $\mathrm{O}_{2}$ activation, much better than with any of the individual components [34,35]. To take advantage of this property in $\mathrm{CH}_{4}$ oxidation, a small amount of palladium was added to YSZ allowing good activation of the $\mathrm{CH}_{4}$ molecule. 


\subsection{Oxidation of carbon monoxide}

$\mathrm{CO}$, which is highly toxic, is an important constituent of the automotive exhaust gases and its abatement is crucial not only to limit the environment pollution but also to prevent health damage or death. The CO molecule is also inevitably produced in the reforming process which aims to generate hydrogen. When hydrogen is produced to feed a proton-exchanged membrane fuel cell, few ppm of CO can cause dramatic poisoning of the electrode. Low-temperature CO oxidation is then essential to prevent the deactivation of the cell. It certainly makes the catalytic $\mathrm{CO}$ oxidation one of the most investigated catalytic reactions. Precious metals such as $\mathrm{Au}$, Pt, Pd, and Rh supported catalysts are highly active for catalytic CO oxidation. However the increasing price as well as decreasing reserves of noble metals makes essential the development of cheaper catalysts constituted of more abundant metals but with comparable catalytic activity. Transition metal oxide catalysts appear as very interesting alternative of the noble metal-based catalysts and reviews regularly update the works which report a better comprehension of the catalytic mechanism as well as the optimization of the transition metal oxidebased formulation with improved catalytic performances [16]. Cobalt, Cerium, Manganese, Iron and Copper oxides are among the most studied samples for catalytic CO oxidation.

\subsubsection{Cobalt oxide}

For half a century, unsupported $\mathrm{CO}_{3} \mathrm{O}_{4}$ is known as very active base oxide catalyst for $\mathrm{CO}$ oxidation [53]. A significant result was obtained by Haruta et al.[54] who reported that in very dried conditions of reactant flow, $\mathrm{CO}$ oxidation was observed over the $\mathrm{C}_{3} \mathrm{O}_{4}$ metal oxide at temperatures as low as $-54^{\circ} \mathrm{C}$. With this study, they also demonstrated that the cobalt oxide was dramatically sensitive to the presence of water traces (Figure 6.3). Indeed they clearly observed the inhibiting effect of water by comparing the light-off temperature $T_{50}$ which increased from $-54^{\circ} \mathrm{C}$ for $850 \mathrm{ppb} \mathrm{H}_{2} \mathrm{O}$ up to $50^{\circ} \mathrm{C}$ for $3 \mathrm{ppm} \mathrm{H}_{2} \mathrm{O}$ and $90^{\circ} \mathrm{C}$ for $0.6 \% \mathrm{H}_{2} \mathrm{O}$.

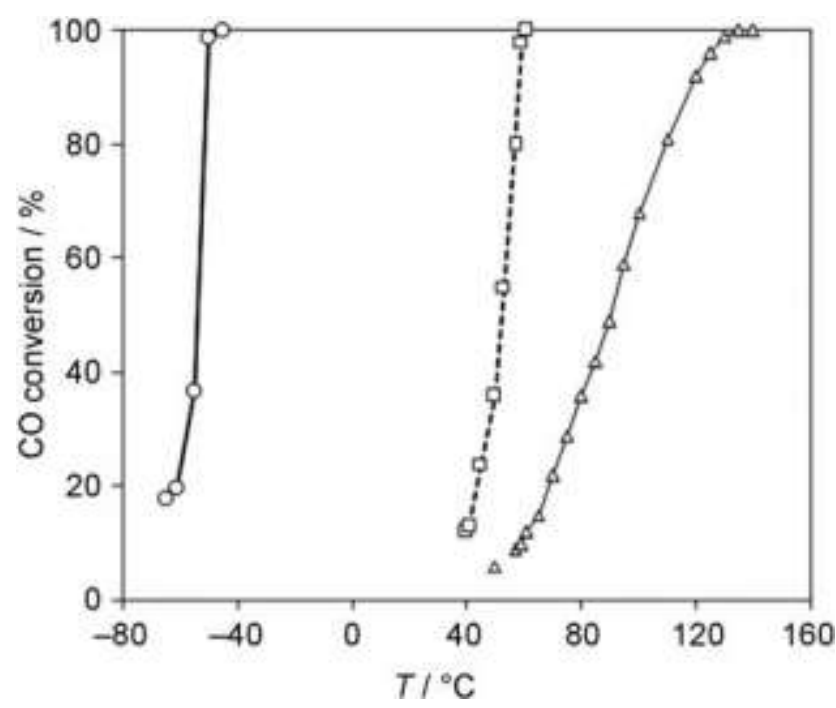

Figure 6.3 : Effect of water on $\mathrm{CO}$ conversion over $\mathrm{CO}_{3} \mathrm{O}_{4}$. Dry conditions: $850 \mathrm{ppb}_{2} \mathrm{O}$ (trapping of moisture on zeolite at $80^{\circ} \mathrm{C}$ ); normal conditions: 3 ppm $\mathrm{H}_{2} \mathrm{O}$; wet conditions $6000 \mathrm{ppm} \mathrm{H}_{2} \mathrm{O}$ : dry (o); normal $(\square)$; wet $(\Delta)$. Taken from Ref. $[54]$. 
Contrary to $\mathrm{H}_{2} \mathrm{O}, \mathrm{CO}_{2}$ is not an inhibitor but the formation of carbonate species might lead to a deactivation of the catalyst when the reaction is performed at low temperatures. However, Jansson et al.[55] showed that carbonyls, carbonates and other surface $\mathrm{C}$ species were not directly responsible of cobalt oxide deactivation. They concluded suggesting that the slow deactivation during the reaction was likely due to a surface restructuration hindering the $\mathrm{Co}^{2+} / \mathrm{Co}^{3+}$ redox at the origin of the good activity. They also demonstrated that the active sites of the $\mathrm{CO}_{3} \mathrm{O}_{4}$ were regenerated with oxidative step at $250^{\circ} \mathrm{C}$.

Recent research focused on nanostructured cobalt oxide catalysts $[56,57,58] . \mathrm{Co}_{3} \mathrm{O}_{4}$ has a spinel structure with a cubic close-packed array of $\mathrm{O}^{2-}$ in which one eighth of the tetrahedral sites and half of the octahedral sites are occupied by $\mathrm{CO}^{2+}$ and $\mathrm{Co}^{3+}$ respectively. Xie et al. reported in 2009 a remarkable illustration of the structurereactivity relationship [59]. The activity as well as the stability of $\mathrm{Co}_{3} \mathrm{O}_{4}$ for $\mathrm{CO}$ oxidation reaction was considerably improved by changing the morphology of the oxide from spherical nanoparticles to nanorods. The difference of activity was associated to the surface enrichment in nanorods of $\mathrm{Co}^{3+}$ sites which are known as active site for the $\mathrm{CO}$ adsorption [6o]. Indeed the (110) planes which contain mainly $\mathrm{Co}^{3+}$ sites are preferentially exposed in the nanorods while the spherical nanoparticles of $\mathrm{CO}_{3} \mathrm{O}_{4}$ are only enclosed of $\mathrm{Co}^{2+}$-containing (111) and (001) planes. Morphology-dependent activity of $\mathrm{CO}_{3} \mathrm{O}_{4}$ was confirmed by $\mathrm{Hu}$ et al [61]. These authors showed that $\mathrm{CO}_{3} \mathrm{O}_{4}$ nanobelts which have a predominance of (011) facets were much more active than nanocubes terminated by the (001) planes. Contrary to Xie et al., they calculated a difference of TOF depending on the exposed crystal plane with TOF of $\mathrm{CO}^{3+}$ sites on (011) planes 2.7 times higher than those on (oo1) planes. Note that the crystal sizes of nanorods, nanobelts or nanocubes described previously are larger than $10 \mathrm{~nm}$. Recently lablokov et al. reported a study which aims to investigate the size effect in the CO oxidation activity over cobalt oxide catalysts by varying the size of the $\mathrm{Co}_{3} \mathrm{O}_{4}$ nanoparticles 3.5 and $12.2 \mathrm{~nm}$ [62]. They concluded that the $\mathrm{CO}$ oxidation was clearly structure sensitive over $\mathrm{Co}_{3} \mathrm{O}_{4}$ with higher activity for 5 to $8 \mathrm{~nm}$ particles and they again confirmed the crucial role of $\mathrm{Co}^{3+}$ by establishing a correlation between the $\mathrm{Co}^{3+}$ trivalent oxidation state and the CO oxidation rate using X-ray photoelectron spectroscopy. For smaller and larger particles the intrinsic activity decreased drastically (Figure 6.4). It completes the precursor work reported by Yu Yao in which the intrinsic activity varied little with BET surface area in the case of large particles [53].

Finally, the influence on $\mathrm{CO}$ oxidation activity of the pretreatment effect for low-temperature calcined $\mathrm{Co}_{3} \mathrm{O}_{4}$ oxides was reported [63]. Typically, when calcined below $400{ }^{\circ} \mathrm{C}$, a pre-treatment of $\mathrm{CO}_{3} \mathrm{O}_{4}$ in dry air, in inert or reducing oxidizing dry atmospheres $\left(\mathrm{N}_{2}\right.$ or $\left.\mathrm{CO} / \mathrm{air}\right)$ in the temperature range of $150-250^{\circ} \mathrm{C}$ induces the formation of surface oxygen vacancies resulting in an enhancement of the catalytic activity at a temperature as low as -80 ${ }^{\circ} \mathrm{C}$. 


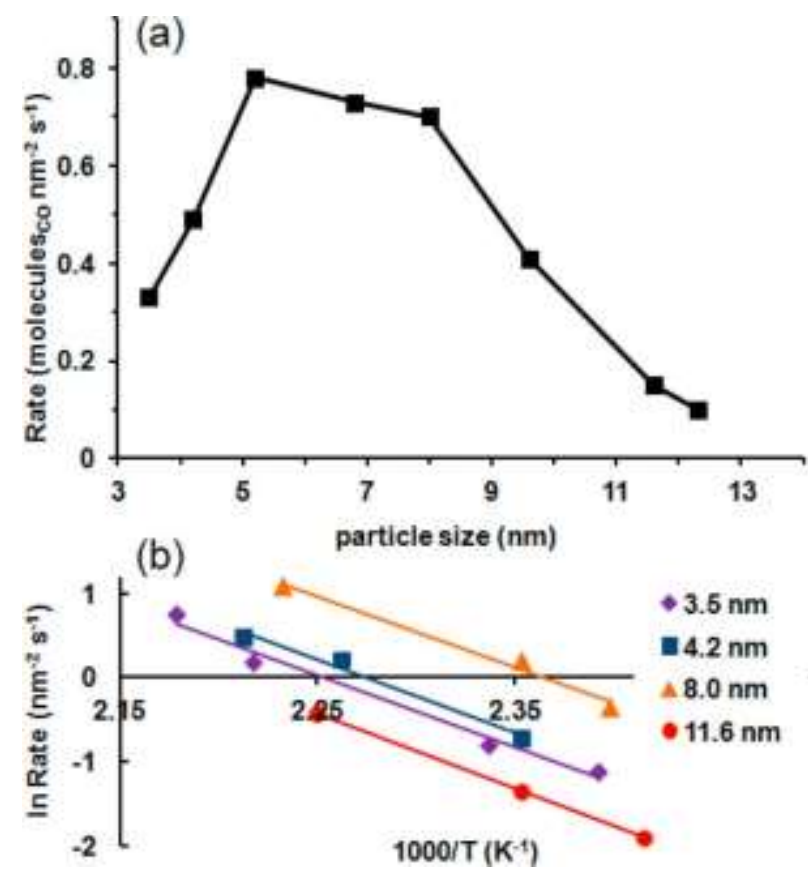

Figure 6.4: (a) $\mathrm{CO}$ oxidation activity $\left(\mathrm{CO}+\mathrm{O}_{2}, 2 \%\right.$ each, $150^{\circ} \mathrm{C}$ ) vs particle size, (b) Arrhenius plots for $\mathrm{Co}_{3} \mathrm{O}_{4} / \mathrm{MCF}-17$ samples. Taken from [62]

\subsubsection{Cerium oxides}

The considerable attention that has received cerium oxide in numerous catalytic reactions is generally associated to the redox properties of this oxide [64]. For example, the application in automobile industry of ceria and ceria-based oxides as component of the Three-Way Catalysts (TWC) is related to their capacity to store and release oxygen, classically known as Oxygen Storage Capacity (OSC). The pioneering work to measure OSC in cerium-based oxides was established by $\mathrm{Yao}$ et al. who used the transient oxidation of $\mathrm{CO}$ in absence of $\mathrm{O}_{2}$ in the gas-phase using a pulse injection method [65]. The measurement is based on the fact that the $\mathrm{CO}$ oxidation proceeds over ceria via a Mars-van Krevelen mechanism involving the participation of $O$ atoms from the lattice by oxygen vacancy generation and their subsequent replenishment with gas-phase oxygen [66]. The association of ${ }^{16} \mathrm{O} /{ }^{18} \mathrm{O}$ isotopic exchange and OSC measurements were shown very powerful to investigate the oxygen activation process [67] as well as oxygen diffusivities on the surface and bulk of the ceria and ceria-basedmaterials $[68,69]$. By combining the FTIR spectroscopy to these techniques, correlation was obtained between adsorption and exchange of superoxide $\mathrm{O}_{2}{ }^{-}$species and OSC values measured at $400^{\circ} \mathrm{C}$ [70]. Fornasiero et al. very recently published an exhaustive review in which the main results obtained by OSC measurement and correlation with $\mathrm{CO}$ oxidation have been largely described [71]. Recent literature on $\mathrm{CO}$ oxidation over pure ceria focused on the structure-activity relationship $[56,72,73]$. Contrary to cobalt oxide, a consensus was rapidly found on the basis of studies over polycrystalline materials that the $\mathrm{CO}$ oxidation was a structure sensitive reaction on ceria [74]. Recent advances in nanostructured ceria synthesis [75] and in transmission electron microscopy enabled a better determination of the most active facets and theoretical studies confirmed the influence of the crystallographic plane on the $\mathrm{CO}$ adsorption and the oxygen vacancy formation [76]. The higher catalytic activity in CO oxidation is obtained in nanorods that preferentially exposed (110) planes. This morphology also 
exhibits the higher lattice oxygen mobility as determined by oxygen isotopic exchange. There is a very good correlation between oxygen mobility and CO oxidation which follow the same trends: rods with (110) and (100) facets > cubes with (100) facets > octahedra with (111) facets [72]. Another important correlation exists between the concentration of large-sized oxygen vacancy clusters and the reactivity of ceria nanoparticles [77]. An elegant illustration of the crucial role of oxygen vacancies was given by Gao et al. who prepared pits confined in three-atomic-layer thin ceria sheet as model material to study the CO oxidation at different sites $[78,79]$. The creation of this coordinately unsaturated pit-surrounded cerium sites (average coordination numbers of 4.6 ) induces the generation of more oxygen vacancies. It results in very active sites not only for $\mathrm{O}_{2}$ activation but also for $\mathrm{CO}$ adsorption and diffusion. As a consequence the specific nanostructure lowered the apparent activation energy of CO oxidation from 122.9 to $61.7 \mathrm{~kJ} \mathrm{~mol}^{-1}$ and drastically decreased the $\mathrm{CO}$ conversion temperatures (Figure 6.5).

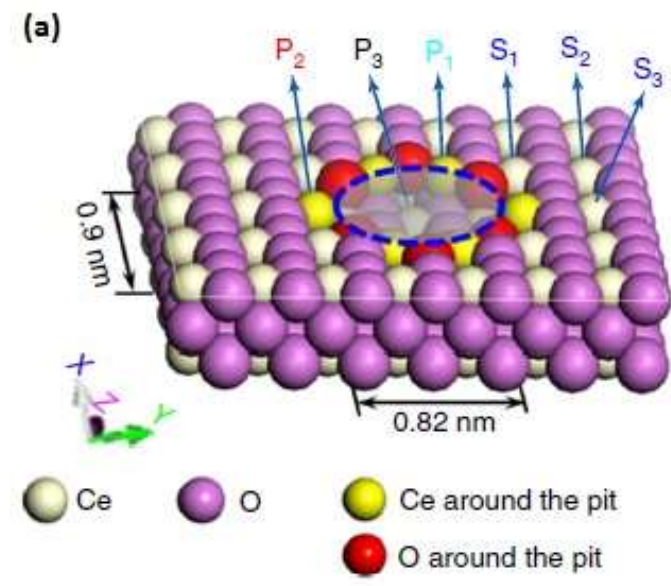

(b)

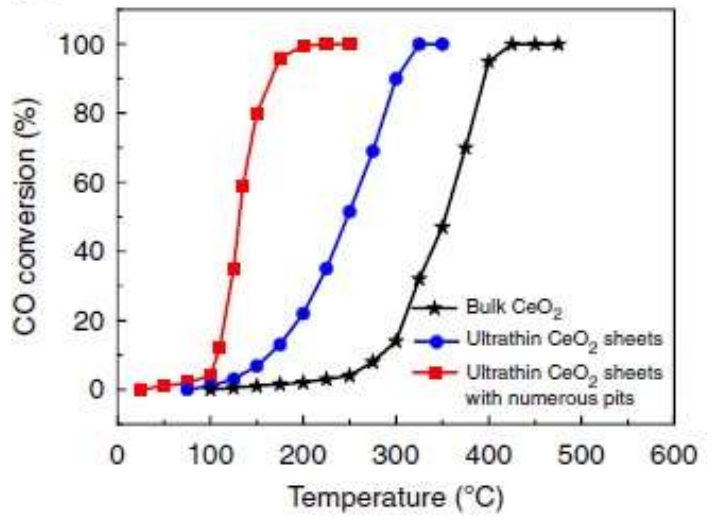

Figure 6.5 : (a) Overhead and top views of schematic structures for the three-atom-thick $\mathrm{CeO}_{2}$ sheets with a pit size of $0.90 \mathrm{~nm} \times 0.82 \mathrm{~nm}$; the $\mathrm{CO}$ molecules prefer to adsorb at $\mathrm{P}_{2}$ site, while the $\mathrm{O}_{2}$ molecules tend to adsorb and dissociate at the adjacent $\mathrm{P}_{1}$ sites. (b) Catalytic activity for $\mathrm{CO}$ oxidation versus reaction temperatures (experimental error: $\pm 3 \%$ ). Taken from [78]

\subsubsection{Manganese oxides}

Gao et al. studied the doping of $\alpha-\mathrm{MnO}_{2}$ by transition metal like $\mathrm{Fe}, \mathrm{Ni}$, Co and $\mathrm{Cu}$ for the $\mathrm{CO}$ oxidation reaction. On the basis of experimental data and DFT calculations, the authors concluded that the better activity of Cu doping (Figure 6.6 ) is associated with the easier formation of oxygen vacancies in the $\mathrm{MnO}_{2}$ lattice which is considered as the rate-determining step for CO oxidation [80]. 


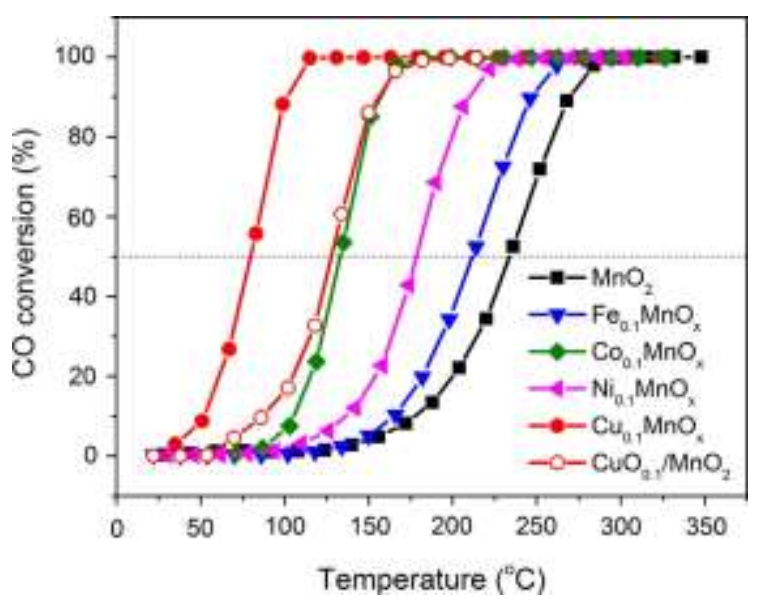

Figure 6.6: $\mathrm{CO}$ oxidation activity tests of the $\mathrm{MnO}_{2}, \mathrm{CuO}_{0.1} / \mathrm{MnO}_{2}$, and $\mathrm{Fe}-$, $\mathrm{Co}-$, $\mathrm{Ni}-$, and $\mathrm{Cu}$-doped $\mathrm{MnO}_{2}$ catalysts. Taken from [8o]

$\alpha-\mathrm{MnO}_{2}$ was chosen because other authors previously synthesized $\alpha-, \beta-, \gamma^{-}$, and $\delta-\mathrm{MnO}_{2}$ nanorods by the hydrothermal method and compared their catalytic performances [81]. An effect of the phase structure was clearly evidenced since the activities of the catalysts decreased in the order $\alpha-z \delta->\gamma->\beta-\mathrm{MnO}_{2}$. The low activity of $\beta-\mathrm{MnO}_{2}$ phase was associated with a collapse of its structure during the Mars-Van Krevelen type redox cycle. Indeed during the cycle, $\mathrm{CO}$ is oxidized with lattice oxygen leading to the transformation of $\mathrm{MnO}_{2}$ in the intermediate $\mathrm{Mn}_{2} \mathrm{O}_{3}$ and $\mathrm{Mn}_{3} \mathrm{O}_{4}$ oxides which are reoxidized by gas-phase $\mathrm{O}_{2}$. The reoxidation of $\mathrm{Mn}_{2} \mathrm{O}_{3}$ and $\mathrm{Mn}_{3} \mathrm{O}_{4}$ into $\mathrm{MnO}_{2}$ is controversial if we consider the work of Stobbe et $a$ l. who reported that $\mathrm{Mn}_{2} \mathrm{O}_{3}$ corresponds to the highest obtainable manganese valency because further oxidation to $\mathrm{MnO}_{2}$ can only occur under extremely high oxygen pressures [82]. The existence of intermediate structure of a non-stoichiometric manganese oxide could explain the good activity of $\alpha-\approx \delta-\mathrm{MnO}_{2}$ as reported by lablokov et al. who directly synthesized by oxalate precipitation and temperature-programmed reduction the non-stoichiometric $\mathrm{MnO}_{x}$ phases with $\mathrm{x}=1.61 \ldots 1.67$. Such intermediate phases were found much more active than $\mathrm{Mn}_{2} \mathrm{O}_{3}$ and $\mathrm{Mn}_{3} \mathrm{O}_{4}\left[6_{2}\right]$ $\mathrm{Xu}$ et al. reported an elegant study by real time in situ and operando RAMAN spectroscopy in which the Langmuir-Hinshelwood mechanism would be predominant on $\alpha-\mathrm{Mn}_{2} \mathrm{O}_{3}$ at low temperature (below $200^{\circ} \mathrm{C}$ ) despite the suggestion of an intermediate $\mathrm{MnjO}_{\mathrm{k}}(1<j<2,1<k<3$, and $1<k / j<1$.5) phase formed on the nearsurface region during $\mathrm{CO}$ adsorption. By performing temperature-programmed surface reaction, $\mathrm{CO}$ oxidation was found to proceed through Mars van Krevelen only when temperature reached $350^{\circ} \mathrm{C}$ [83].

Nanostructured $\mathrm{Ce}_{0.7} \mathrm{Mnn}_{0.3} \mathrm{O}_{2-\delta}$ solid solutions, prepared by Venkataswamy et al. simple coprecipitation method, are able to oxidize $\mathrm{CO}$ at lower temperature than pure ceria when calcined at $500{ }^{\circ} \mathrm{C}$. Deep characterization showed that the presence of dual valences for both $\mathrm{Ce}\left(4^{+}\right.$or $\left.3^{+}\right)$and $\mathrm{Mn}\left(3^{+}\right.$and $\left.2+\right)$ cations and the very good activity is associated to the incorporation of highly dispersed $\mathrm{Mn}^{2+} / \mathrm{Mn}^{3+}$ in the ceria matrix which increases the concentration of oxygen vacancies, still at the origin of oxidation activity [84].

\subsubsection{Perovskite catalysts}

Perovskite, $\mathrm{LnBO}_{3}$ in which $\mathrm{Ln}$ is a lanthanide (usually $\mathrm{La}$ ) and $\mathrm{B}$ cation possesses two valence states like $\mathrm{Mn}, \mathrm{Co}$ or $\mathrm{Fe}$ is active for $\mathrm{CO}$ oxidation [22,23]. In 2013, our group reviewed the catalytic performances of perovskite in 
CO oxidation reaction which is governed by a suprafacial mechanism involving only surface oxygen species[16]. For several decades, $\mathrm{LaMnO}_{3}$ (manganites) and $\mathrm{LaCoO}_{3}$ (cobaltites) are considered as the most active $\mathrm{ABO}_{3}$ compositions for the reaction. Because of the participation of surface oxygen atoms in the mechanism, numerous studies focused on the development of new synthesis routes in order to enhance the specific surface area. Barnard et al. prepared $\mathrm{LaCoO}_{3}$ by calcination of mixed hydroxide precursors and reported that the rate for $\mathrm{CO}$ oxidation exhibited a linear dependence with the surface area [85]. Shu et al. developed a complexation technique with additional introduction of zinc nitrate to synthesize cobaltite. After calcination $\mathrm{ZnO}$ is removed resulting in a $30 \mathrm{~m}^{2} \mathrm{~g}^{-1} \mathrm{LaCoO}_{3}$ higher than the $9 \mathrm{~m}^{2} \mathrm{~g}^{-1}$ obtained with conventional complexation method. The sample with high surface area also showed the best catalytic performances for oxidation of $\mathrm{CO}$ [86]. Another way to increase the surface area of perovskite was the utilization of the reactive grinding method which permits to Levasseur et al. to obtain $\mathrm{LaCoO}_{3}$ with $35 \mathrm{~m}^{2} \mathrm{~g}^{-1}$ surface area and good activity in $\mathrm{CO}$ oxidation [87].

The partial substitution of the $A$ and $B$ cations was also intensively investigated to improve the catalytic performances of the perovskite catalysts. La substituted by Sr has usually given the best activity: preferential substitution rate in $\mathrm{La}_{1-x} \mathrm{Sr}_{x} \mathrm{CoO}_{3}$ has been found for $\mathrm{x}=0.3$ and 0.8 [88]. The same improvement of the activity for the Sr incorporation was observed for manganite perovskites even if the optimal composition was depending on the reaction temperature [89]: $\mathrm{La}_{0.4} \mathrm{Sr}_{0.6} \mathrm{MnO}_{3}$ was the most active for low temperature (below $200^{\circ} \mathrm{C}$ ) while Lao.8Sro.2 $\mathrm{MnO}_{3}$ gives the highest activity for $\mathrm{CO}$ oxidation performed above $250^{\circ} \mathrm{C}$. In this last work, the substitution of $\mathrm{B}$ cation was also studied like in numerous other papers in order to modify the redox properties of the perovskite. The manganese substitution by the copper induced a higher activity which originated from the increase of oxygen mobility and the reductive non-stoichiometry in the substituted solids. Cu also allows to increase the activity of pure $\mathrm{LaFeO}_{3}$ and ${ }^{18} \mathrm{O} /{ }^{16} \mathrm{O}$ isotopic exchange experiments revealed that bulk oxygen atoms of Cu-substituted materials can participate in the $\mathrm{CO}$ oxidation reaction [90]. Finally the possibility of a simultaneous substitution of $A$ and $B$ cations makes almost infinite the number of compositions and their impact on the $\mathrm{CO}$ oxidation activity.

\subsection{Methane oxidation}

The total oxidation of methane or catalytic combustion of methane has been also widely studied for many years. Indeed this process is an alternative to conventional thermal combustion for power generation but also enables the limitations of pollutant emissions from natural gas or methane combustion devices. It is important to keep in mind that methane has a Global Warming Potential (GWP) twenty-three times higher than carbon dioxide. With the recent increase of shale-gas development, Howarth et al. estimated that $3.6 \%$ to $7.9 \%$ of the methane from shale-gas production escapes to the atmosphere over the life-time of a well [91]. The growing of leanburn natural gas vehicules which require the abatement of emissions of methane at low-temperature is also expected in most of the industrial countries. The noble-metal catalysts are considered as very active for methane combustion [92] and among them supported-Pd catalyst is certainly the most studied [45,93] but transition metal catalysts are also regarded as alternative catalysts and a recent review illustrates this interest [94]. Here we will focus some single oxides and will explore the research performed on perovskite and hexaaluminate catalysts. 


\subsubsection{Single oxides}

Like for carbon monoxide oxidation, cobalt oxide attracts considerable attention for methane catalytic combustion [57,94]. A clear morphology effect has been shown for the combustion of methane over nanostructures $\mathrm{Co}_{3} \mathrm{O}_{4}$. Hu et al. [95] prepared nanosheets, nanobelts and nanocubes by a hydrothermal process using cobalt hydroxide precursor and subsequent thermal decomposition. The catalytic performances followed the trend: nanosheets with (112) planes predominantly exposed > nanocubes with (011) exposed planes > nanobelts with (001) exposed facets. A similar trend was also observed for the redox properties. A more open structure was revealed for the (112) planes resulting in a lower electric energy barrier for $\mathrm{C}-\mathrm{H}$ bond breaking compared with other exposed close packing planes. Highly porous $\mathrm{Co}_{3} \mathrm{O}_{4}$ nanorods are prepared by a simple hydrothermal method and compared to bulk $\mathrm{CO}_{3} \mathrm{O}_{4}$ prepared by thermal decomposition of cobalt nitrate [96] . $\mathrm{CO}_{3} \mathrm{O}_{4}$ nanorods show a higher activity for $\mathrm{CH}_{4}$ combustion particularly for high GSHV (100 ooo ${ }^{-1}$ ) tests due to the higher surface area and the advanced porous structure. Doping of cobalt oxide with other transition-metal oxides was also widely investigated. An example is given with the work of Li et al. who studied the methane combustion over manganese cobalt oxides with different $\mathrm{Mn} / \mathrm{Co}$ ratios [97]. The $T_{90}$ (the temperature needed to reach $90 \% \mathrm{CH}_{4}$ conversion) was used to rank the catalytic performances and the following descending order of activity was obtained: $\mathrm{Co}_{5} \mathrm{Mn} 1>\mathrm{C}_{3} \mathrm{Mn}_{1}>\mathrm{Co} 10 \mathrm{Mno}>>\mathrm{Co}_{1} \mathrm{Mn}_{1}>\mathrm{Co}_{1} \mathrm{Mn}_{3} \approx \mathrm{CooMn} 10$. Co/Mn molar ratio of $5: 1$ was thus the optimum composition.

Mn doping into the cobalt spinel structure was supposed to generate disorders causing an enhancement of the activity of the reactive ions in the octahedral sites. Doping with ceria resulted for Li et al. [98] in two advantages: an increase of activity and stability. Indeed Co-Ce-O mixed oxide with a Co/Ce bulk atomic ratio of 3/1, shows the highest oxygen vacancies concentration, the strongest interface interaction between $\mathrm{Ce}$ and $\mathrm{Co}$ at the origin of the best activity and stability. Single manganese oxide is also reported as active catalyst for methane catalytic combustion following a Mars-van Krevelen mechanism even if Han et al. suggested with a kinetic study that $\mathrm{CH}_{4}$ combustion is mainly through a Langmuir-Hinshelwood mechanism over $\alpha-\mathrm{Mn}_{2} \mathrm{O}_{3}$ [99]. $\mathrm{Mn}_{3} \mathrm{O}_{4}$ will oxidize methane under the formation of water, carbon dioxide and $\mathrm{MnO}$. Subsequently $\mathrm{MnO}$ will be regenerated, with air to $\mathrm{Mn}_{3} \mathrm{O}_{4}$. Only negligible carbon deposition was observed. This carbon laydown can be prevented completely by adding small amounts of water to the feed [82]. Doping $\mathrm{MnO}_{x}$ with $\mathrm{Ce}$ also promotes the catalytic activity and stability as compared to $\mathrm{CeO}_{2}$ and $\mathrm{Mn}_{2} \mathrm{O}_{3}[100]$.

\subsubsection{Perovskite catalysts}

As seen for carbon monoxide oxidation, cobaltites and manganites are the most active perovskite catalyts in methane combustion and the catalytic performances can be widely tuned either by changing the A cation or by substituting partially the manganese or cobalt element which gives rise to an infinite number of compositions[23,94]. Contrary to CO oxidation, methane combustion occurs over perovskite catalysts at higher temperature and implies the participation of the bulk oxygen atoms via an intrafacial mechanism in a Mars-van Krevelen catalytic cycle. In $\mathrm{La}_{1-\mathrm{x}} \mathrm{M}_{\mathbf{x}} \mathrm{MnO}_{3+\delta}(\mathrm{M}=\mathrm{Ce}$, Sr) substituted manganese perovskite catalysts, methane catalytic combustion was correlated to the formation of $-\mathrm{Mn}^{3+}-\mathrm{O}-\mathrm{Mn}^{4^{+}}$- chains, favoring the double exchange 
electron delocalization and hence the Mars van Krevelen mechanism [101]. The best activity was obtained for $x$ $=1 \mathrm{Sr}$-doped perovskite which also has the higher concentration of $\mathrm{Mn}^{4^{+}}$ions, favoring the electron delocalization through the -Mn3+--O-Mn4+- chains. To study the effect of the synthesis conditions of $\mathrm{LaCoO}_{3}$ on the redox properties and the catalytic activity for the $\mathrm{CH}_{4}$ catalytic combustion, Royer et al. compared five $\mathrm{LaCoO}_{3}$ samples prepared by different methods: solid state (SS), coprecipitation (COP), citrate complexation $(\mathrm{CIT})$ and reactive grinding of the single oxides (RG) and of an amorphous precursor (COPRG) [102]. In the $\mathrm{CH}_{4}$ oxidation reaction not all samples presented the same specific activity per unit surface area (Figure 6.7). These differences are explained by some different behaviour in oxygen mobility in the bulk of the solid samples. Neither TPD $-\mathrm{O}_{2}$ nor TPR $-\mathrm{H}_{2}$ results could however be simply and uniquely related to the rates of oxidation reactions. $\mathrm{LaCoO}_{3}$ prepared with these different methods was investigated by Royer et al. in terms of oxygen mobility using the oxygen isotopic exchange (OIE) technique and compared with the results obtained for the

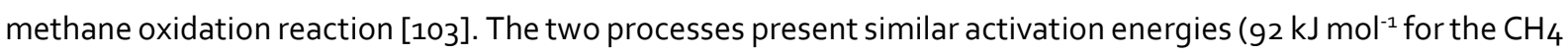
oxidation reaction). In contrast to the OIE reaction, an effect of the BET surface area on the $\mathrm{CH}_{4}$ oxidation reaction is observed, but the mobility of the bulk oxygen remains of great importance.

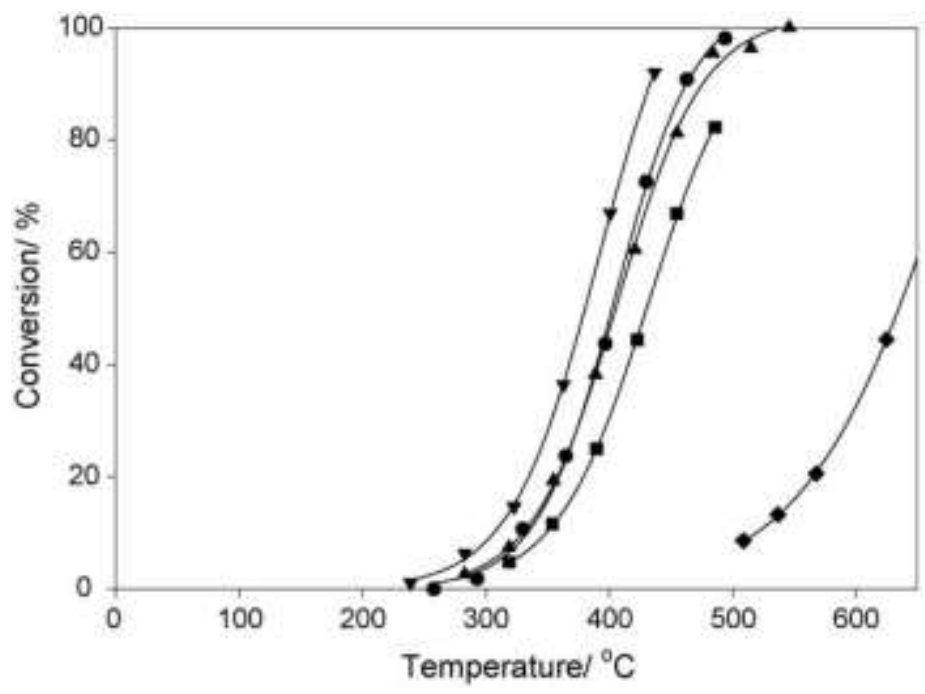

Figure 6.7 : Steady state conversions obtained for the oxidation reaction of $0.25 \% \mathrm{CH}_{4}$ as a function of the reaction temperature for: $(\boldsymbol{\nabla}) \mathrm{COPRG}_{i}(\bullet) \mathrm{RG}_{i}(\boldsymbol{\Delta}) \mathrm{CIT}_{i}(\boldsymbol{\bullet}) \mathrm{COP}_{\mathbf{i}}(\bullet) \mathrm{SS} \mathrm{LaCoO}_{3}$. Taken from [102]

$\mathrm{LaFeO}_{3}$ was less studied because of its lower stability compared with manganites and cobaltites perovskites. For ferrite perovskite the oxygen mobility was evidenced as a crucial parameter. For example, substitution of $\mathrm{La}^{3+}$ by $\mathrm{Sr}^{2+}$ induces a generation of oxygen vacancies favoring the diffusion of lattice oxygen from the bulk to the surface and decreases significantly the T50 to lower temperature [104]. The increasing of oxygen transport properties is also at the origin of the promotion of catalytic activity for Ce doping at A-site of $\mathrm{LaFeO}_{3}[105]$.

\subsubsection{Hexaaluminate catalysts}

Hexaaluminate $(H A)$ mixed oxides with general formula of $A B_{x} A l_{12-x} O_{19-\delta}\left(A_{x+}\right.$ and $B_{y+}$ being respectively a lanthanide a transition/noble metal cations) consist of alternate layer of alumina spinel blocks and mirror planes 
in which a large A cation is located [106]. Despite their lower performances compared with noble metal or perovskite catalysts, HA gained an increased attention in oxidation reaction at high temperature for their exceptional resistance to sintering [107]. Series of cation-substituted barium $\mathrm{HA}, \mathrm{BaMAl}_{11} \mathrm{O}_{19-\delta}(\mathrm{M}=\mathrm{Cr}, \mathrm{Mn}, \mathrm{Fe}$, $\mathrm{Co}$, and $\mathrm{Ni}$ ), was tested in methane combustion by Machida et al.[108] Among the substituted HA which exhibit higher activity than non-substituted one, Mn-substituted HA provided the best catalytic performances. The catalytic activity was related to the reversible redox cycle between di- and tri-valent states of manganese element in HA structure. During methane combustion over HA materials, methane is oxidized by surface active oxygen resulting in the formation of $\mathrm{CO}_{2}, \mathrm{H}_{2} \mathrm{O}$ and oxygen vacancies sites which are regenerated by the gaseous phase oxygen. The catalytic performances of HA are then significantly influenced by oxygen mobility and diffusion. In their study, Laassiri et al. confirmed the crucial role of oxygen mobility for methane combustion over HA materials prepared by Activated Reactive Synthesis (ARS) even if multiple factors like transition metal reducibility and concentration can also determine the catalytic activity as it can be seen in Figure 6.8. They also demonstrated that manganese containing HA were more active than the iron and cobalt containing materials. In another work the same authors compared the activity of perovskite and HA materials prepared by solvent free two steps (high energy - low energy) ARS method which results in an improvement of the solid surface area [33]. They concluded that the catalytic activity of these materials does not directly depend on the accessible surface area but is strongly related to the oxygen mobility. The higher activity of Mn-substituted perovskite originates from its higher oxygen mobility properties.
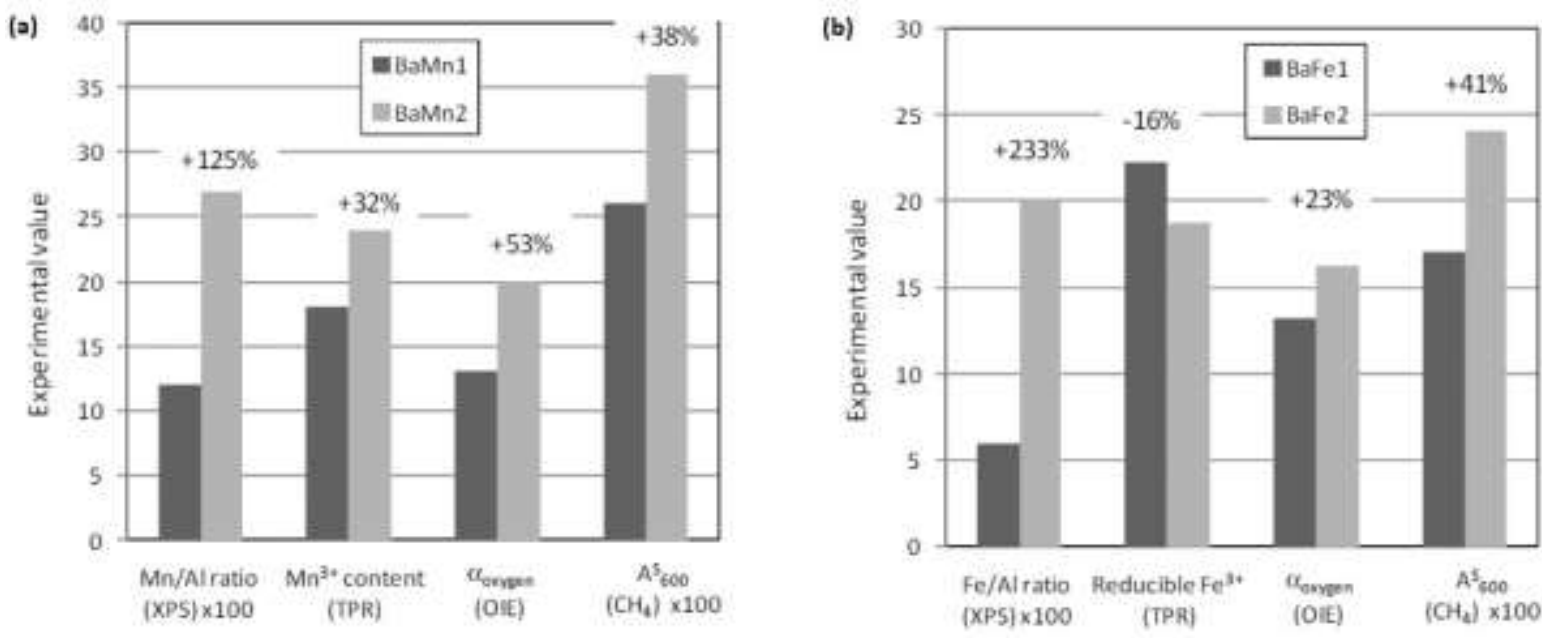

Figure 6.8: Impact of the degree of substitution on: transition metal surface content determined by XPS; reducible metal content as evaluated by TPR- $\mathrm{H}_{2}$; oxygen mobility measured by oxygen isotopic exchange (OIE); specific activity for the $\mathrm{CH}_{4}$ oxidation reaction ( $\mathrm{A}_{600}^{\mathrm{s}}$ : $\mathrm{mmol}$ of $\mathrm{CH}_{4}$ converted at $600^{\circ} \mathrm{C}$ per unit of surface) for (a) $\mathrm{Mn}$ - and (b)Fe-substituted hexaaluminates. Taken from [33]

\subsection{Other hydrocarbons and oxygenates}

These molecules are classically referred to as Volatile Organic Compounds (VOC) in the literature. Oxidation of VOC over perovskites was reviewed by Royer et al. up to 2013 [23] while two recent papers give insights on VOC oxidation over oxides (compared to metals) up to 2015-16 [109,110]. As for $\mathrm{CO}$ and $\mathrm{CH}_{4}$ oxidation, copper, manganese, cobalt and iron oxides are mainly used in VOC oxidation. Rare earth oxides $\left(\mathrm{La}_{2} \mathrm{O}_{3}, \mathrm{CeO}_{2}\right.$ or $\mathrm{CeO}_{2}$ - 
$\left.\mathrm{ZrO}_{2}\right)$ are often added as dopant to improve surface area, oxygen storage properties and stability of the single oxides $[111,112,113,114,115]$. Catalytic oxidation of hydrocarbon VOCs (including oxide as catalysts) was recently reviewed by Garcia et al. [116] while special properties of the interaction between copper and ceria and their implication in catalysis was overviewed by Konsolakis [117].

\subsubsection{Hydrocarbons}

Light alkanes. Propane oxidation has been widely used as model reaction of light alkane oxidation. It is often carried out for testing three-way catalysts (TWC) or Diesel Oxidation Catalysts (DOC). Noble metals (NM) are currently used in these tests but oxide catalysts have been considered as alternatives of NM catalysts [23]. Compared to $\mathrm{CO}$ whose oxidation occurs below $200^{\circ} \mathrm{C}$, propane is fully oxidized in the $200-400^{\circ} \mathrm{C}$ temperature range on many oxide catalysts. Faure and Alphonse have compared the oxidation of $\mathrm{CO}$ and of propane on a series of $\mathrm{Co}_{x} \mathrm{Mn}_{3-\mathrm{x}} \mathrm{O}_{4}$ spinel oxides [118]. Figure 6.9 represents their results for $0<x<3$.
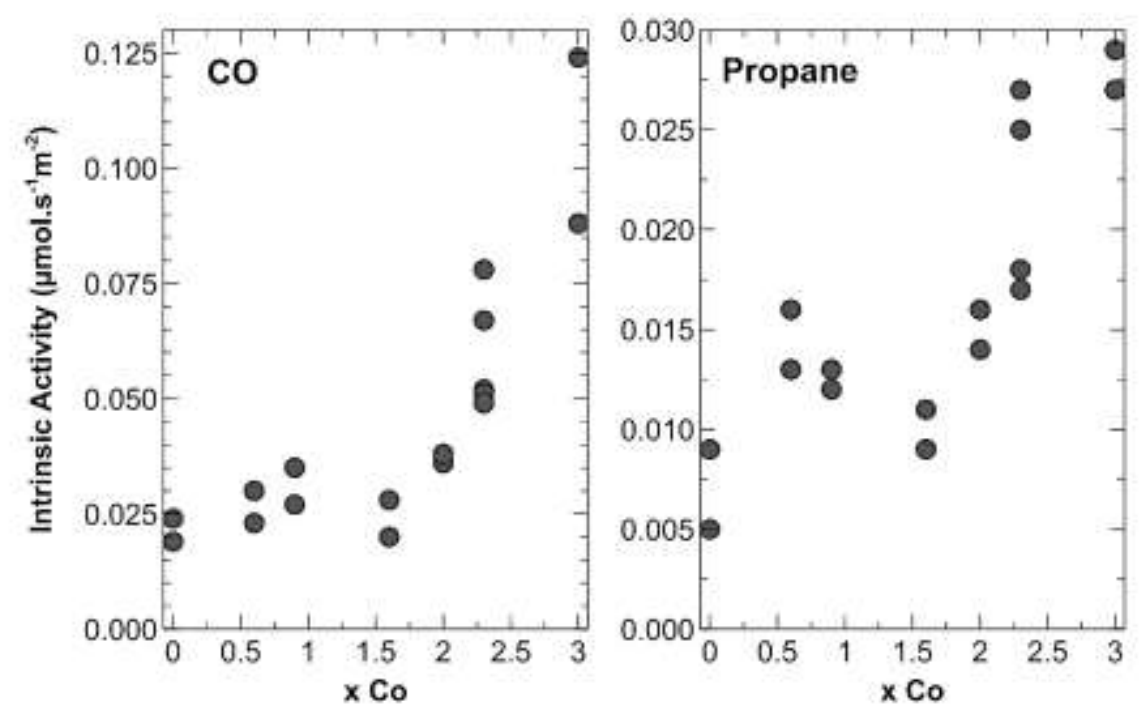

Figure 6.9. Intrinsic activity per $\mathrm{m}^{2}$ of $\mathrm{Co}_{x} \mathrm{Mn}_{3-x} \mathrm{O}_{4}$ spinel oxides for $\mathrm{CO}$ oxidation at $60^{\circ} \mathrm{C}$ (left) and for propane oxidation at $200^{\circ} \mathrm{C}$ (right). From ref. [118].

Catalytic activity significantly increases with the faction $x$ of cobalt in the spinel. $\mathrm{Co}^{2+}$ ions replace first $\mathrm{Mn}^{2+}$ ions in tetrahedral position. For higher values of $\mathrm{x}_{1} \mathrm{Co}^{3+}$ replaces $\mathrm{Mn}$ in octahedral position, which is more favorable to activity in oxidation. BET area being maximal for $\mathrm{x}=2.3$, the $\mathrm{Co}_{2.3} \mathrm{Mn}_{0.7} \mathrm{O}_{4}$ sample has the highest specific activity per gramme of catalyst. The activity ratio between $\mathrm{CO}$ and $\mathrm{C}_{3} \mathrm{H}_{8}$ oxidation can be calculated at $60^{\circ} \mathrm{C}$ on the basis of activation energy of $60 \mathrm{~kJ} \mathrm{~mol}^{-1}$ for the propane oxidation reaction. This ratio is close to 2500 for the pure cobalt spinel $\left(\mathrm{CO}_{3} \mathrm{O}_{4}\right)$ and 1200 for $\mathrm{CoMn}_{2} \mathrm{O}_{4}$, which shows that $\mathrm{Co}$ accelerates more $\mathrm{CO}$ than propane oxidation. Propane oxidation was investigated over mesoporous $\mathrm{Co}_{3} \mathrm{O}_{4}$ by Garcia et al. [119] and over Ni doped$\mathrm{CO}_{3} \mathrm{O}_{4}$ nano-arrays deposited on cordierite honeycomb by Ren et al. [120]. Mesoporous $\mathrm{CO}_{3} \mathrm{O}_{4}$ was synthetized by a nanocasting route using KIT- 6 silica as template. Depending on the aging temperature during the synthesis of the silica template (from 40 to $100^{\circ} \mathrm{C}$ ) and the calcination temperature of the cobalt oxide (after silica elimination), unimodal, bimodal and partially ordered $\mathrm{Co}_{3} \mathrm{O}_{4}$ were obtained. The last oxide was the most active catalyst for $\mathrm{C}_{3} \mathrm{H}_{8}$ oxidation with a $\mathrm{T}_{50}$ at $200^{\circ} \mathrm{C}$. It was proven that a certain degree of disorder favors the 
formation of surface $\mathrm{O}$ vacancies together with a higher $\mathrm{Co}^{2+} / \mathrm{Co}^{3+}$ ratio, beneficial for a higher oxidation activity [119]. SEM and TEM pictures of the $\mathrm{CO}_{3} \mathrm{O}_{4}$ nano-array prepared by Ren et al. [120] are shown in Figure 6.10.

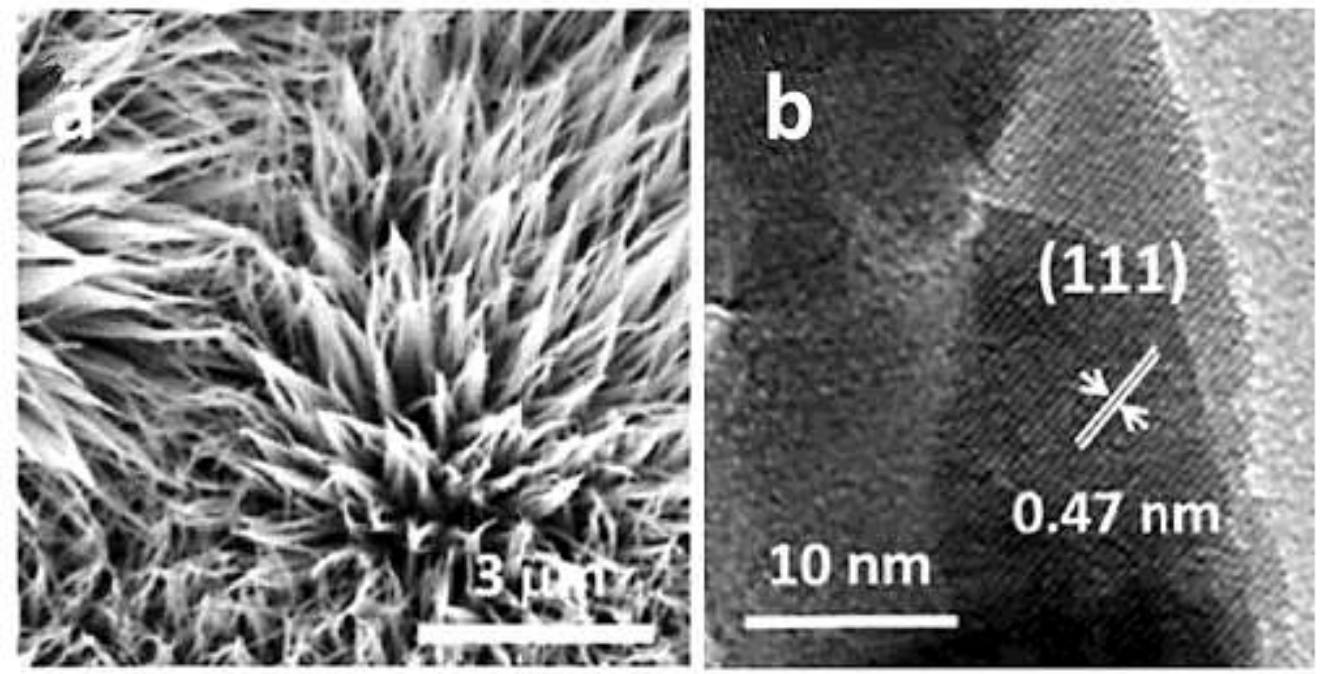

Figure 6.10. SEM (a) and HRTEM (b) image of the $\mathrm{Co}_{3} \mathrm{O}_{4}$ nano-arrays deposited on honeycomb cordierite. The cordierite was suspended in a Co nitrate aqueous solution, and then treated in urea. From ref. [120].

Similar pictures were obtained with $\mathrm{Ni}$-doped cobalt oxide $\left(\mathrm{Ni}_{0.27} \mathrm{Co}_{2.73} \mathrm{O}_{4}\right)$. In spite of a high surface area of these nano-arrays (close to $150 \mathrm{~m}^{2} \mathrm{~g}^{-1}$ after "scratching" from the honeycomb monolith), activities for propane oxidation are relatively modest ( 550 close to $350^{\circ} \mathrm{C}$ ).

The nanocasting route used for $\mathrm{CO}_{3} \mathrm{O}_{4}$ was extended by Solsona et al. to the fabrication of mesoporous $\alpha-\mathrm{Fe}_{2} \mathrm{O}_{3}$ for oxidation reaction [121]. The resulting materials were compared to a mesoporous oxide prepared by particle aggregation. This non-ordered oxide $\left(71 \mathrm{~m}^{2} \mathrm{~g}^{-1}\right)$ was shown to be more active than the ordered-mesoporous $\mathrm{Fe}_{2} \mathrm{O}_{3}\left(208 \mathrm{~m}^{2} \mathrm{~g}^{-1}\right)$ in propane oxidation. The dominant parameter for this reaction would be the redox properties of iron oxide. $\mathrm{H} 2-\mathrm{TPR}$ of $\mathrm{Fe}_{2} \mathrm{O}_{3}$ shows two main peaks, at $300-370^{\circ} \mathrm{C}\left(\mathrm{Fe}_{2} \mathrm{O}_{3} \rightarrow \mathrm{Fe}_{3} \mathrm{O}_{4}\right)$ and at $400-600^{\circ} \mathrm{C}\left(\mathrm{Fe}_{3} \mathrm{O}_{4}\right.$ $\left.\rightarrow \mathrm{FeO} \rightarrow \mathrm{Fe}^{\circ}\right)$. The non-ordered iron oxide reduces at the lowest temperature.

Total oxidation of isobutane was investigated by Almukhlifi and Burns on a variety of oxides [122] and ceriasupported oxide catalysts (doped or not with gold) [123]. $\beta-\mathrm{MnO}_{2}, \alpha-\mathrm{Fe}_{2} \mathrm{O}_{3}, \mathrm{CO}_{3} \mathrm{O}_{4}$ and $\mathrm{NiO}$ are active for the complete oxidation of $i-\mathrm{C}_{4} \mathrm{H}_{10}$. Cobalt oxide is the most active catalysts which can be ranked according to their $\mathrm{T}_{50}: \mathrm{CO}_{3} \mathrm{O}_{4}\left(218^{\circ} \mathrm{C}\right)>\beta-\mathrm{MnO}_{2}\left(233^{\circ} \mathrm{C}\right)>\alpha-\mathrm{Fe}_{2} \mathrm{O}_{3}\left(345^{\circ} \mathrm{C}\right)$. Reaction on $\mathrm{NiO}$ starts at low temperature but, compared to other oxides, $i-\mathrm{C}_{4} \mathrm{H}_{10}$ conversion increases slowly with the temperature $\left(\mathrm{T}_{50}=319^{\circ} \mathrm{C}\right)$. Full conversion is not reached before $450^{\circ} \mathrm{C}$ on $\mathrm{NiO}$ compared to $220^{\circ} \mathrm{C}$ on $\mathrm{CO}_{3} \mathrm{O}_{4}$ [122]. High surface area ceria is a good support for these oxides. Ceria has a significant oxidation activity when alone and it changes the ranking of the oxides whose activity on ceria becomes: $\beta-\mathrm{MnO}_{2}>\mathrm{CO}_{3} \mathrm{O}_{4}>\mathrm{NiO}>\alpha-\mathrm{Fe}_{2} \mathrm{O}_{3}[123]$.

Alkenes and Alkynes. Certain oxides used as supports $\left(\mathrm{TiO}_{2}, \mathrm{CeO}_{2}\right)$ show a relatively good performance in propene oxidation $\left(T_{50}\right.$ around $350^{\circ} \mathrm{C}$ ). Cobalt oxides significantly improve the activity of these oxides lowering the light-off temperature down to $210^{\circ} \mathrm{C}$. The best catalyst is $\mathrm{CO}_{3} \mathrm{O}_{4} / \mathrm{CeO}_{2}$ with ethylenediamine added during the impregnation of cobalt nitrate [124]. Oxidation of propene and acetylene was studied by Assebban et al. 
on cordierite or clay monoliths coated with $\mathrm{CO}_{3} \mathrm{O}_{4}$ [125]. Monoliths were coated with cobalt oxide by chemical vapor deposition of cobalt acetylacetonate as precursor. Clay monolith is a better support than cordierite: it possesses a non-negligible intrinsic activity due to a high content of $\mathrm{Fe}_{2} \mathrm{O}_{3}(11 \%)$. Acetylene $\left(\mathrm{T}_{50} \approx 280^{\circ} \mathrm{C}\right)$ oxidizes at lower temperature than propene $\left(\mathrm{T}_{50} \approx 310^{\circ} \mathrm{C}\right)$. On clay monolith, cobalt oxide has little impact on acetylene oxidation while it decreases by $35^{\circ} \mathrm{C}$ the light-off temperature of propene.

Aromatics. Benzene combustion was recently investigated over $\mathrm{Mn}$-based mixed oxides: $\mathrm{CeO}_{2}-\mathrm{MnO}_{x}$ composites [126], mesoporous Cu-Mn (221 $\left.\mathrm{m}^{2} \mathrm{~g}^{-1}\right)$ [127], mesoporous CoMnAl oxides prepared from hydrotalcites [128] and $\mathrm{NiMnO}_{3}-\mathrm{CeO}_{2}$ supported on cordierite [129]. In most cases, benzene oxidation starts around $120-140^{\circ} \mathrm{C}$ with $\mathrm{T}_{50}$ ranging from 180 to $240^{\circ} \mathrm{C}$. Best compositions are $\mathrm{Ce}_{0.3} \mathrm{Mn}_{0.7}$ [126], CUo.6 $\mathrm{Mn}$ [127] and $\mathrm{CoMn}_{2} \mathrm{Al}$ [128]. A detailed kinetic analysis performed on the $\mathrm{NiMnO}_{3} / \mathrm{CeO}_{2} /$ cordierite catalyst reveals that the apparent kinetic order with respect to benzene is close to 0.2 but the MvK mechanism best fits the kinetic results with a reaction rate expression analogous to Eq. 6.4 [129]. All the studies showed that $\mathrm{O}_{2}$ adsorption and availability for oxidizing adsorbed benzene is a key step of the reaction.

Tolvene oxidation was in-depth investigated on oxide catalysts as a model compound for removal of aromatics from gases. $\mathrm{LaMnO}_{3}$ perovskites present interesting properties for the total oxidation of tolvene $[130,131,132]$. Zhang et al. have prepared a series of $\mathrm{LaMnO}_{3}$ by different ways. The perovskite prepared by the citrate sol-gel route (LMO-SG) has the highest BET area $\left(35 \mathrm{~m}^{2} \mathrm{~g}^{-1}\right.$ ), the highest amount of $\mathrm{O}_{\alpha}$ (desorbing at $250^{\circ} \mathrm{C}$ ) and the best performance in oxidation (1000 ppm TOL in air) with a $\mathrm{T}_{50}$ at $193^{\circ} \mathrm{C}$ [130]. LaMnO $\mathrm{may}_{3}$ also be supported on $\mathrm{TiO}_{2}$ or yttrium-stabilized zirconia (YSZ) for a better practical use in dynamic reactor. Again, $\mathrm{O}$ adsorption and exchange properties seem to correlate the catalytic activity [131]. Morphological control of $\mathrm{LaMnO}_{3} \mathrm{Was}$ performed by Wang et al. who succeeded in preparing isolated cubes of perovskites [132]. These cubes $\left(\mathrm{T}_{50}=\right.$ $170^{\circ} \mathrm{C}$ ) are about ten times more active than porous spherical particles in toluene oxidation. An interesting improvement of the performance of $\mathrm{LaMnO}_{3}$ was realized by eliminating $\mathrm{La}$ from the surface layer of $\mathrm{LaMnO}_{3}$. $\mathrm{MnO}_{2} / \mathrm{LaMnO}_{3}$ can thus be prepared which has a much surface area $\left(144 \mathrm{~m}^{2} \mathrm{~g}^{-1}\right)$ than the untreated perovskite $\left(3 \mathrm{~m}^{2} \mathrm{~g}^{-1}\right)$ [133]. The $\mathrm{Mn}^{4+} / \mathrm{Mn}^{3+}$ ratio and the catalytic activity are also significantly greater than in $\mathrm{LaMnO}_{3}$. $\mathrm{Non}^{-}$ perovskitic $\mathrm{Mn}$ oxides are also active in oxidation reactions. $\mathrm{CU}_{1.5} \mathrm{Mn}_{1.5} \mathrm{O}_{4}$ spinels synthetized via an alginate route are more active than the simple $\mathrm{Mn}_{3} \mathrm{O}_{4}$ oxide [134]. Total oxidation of toluene is achieved below $240^{\circ} \mathrm{C}$, most probably following a MvK mechanism. OMS-2 $\left(\mathrm{KMn}_{8} \mathrm{O}_{16} \cdot \mathrm{nH}_{2} \mathrm{O}\right)$ is a tunnel-structured manganese oxide with excellent properties in oxidation reaction. Sun et al. have demonstrated the decisive role of lattice oxygen on the activity of OMS-2 for the total oxidation of tolvene [135]. Even in absence of gaseous oxygen, OMS-2 is able to oxidize toluene via benzoyl and benzoate intermediate species (Figure 6.11). 


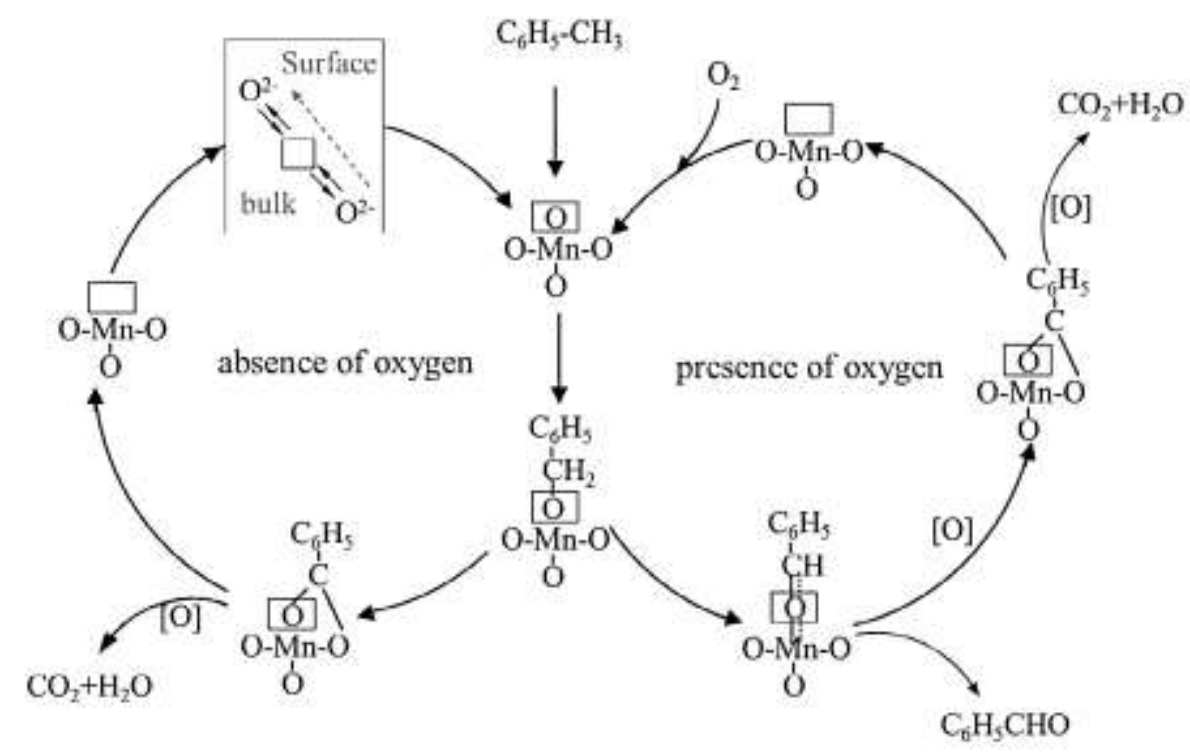

Figure 6.11 Mechanism of toluene oxidation over OMS-2 catalyst. Effect of the presence or not of $\mathrm{O}_{2}$ in gas phase on the initial steps of reaction. From ref. [135].

$\mathrm{Mn}$ oxides are more stable and better dispersed when they are deposited on adequate supports. Hydroxyapatite $\mathrm{Ca}_{10}\left(\mathrm{PO}_{4}\right)_{6}(\mathrm{OH})_{2}$ was shown to be a good support of $\mathrm{MnOx}$ for toluene oxidation [136]. Good performances were obtained with $\mathrm{Ca}^{2+}$ enriched apatites and with nitrate precursors of $\mathrm{Mn}$. Although they were less studied than Mn-containing catalysts, cobalt oxides show interesting properties in tolvene oxidation. $\mathrm{Co}_{6} \mathrm{Al}_{2} \mathrm{HT}$ hydrotalcite-like compounds are excellent precursors of catalysts [137]. There is a good relationship between the surface concentration of $\mathrm{CO}^{2+}$, the oxide reducibility and the catalytic activity, suggesting a MvK mechanism for these Co-catalysts. CoMgAl hydrotalcites were also developed by Pérez et al. who showed that doping these materials by ceria led to very active catalysts [138]. The use of EDTA for chelating Ce before impregnation gives more efficient catalysts. Ce-Co and La-Co mixed oxides were investigated by Carabineiro et al. [139] Mixed oxides prepared by the exotemplating method (using carbon as template) are more active than the solids prepared by evaporation of oxalate precursors. Interestingly, the authors propose a MvK mechanism in which oxygen mobility could be linked to the acidity of oxide, as already proposed by Soylu et al. for zeolite-supported oxides [140]. Copper oxide catalysts were less studied than those based on Mn and Co. The investigation of the reaction network performed by Menon et al. in 2011 deserves citation [141]. The reaction was studied by TAP using labeled molecules $\left({ }^{13} \mathrm{C}, \mathrm{D}\right.$ and $\left.{ }^{18} \mathrm{O}\right)$. The MvK mechanism was confirmed (preliminary formation of $\mathrm{C}^{16} \mathrm{O}_{2}$ upon a pulse of $\mathrm{C}_{6} \mathrm{H}_{5}-\mathrm{CH}_{3} /{ }^{18} \mathrm{O}_{2}$ ) together with a deep insight into the reaction intermediates. More recently, Zabihi et al. have compared the total oxidation of tolvene and cyclohexane over Cu-Co mixed oxides supported on carbons [142]. Cu-Co oxide alloys are slightly more active than CuO covered with $\mathrm{CoO}$ or the reverse, $\mathrm{CoO}$ covered with $\mathrm{CuO}$. Copper oxides supported on ceria-alumina supports were also used to oxidize $p$-xylene and xylene-CO mixtures [143]. Interestingly, these authors showed that small amounts of xylene can inhibit $\mathrm{CO}$ oxidation. This is due to competitive adsorption phenomenon but also to formation of new intermediates of reaction in the simultaneous oxidation of xylene and $\mathrm{CO}$. 
Naphthalene is generally chosen as model compound of bicyclic aromatics and, more generally, of PAH, polycyclic aromatic hydrocarbons. The following order of reactivity was reported by Garcia et al.: $\mathrm{CeO}_{2}>\mathrm{MnOx}$ $>\mathrm{CoOx}>\mathrm{CuOx}>\mathrm{Fe}_{2} \mathrm{O}_{3}$ [144]. These authors have compared the performances of various oxides for propane and naphthalene oxidation (Table 6.1)

Table 6.1. Total oxidation of propane and naphthalene over various oxides. $T_{90}$ is the temperature for a $90 \%$ conversion of hydrocarbon. All the oxides are prepared by precipitation of nitrates by sodium carbonate, except $\mathrm{CeO}_{2}-\mathrm{U}$ which is prepared by urea precipitation. Reaction conditions: $0.5 \% \mathrm{C}_{3} \mathrm{H}_{8}$ in air (propane) at a gas hourly space velocity (GHSV) of $15000 \mathrm{~h}^{-1}$ or $100 \mathrm{vpm} \mathrm{C}_{10} \mathrm{H}_{8}$ in air (naphthalene) at a GHSV of $60000 \mathrm{~h}^{-1}$. Adapted from ref. [144].

\begin{tabular}{|l|c|l|c|c|}
\hline Oxide & BET area $\left(\mathrm{m}^{2} \mathrm{~g}^{-1}\right)$ & Main phase & $\mathrm{T}_{90}$ Propane $\left({ }^{\circ} \mathrm{C}\right)$ & $\mathrm{T}_{90}$ Naphthalene $\left({ }^{\circ} \mathrm{C}\right)$ \\
\hline $\mathrm{Al}_{2} \mathrm{O}_{3}$ & 180 & $\mathrm{\gamma}-\mathrm{Al}_{2} \mathrm{O}_{3}$ & - & $38 \%$ conv. @ 350 \\
\hline $\mathrm{CeO}_{2}$ & 86 & $\mathrm{CeO}_{2}$ & - & 315 \\
\hline $\mathrm{CeO}_{2}-\mathrm{U}$ & 171 & $\mathrm{CeO}_{2}$ & 360 & 210 \\
\hline $\mathrm{CoOx}$ & 69 & $\mathrm{Co}_{3} \mathrm{O}_{4}$ & 180 & 270 \\
\hline $\mathrm{CuOx}$ & 20 & $\mathrm{CuO}$ & 350 & 270 \\
\hline $\mathrm{CuOx}-\mathrm{ZnOx}$ & 29 & $\mathrm{CuO}_{1} \mathrm{ZnO}$ & 335 & 250 \\
\hline $\mathrm{Fe}_{2} \mathrm{O}_{3}$ & 51 & $\mathrm{Fe}_{2} \mathrm{O}_{3}$ (haematite) & - & 295 \\
\hline $\mathrm{MnOx}_{\mathrm{TiO}}$ & 76 & $\mathrm{Mn}_{2} \mathrm{O}_{3}$ & 320 & 240 \\
\hline $\mathrm{ZnO}$ & 50 & $\mathrm{Anatase}+$ rutile & - & $66 \%$ conv. @ 350 \\
\hline
\end{tabular}

Except $\mathrm{CoOx}$, the oxides investigated by Garcia et al. are more active for naphthalene than for propane oxidation. Worthy of note is the behavior of $\mathrm{CeO}_{2}-\mathrm{U}$ much more active than the solid prepared by sodium carbonate precipitation. The factor 2 on the BET area is obviously not the only reason of the superiority of $\mathrm{CeO}_{2}-U$. A detailed study performed on $\mathrm{CeO}_{2}-U$ showed that activity of this oxide was clearly related to the number of surface defects measured by the full width at half maximum of the Raman band at $464 \mathrm{~cm}^{-1}[145]$. Mesoporous cerias prepared by a nanocasting route (using KIT-6 as template) were also tested in naphthalene oxidation [146]. These materials are not more active than the precipitated $\mathrm{CeO}_{2}-\mathrm{U}$ but they show excellent stability. Further refinement of the catalysis by ceria includes: shape-selective preparation of ceria (nanocubes, nanorods, nanoparticles) [147] and addition of copper [148]. Ceria nanoparticles are more active than nanocubes and nanorods, in line with the higher concentration of surface defects in the materials [147]. Copper is a good promoter of ceria for naphthalene oxidation. Optimum is obtained for the composition $\mathrm{Ce}_{0.984} \mathrm{CU}_{0.016} \mathrm{Ox}$; the intrinsic activity at $200^{\circ} \mathrm{C}\left(\right.$ per $\left.\mathrm{m}^{2}\right)$ is then 20 times greater than that of pure ceria [148].

\subsubsection{Oxygenates}

Oxides may be good oxidation catalysts for oxygenated VOC, still better than for hydrocarbons. However, significant amounts of intermediates (most often, other oxygenates) are currently observed before complete oxidation [149]. Moreover, the reactivity depends very much on the chemical structure, ethers and esters being generally more difficult to oxidize than alcohols, aldehydes and ketones of the same number of carbons $[23,150]$. Assebban et al. have compared the reactivity of VOCs, including hydrocarbons, oxygenates and chlorinated compounds, on an extruded clay honeycomb monolith [151]. The chemical composition of the clay is $\mathrm{SiO}_{2}\left(58.50\right.$ wt.\%), $\mathrm{Al}_{2} \mathrm{O}_{3}(23.90 \%), \mathrm{Fe}_{2} \mathrm{O}_{3}(11.11 \%), \mathrm{K}_{2} \mathrm{O}(2.29 \%), \mathrm{MgO}(1.55 \%), \mathrm{Na}_{2} \mathrm{O}(1.46 \%), \mathrm{TiO}_{2}(0.63 \%)$, 
$\mathrm{CaO}(0.22 \%), \mathrm{ZrO}_{2}(0.02 \%)$, and $\mathrm{MnO}_{2}(0.02 \%)$. Iron oxide is the active compound of the clay for oxidation reactions. The light-off temperatures recorded for the VOC studied by Assebban et al. are reported in Table 6.2

Table 6.2. Reactivity of various $\mathrm{VOC}$ compounds on a extruded clay honeycomb monolith $\left(11.1 \% \mathrm{Fe}_{2} \mathrm{O}_{3}\right)$. Reaction conditions: $1 \% \mathrm{VOC}+10 \% \mathrm{O}_{2}$ at a GHSV (gas hourly space velocity) of $2300 \mathrm{~h}^{-1}$ with respect to the volume of monolith. Variable amounts of $\mathrm{CO}$ are observed in addition to $\mathrm{CO}_{2}$ for all the VOC. Aldehydes are the main reaction intermediate of alcohol oxidation (formaldehyde, acetaldehyde, propanal, butanal in oxidation of methanol, ethanol, propanol, butanol, respectively). From ref. [151].

\begin{tabular}{|c|c|c|c|}
\hline $\begin{array}{c}\text { VOC compounds } \\
(\mathrm{CO} \& \mathrm{HC})\end{array}$ & $\mathrm{T}_{50}\left({ }^{\circ} \mathrm{C}\right)$ & $\begin{array}{c}\text { VOC compounds } \\
\text { (Oxygenates \& Cl-compounds) }\end{array}$ & $\mathrm{T}_{50}\left({ }^{\circ} \mathrm{C}\right)$ \\
\hline CO & 295 & Methanol & 261 \\
\hline Methane & 512 & Ethanol & 272 \\
\hline Propane & 420 & n-Propanol & 271 \\
\hline Propene & 355 & n-Butanol & 278 \\
\hline Acetylene & 299 & Acetone & 228 \\
\hline Benzene & 345 & Dimethylether (DME) & 286 \\
\hline Toluene & 329 & Chlorobenzene & 395 \\
\hline o-Xylene & 321 & 1,2 -Dichlorobenzene & 414 \\
\hline
\end{tabular}

The reactivity sequence on iron oxides of the clay mineral was found to be as follows: ketone > alcohol > ether $>\mathrm{CO}>$ alkyne $>$ aromatic $>$ alkene $>$ chlorinated aromatic $>$ alkane. As iron oxide is not the most active catalyst for VOC oxidation, T50 of the clay are shifted to higher temperatures if compared to Mn or Co oxides. However, it is confirmed that the reactivity of oxygenates is higher than that of any hydrocarbons, saturated or not.

Acetone. Among the oxygenates, appears as very reactive with a $\mathrm{T} 50$ of $228^{\circ} \mathrm{C}$, that is $33^{\circ} \mathrm{C}$ lower than the lightoff temperature of the alcohols tested by Assebban et al. [151]. Acetone combustion was studied over spinels $\left(\mathrm{CuFe}_{2} \mathrm{O}_{4}, \mathrm{MgFe}_{2} \mathrm{O}_{4}, \mathrm{Ni}_{0.5} \mathrm{Co}_{0.5} \mathrm{Fe}_{2} \mathrm{O}_{4}\right)$ and perovskites catalysts $\left(\mathrm{SrMnO}_{3}, \mathrm{FeMnO}_{3}, \mathrm{La}_{0.6} \mathrm{~Pb}_{0.2} \mathrm{Ca}_{0.2} \mathrm{MnO}_{3}\right)$ by Rezlescu et al.[152]. $\mathrm{SrMnO}_{3}\left(2.2 \mathrm{~m}^{2} \mathrm{~g}^{-1}\right)$ is the most active catalyst with $\mathrm{T}_{50}$ at $185^{\circ} \mathrm{C}$. Presence of ceria in the materials allows obtaining very good performances for acetone oxidation. $\mathrm{M}-\mathrm{Ce} / \mathrm{Al}-\mathrm{SiO} 2$ composites ( $\mathrm{M}=\mathrm{Mn}$, $\mathrm{Co}, \mathrm{Cu}, \mathrm{Ni}, \mathrm{Fe}$ ) were developed by Lin and Bai [153] while Oin et al. focused their attention on CuCeOx nanofibers prepared by an electrospinning method [154]. In every case, cerium ions play a decisive role by creating numerous $\mathrm{O}$ vacancies in the materials. Light-off temperatures are below $200^{\circ} \mathrm{C}$ with an exceptional behavior of the $\mathrm{Mn}_{0.5} \mathrm{Ce}_{0.5} \mathrm{O}_{x} / \mathrm{Al}-\mathrm{SiO}_{2}$ catalyst of $\mathrm{Lin}$ and $\mathrm{Bai}\left(\mathrm{T}_{50}=110^{\circ} \mathrm{C}\right)$.

Ethanol. In the last decades, great efforts were made to produce hydrogen by ethanol steam reforming [155]. The reaction being endothermic, the most practical way is to heat the reformer by combustion of ethanol. Steam reforming or oxidation of ethanol can lead to ethylene, acetaldehyde and acetone as intermediates [156]. Total oxidation thus requires a good performance of the catalysts for alkene, aldehyde and ketone oxidation. Acetaldehyde is the main oxidation intermediate on basic oxides such as ceria [157]. Minor amounts of acetic acid and ethyl acetate are also observed. Total conversion of ethanol is reached on ceria nanorods at $235^{\circ} \mathrm{C}$ but complete selectivity to $\mathrm{CO}_{2}$ requires much higher temperatures to oxidize all the intermediates, acetic acid being the most refractory compound. Mn-based oxides are more active catalysts for ethanol oxidation. Nanorods $\left(1 \mathrm{D}-\mathrm{MnO}_{2}\right)$ and mesostructured $\mathrm{MnO}_{2}$ using SBA-15 $\left(2 \mathrm{D}-\mathrm{MnO}_{2}\right)$ or KIT-6 $\left(3 \mathrm{D}-\mathrm{MnO}_{2}\right)$ as templates were synthetized by Bai et al. [158]. These materials were tested in ethanol and acetaldehyde oxidation. The turnover frequency per mol of $\mathrm{Mn}^{4^{+}}$was the highest for $3 \mathrm{D}-\mathrm{MnO}_{2}\left(0.17 \mathrm{~h}^{-1}\right.$ at $110^{\circ} \mathrm{C}$ instead of $0.14 \mathrm{~h}-1$ for $2 \mathrm{D}$ - 
$\mathrm{MnO}_{2}$ and only $0.03 \mathrm{~h}-1$ for $1 \mathrm{D}-\mathrm{MnO}_{2}$ ). This is clearly linked to the higher reducibility and to more surface adsorbed oxygen species and $\mathrm{Mn}^{4+}$ ions on $3 \mathrm{D}-\mathrm{MnO}_{2}$ [158]. Ethanol oxidation was also investigated over $\mathrm{Mn}$ cryptomelane OMS-2 $[159,160]$. Cryptomelanes $\mathrm{KMn}_{8} \mathrm{O}_{16}$ prepared by a sol-gel technique $\left(\mathrm{KMnO}_{4}\right.$ in fumaric acid) or by a reflux method $\left(\mathrm{KMnO}_{4}\right.$ added to a boiling solution of $\mathrm{Mn}$ acetate in acetic acid) show the best performance in ethanol oxidation $\left(\mathrm{T}_{50}\right.$ at $\left.120^{\circ} \mathrm{C}\right)$ [159]. Sulfate-doped OMS-2 are more active than undoped catalysts. A suitable amount of $\mathrm{SO}_{4}{ }^{2-}$ species into the OMS-2 catalyst could decrease the Mn-O bond strength and also enhance the lattice oxygen concentration and number of acid sites, which then effectively promoted the catalytic activity of OMS-2 [160]. Co-Mn-Al mixed oxides of spinel structure were prepared by Kovanda et al. by calcination of layered double hydroxides (LDH) precursors deposited on anodized aluminum [161]. They are more active in ethanol oxidation $\left(T_{50}=123^{\circ} \mathrm{C}\right)$ than mixed oxides formed from coprecipitated salts $\left(T_{50}\right.$ ranging from 150 to $190^{\circ} \mathrm{C}$ ). However, acetaldehyde being less oxidizable than ethanol, there is a shift between the light-off temperature of ethanol consumption and the $\mathrm{T}_{5} \mathrm{O}$ observed on the production of $\mathrm{CO}_{2}$. The preparation by calcination of LDH was extended by Jirátová et al. to different mixed oxides containing Mn, Co, $\mathrm{Cu}$ and $\mathrm{Ni}$ [162]. Catalysts containing $\mathrm{Mn}$ are very active with $\mathrm{T}_{50}$ below $150^{\circ} \mathrm{C}$. The best system was a ternary oxides containing Cu-Ni-Mn. Addition of $\mathrm{Ni}$ to a perovskite $\mathrm{LaMnO}_{3}$ is also an excellent way to improve the performance of the perovskite $\mathrm{LaMnO}_{3}$ [163]. The optimum is reached for the perovskite $\mathrm{LaMn}_{0.9} \mathrm{Ni}_{\text {o.1 }} \mathrm{O}_{3}$ which converts ethanol and acetaldehyde at the lowest temperature. Incorporating $\mathrm{Ni}$ generates $\mathrm{Ni}-\mathrm{O}-\mathrm{Mn}$ sites, assumed to play a key role in enhancing catalytic activity. Very few studies were devoted to Mn-free catalysts. $\mathrm{CoFe}_{2} \mathrm{O}_{4}$ spinels (119 $\mathrm{m}^{2} \mathrm{~g}^{-1}$ ) were investigated by Hammiche-Bellal et al. with good performance above $200^{\circ} \mathrm{C}$ [164]. It is necessary to reach $300^{\circ} \mathrm{C}$ to avoid formation of acetaldehyde and acetic acid. Motak et al. have studied ethanol oxidation (1000 ppm) in the presence of NOx (500 ppm) over clays minerals (vermicullite, bentonite or montmorillonite) doped with copper or silver [165]. Relatively high temperatures $\left(>350^{\circ} \mathrm{C}\right)$ are required to reach a 50\% conversion. Ag-doped clays give better performances than those doped with Cu. They are also less sensitive to the presence of NOx.

Ethyl acetate. Oxidation of this compound was investigated as a model of esters and also because it is widely used in industry as solvent. Copper-ceria or cobalt-ceria oxides are quite effective catalysts for ethyl acetate abatement below $200^{\circ} \mathrm{C}[166,167]$. Cu-Ce oxides were supported on SBA-15 or KIT- 6 by Tsoncheva et al. to give catalysts of $600-700 \mathrm{~m}^{2} \mathrm{~g}^{-1}$ (SBA-15) or 300-500 $\mathrm{m}^{2} \mathrm{~g}^{-1}$ (KIT-6) but Cu-Ce/KIT-6 are more active than Cu-Ce on SBA-15 [166]. Unsupported oxides were prepared by Chen et al. by an exotemplating or an evaporation method [167]. Catalytic activity seems linked to the onset temperature of reduction suggesting that a MvK mechanism is taking place [167]. The $\mathrm{Cu} / \mathrm{Ce}$ or the $\mathrm{Co} / \mathrm{Ce}$ ratio of 1 gives the best performances (467 ppm ethyl acetate in air, GHSV of $53000 \mathrm{~h}^{-1}$ ) with virtually no production of CO. Iron oxides may be used for ethyl acetate oxidation provided that iron be stabilized by another oxide. In this respect, Tsoncheva et al. have developed a new catalytic system based on iron modified titanium-hafnium binary oxides [168]. Small amount of Hf in titania (typically $1.8 \%$ ) facilitates the formation of substituted $\mathrm{Fe}_{\mathrm{x}} \mathrm{Ti}_{1-\mathrm{x}} \mathrm{O}_{2}$ and finely dispersed hematite particles. In spite of the low Fe loading (0.14\%), light-off temperature of $300^{\circ} \mathrm{C}$ can be obtained with these catalysts (1.2\% EA in air). Ethyl acetate being generally mixed with hydrocarbons in air, several studies were devoted to purification of VOC comprising ethyl acetate and tolvene (oxidized separately or mixed together) $[169,170,171]$. 
In most cases, toluene is converted at higher temperatures than ethyl acetate, but with a better selectivity to $\mathrm{CO}_{2}$. The Cu-Ce system gives excellent performances, with a significant effect of the support: SBA-15 [169] or ZSM-5 [171]. MnMgOx oxides prepared by autocombustion are a good alternative to CuCeOx oxides [170]. Interestingly, these catalysts were compared to a $1 \% \mathrm{Pt}-\mathrm{Al}_{2} \mathrm{O}_{3}$, a reference noble metal catalyst for $\mathrm{VOC}$ abatement. It was shown that $\mathrm{Pt}$ is a better catalyst for tolvene oxidation but less good than MnMgOx for ethyl acetate oxidation, which confirms the superiority of oxide catalysts (with respect to noble metals) for ester oxidation. Oxidation of ethyl acetate and $\mathrm{n}$-hexane was studied by Tang et al. over Mn-Co oxide nanorods (105 $\mathrm{m}^{2} \mathrm{~g}^{-1}$ ) [172]. Hexane being more reactive than toluene, the ester and the hydrocarbon are oxidized at the same temperature $\left(190-210^{\circ} \mathrm{C}\right)$ and total oxidation is achieved below $230^{\circ} \mathrm{C}$.

Other oxygenates. Formaldehyde is a toxic VOC emitted indoor by resins and glues of furniture and floor coverings. Most active catalysts can oxidize formaldehyde at room temperature but they contain generally noble metals. Attempts at replacing noble metals by transition metal oxides were made recently. Cobalt oxide encapsulated in cyclodextrin is a promising catalyst based on $\mathrm{Co}^{3+} / \mathrm{Co}^{2+}$ redox sites [173]. Nevertheless, temperatures close to $170^{\circ} \mathrm{C}$ are required for a good oxidation activity. Nanosheets of $\mathrm{NiCO}_{2} \mathrm{O}_{4}$ spinels doped with $\mathrm{NaOH}\left(48-71 \mathrm{~m}^{2} \mathrm{~g}^{-1}\right.$ ) are more active since they are able to convert formaldehyde at room temperature while total oxidation is achieved over untreated $\mathrm{NiCoO}_{4}$ at $150^{\circ} \mathrm{C}$ only [174]. Mn-substituted ferrites (general formula: $\left.\mathrm{Fe}_{3-\mathrm{x}} \mathrm{Mn}_{\mathrm{x}}\right)_{1-\delta} \mathrm{V}_{3 \delta} \mathrm{O}_{4}, \mathrm{~V}$ being a vacant position of the spinel ferrite) are a good alternative to noble metal catalysts but the best catalysts $(x=0.1)$ has a $T_{50}$ of $126^{\circ} \mathrm{C}$ and requires temperatures close to $200^{\circ} \mathrm{C}$ for a complete conversion of $\mathrm{HCHO}$ [175]. Total oxidation of isopropanol was also investigated, in most case over Mnbased catalysts [176], sometimes assisted by plasma discharge to get oxidation at room temperature [177]. Though oxidation of acetic acid in water was extensively studied by wet air oxidation techniques [178], oxidation of acetic acid in gas phase was more rarely studied. Melang Me Nze et al. have investigated this reaction over MgAlCe mixed oxides [179]. Cooperation between redox sites for $\mathrm{O}_{2}$ activation and basic sites for $\mathrm{CH}_{3} \mathrm{COOH}$ adsorption is beneficial to catalytic activity. However, strength of basic sites should be moderated to avoid carbonate formation and catalyst deactivation.

\subsection{Oxidation of chlorine- and sulfur-containing compounds}

\subsubsection{Chlorinated VOCs}

Chlorinated compounds are toxic VOCs. They also contribute to the depletion of the ozone layer. Therefore, drastic rules regulate their use, some of them (CFC, chloroflurorocarbons) being prohibited. Several reviews or book chapters were devoted to the oxidation of chlorinated hydrocarbons by the group of Bilbao [180,181] while the specific use of zeolites for the abatement of persistent organic pollutants (including PCDD/Fs, polychlorinated dibenzo-dioxins/furans) was reviewed by Marie-Rose et al. [182]. Only the most recent works on some chlorinated hydrocarbons (methane, ethane, ethylene, benzene) will be reviewed.

Dichloromethane (DCM). The oxidative dechloration of DCM can lead to the following reactions:

$$
\begin{aligned}
& \mathrm{CH}_{2} \mathrm{Cl}_{2}+\mathrm{O}_{2} \rightarrow \mathrm{CO}_{2}+2 \mathrm{HCl} \\
& \mathrm{CH}_{2} \mathrm{Cl}_{2}+3 / 2 \mathrm{O}_{2} \rightarrow \mathrm{CO}_{2}+\mathrm{Cl}_{2}+\mathrm{H}_{2} \mathrm{O}
\end{aligned}
$$


Hydrochloric acid is the desired product since it can be easily eliminated by washing of the gases with alkaline solutions. Chlorine may be formed directly by $\mathrm{Cl}$ recombination or by the Deacon reaction (Eq. 6.10):

$$
2 \mathrm{HCl}+1 / 2 \mathrm{O}_{2} \rightarrow \mathrm{Cl}_{2}+\mathrm{H}_{2} \mathrm{O}
$$

Formaldehyde and formic acid may also be produced by DCM hydrolysis over acid sites (Eq. 6.11):

$$
\mathrm{CH}_{2} \mathrm{Cl}_{2}+\mathrm{H}_{2} \mathrm{O} \rightarrow \mathrm{HCHO}+2 \mathrm{HCl}
$$

Total oxidation of DCM (1000 ppm in 10\% $\mathrm{O}_{2}$ ) was investigated over CeOx-doped titania by Cao et al. [183]. Titania has Lewis acid sites responsible for the adsorption and the rupture of $\mathrm{C}-\mathrm{Cl}$ bonds. But titania is rapidly poisoned by accumulation of chlorinated species. The role of ceria would be to allow a fast desorption of $\mathrm{Cl}$ species (as $\mathrm{Cl}_{2}$ or $\mathrm{HCl}$ ). The reaction starts below $200^{\circ} \mathrm{C}$ and total conversion of $\mathrm{DCM}$ is achieved at $350^{\circ} \mathrm{C}$. Significant amounts of reaction intermediates are observed in the $200-35^{\circ} \mathrm{C}$ temperature range on undoped titania: $\mathrm{CO}, \mathrm{CH}_{3} \mathrm{Cl}$, formic acid, methyl formate, ... The presence of ceria drastically reduces the formation of these intermediates.

1,2-Dichloroethane (DCE). DCE oxidation was studied by Yang et al. over $\mathrm{CeO}_{2}-\mathrm{CrOx}$ mixed oxides supported on carbon [184]. They showed that $\mathrm{CeCrOx}$ catalysts could be improved by supporting them over certain acidic supports [185]. Niobia gives the best promotion: the intrinsic activity is slightly higher and is associated with a better selectivity to $\mathrm{HCl}$. DCE oxidation can also give rise to the formation of chloroethylene $\mathrm{C}_{2} \mathrm{H}_{3} \mathrm{Cl}$ which is significantly reduced over $\mathrm{CeCrOx} / \mathrm{Nb}_{2} \mathrm{O}_{5}$ than on unsupported $\mathrm{CeCrOx}$. The promotion of the catalysts by niobia is linked to the increase of $\mathrm{Ce}^{3+}$ and $\mathrm{Cr}^{6+}$ species at the surface of $\mathrm{CeCrOx}$. The simple association of ceria with zeolitic support may give good performances in DCE oxidation. De Rivas showed that impregnation of $\mathrm{H}$ $\mathrm{ZSM}_{5}$ with cerium (III) nitrate in ethanol gives a solid able to totally oxidize DCE below $250^{\circ} \mathrm{C}\left(\mathrm{T}_{50}=195^{\circ} \mathrm{C}\right)[186]$. Al-substituted $\mathrm{LaMnO}_{3}$ perovskites were also studied for DCE oxidation [187]. The most active system is $\mathrm{Al}_{0.2} \mathrm{La}_{0.8} \mathrm{MnO}_{3}$ with a $\mathrm{T}_{50}$ of $295^{\circ} \mathrm{C}$ (1000ppm DCE in wet air, VVH of $20000 \mathrm{~h}^{-1}$ ). Surface analysis revealed that the optimal catalyst has the highest $\mathrm{Mn}^{4+} /\left(\mathrm{Mn}^{3+}+\mathrm{Mn}^{4+}\right)$ ratio.

Cobalt-based catalysts were also developed for DCE oxidation by the Group of Bilbao $[188,189] . \mathrm{Co}_{3} \mathrm{O}_{4}$ supported on Ca-deficient hydroxyapatite are active for DCE oxidation but high selectivity to $\mathrm{CO}_{2}$ requires a high cobalt loading [188]. Catalysts with low-loading of cobalt tend to form CO and vinylchloride. SBA-15 is also a good support of cobalt with $\mathrm{T}_{50}$ around $330^{\circ} \mathrm{C}$ [189]. Cobalt oxide loadings higher than $30 \mathrm{wt} \%$ present an adequate activity for the deep DCE oxidation. An optimum equilibrium between acidic properties (weak Brønsted acidity of the silica support and Lewis acidity of the cobalt oxide particles) and redox properties should be reached in order to favour $\mathrm{HCl}$ formation.

Trichloroethylene (TCE). Oxidation of TCE was studied by Yang et al. over ceria-MOx mixed oxides with a Ce/M ratio of $4(\mathrm{M}=\mathrm{V}, \mathrm{Cr}, \mathrm{Mn}, \mathrm{Fe}, \mathrm{Co}, \mathrm{Ni}$ and $\mathrm{Cu})$ [190]. $\mathrm{CeO}_{2}-\mathrm{CrOx}$ and $\mathrm{CeO}_{2}-\mathrm{CuO}$ are the most active catalysts for TCE oxidation. Final chlorinated products are $\mathrm{HCl}$ and $\mathrm{Cl}_{2}$. Tetrachloroethylene $\left(\mathrm{C}_{2} \mathrm{Cl}_{4}\right)$ is an intermediate of reaction. However $\mathrm{CeO}_{2}-\mathrm{CrOx}$ has the highest selectivity to $\mathrm{HCl}$ and the lowest to $\mathrm{Cl}_{2}$ and $\mathrm{C}_{2} \mathrm{Cl}_{4}$, which makes this catalyst more attractive for $\mathrm{Cl}-\mathrm{VOC}$ abatement. BEA zeolite is a good support of Cu and Co for TCE oxidation [191]. Catalysts prepared by ion exchange of the zeolite beta give the best performance and Cu-BEA is much 
more active than Co-BEA. When Cu or Co salt are incorporated during the zeolite synthesis, activity are relatively modest, probably because this method tends to produce non-acidic catalysts. As for many VOC compounds, association of plasma and catalysis is a good way to oxidize TCE at low temperature [192,193]. However, the control of selectivity is not total (a lot of CO may be produced) and the nature of the oxidant species (ozone, oxygen reactive species, NO issuing from air, ...) is not clarified.

\subsubsection{Sulfur compounds}

Oxidation of sulfur compounds (SVOC) has not been as much studied as that of other VOC. Partial oxidation by $\mathrm{H}_{2} \mathrm{O}_{2}$ or hydroperoxides can be used to transform organic sulfides of gasoils or gasolines into oxidized products (sulfoxides, sulfones) more easily eliminated by extraction. This process is known as "Oxidative desulfurization process" (ODP) developed for the ultimate purification of gasoline or gasoils $[194,195] . \mathrm{H}_{2} \mathrm{O}_{2}$ or hydroperoxides being expensive, attempts were made to oxidize sulfur compounds directly by $\mathrm{O}_{2}$ [196]. Elimination of the $\mathrm{SOx}$ produced in SCOV oxidation is not a facile task. It is advantageous to produce selectively $\mathrm{SO}_{2}$ instead of $\mathrm{SO}_{3}$ which tends to form sulfuric acid in the presence of moisture. Another problem with SVOC is their strong odor at the ppb level, which imposes a severe elimination very close to $100 \%$. While there are numerous reviews on VOC abatement, very few of them deal with the treatment of SVOC. In this respect, the review by Ojala et al. deserves special attention [197]. Methyl mercaptan $\mathrm{CH}_{3} \mathrm{~S}(\mathrm{MM})$, dimethyl sulfide $\mathrm{CH}_{3}-\mathrm{S}-\mathrm{CH}_{3}$ (DMS), dimethyl disulfide $\mathrm{CH}_{3}-\mathrm{S}-\mathrm{S}-\mathrm{CH}_{3}$ (DMDS), thiophene $\mathrm{C}_{4} \mathrm{H}_{4} \mathrm{~S}(\mathrm{~T})$, benzothiophene $\mathrm{C}_{8} \mathrm{H}_{6} \mathrm{~S}(\mathrm{BT})$ or dibenzothiophene $\mathrm{C}_{8} \mathrm{H}_{12} \mathrm{~S}$ (DBT) were generally taken as model compounds of SVOC. DMS is the major product of SCOV present in atmosphere. It can be oxidized by $\mathrm{OH}$ radicals according to the following sequence of reactions (eq. 6.12 and eq. 6.13) [198]:

$$
\begin{aligned}
& \mathrm{OH}+\mathrm{CH}_{3} \mathrm{SCH}_{3} \rightarrow \mathrm{CH}_{3} \mathrm{~S}(\mathrm{OH}) \mathrm{CH}_{3} \\
& \mathrm{CH}_{3} \mathrm{~S}(\mathrm{OH}) \mathrm{CH}_{3}+\mathrm{O}_{2} \rightarrow \text { products }\left(\mathrm{COx}, \mathrm{SOx}, \mathrm{H}_{2} \mathrm{O}\right)
\end{aligned}
$$

Catalytic ozonation of dimethyl sulfide and other VOC was investigated by Devulapelli and Sahle-Demessie over CuO- $\mathrm{MoO}_{3}$ [199] or $\mathrm{V}_{2} \mathrm{O}_{5}-\mathrm{TiO}_{2}$ catalysts [200] and, more recently, by Chand Soni et al. over Fe/ZrO2 catalysts [201]. $\mathrm{H}_{2} \mathrm{O}$ does not affect SVOC conversion [200]. Ozone acts as a strong Lewis base having a great affinity with $\mathrm{O}$ vacancies of $\mathrm{Fe}_{2} \mathrm{O}_{3}-\mathrm{ZrO}_{2}$ [201]. It is supposed that $\mathrm{Fe}^{3+}-\mathrm{O}-\mathrm{Zr}^{4+}$ structures are formed, very active in the C$\mathrm{S}$ bond splitting. A possible mechanism is depicted in Figure 6.12. 


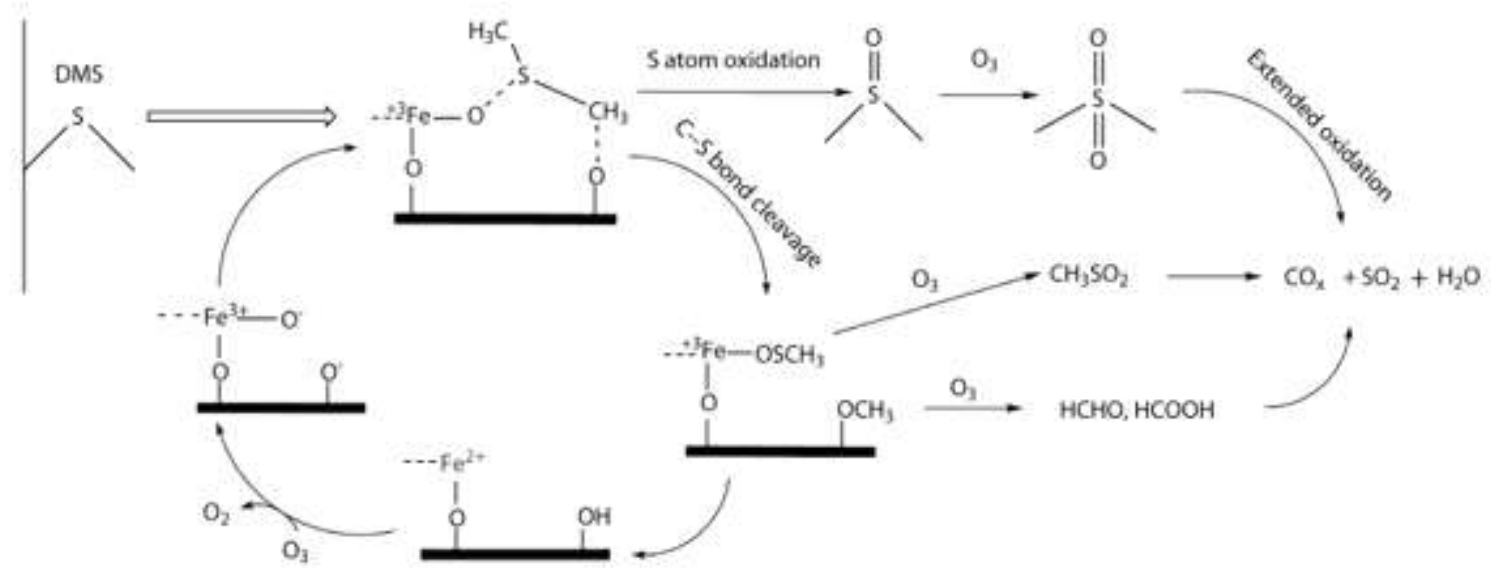

Figure 6.12. Possible reaction mechanism for the catalytic oxidation of DMS in presence of ozone over Fe catalysts. Taken from ref. [201].

Adsorption of SVOC on oxides of high oxidation state can lead to partial oxidation. DMS and ethyl mercaptan can thus be treated over $\mathrm{MnO}_{2}$ [202]. A further desorption in oxidative medium can lead to total oxidation products.

\subsection{Oxidation of automotive soots}

Automotive converters were implanted in Europe after 1990. The first regulation for soot particle emissions (EURO 1) specified that Diesel cars could not emit more than $140 \mathrm{mg}$ particles $/ \mathrm{km}$. Drastic improvements of the Diesel engines such as direct injection at very high pressure allow the car makers to meet the European standards up to 2008. EURO 4 imposing less than $5 \mathrm{mg} / \mathrm{km}$ after 2009, followed by EURO 5 and 6 restricting the emissions at $4.5 \mathrm{mg} / \mathrm{km}$, could not be respected by the most sophisticated, modern engines which emitted 20 $30 \mathrm{mg}$ particles in the best conditions. It was then necessary to implement Diesel particulates filters (DPF) on Diesel cars. These filters should be regenerated to avoid anomalous pressure drops in the exhaust pipe and defective engine operation. This involves burning the soots regularly, in the presence of a catalyst to lower the ignition temperature. The catalyst may be added to the fuel (fuel-borne catalyst, some ppm of a Ce or a Fe compound) or wash-coated on the filter walls. Catalysts added to the filter are generally composed of noble metals (mainly Pt). However, a great number of studies have been made to replace these NPs by oxide catalysts, much less expensive. Most studies are carried out by mixing carbon powder representative of soots with the catalysts. The catalytic activity is evaluated by a temperature-programmed oxidation in air. Single oxides were first evaluated. The study of Neeft et al. gives a good overview of the performance of 14 oxides and 4 alkali metal carbonates [203]. The main results of this study (Table 6.3) are: (i) $\mathrm{Co}_{3} \mathrm{O}_{4}$ is a very performing oxide, combining high combustion rate and quasi-total selectivity to $\mathrm{CO}_{2}$ (ii) oxides commonly used in oxidation may be ranked as follows: $\mathrm{CO}_{3} \mathrm{O}_{4}>>\mathrm{MnO}_{2}>\mathrm{CuO}>\mathrm{Fe}_{2} \mathrm{O}_{3}>\mathrm{Cr}_{2} \mathrm{O}_{3}$; (iii) alkali metal carbonates are excellent combustion agents, their activity increasing with the basicity $(\mathrm{Cs}>\mathrm{K}>\mathrm{Na}>\mathrm{Li})$. 
Table 6.3 Combustion rates at $60 \%$ conversion of carbon and mean $\mathrm{CO}_{2} / \mathrm{CO}$ ratio in the $40-80 \%$ range of conversion. Tight contact between carbon (U-printex Degussa) and catalyst (ratio 1:1). Measurements are made at $383^{\circ} \mathrm{C}$ for oxides and $279^{\circ} \mathrm{C}$ for carbonates. From ref [203].

\begin{tabular}{|c|c|c|c|c|c|}
\hline Oxide & $\begin{array}{l}\text { Reaction rate @ } \\
383^{\circ} \mathrm{C} \\
\left(\mu \mathrm{g} \mathrm{g}_{\text {carbon initial }}{ }^{-1} \mathrm{~s}^{-1}\right)\end{array}$ & $\begin{array}{l}\text { Mean } \\
\mathrm{CO}_{2} / \mathrm{CO} \\
\text { ratio }\end{array}$ & Carbonate & $\begin{array}{l}\text { Reaction rate @ } \\
279^{\circ} \mathrm{C} \\
\left(\mu \mathrm{g} \mathrm{g}_{\text {carbon initial }} \mathrm{S}^{-1}\right) \\
\end{array}$ & $\begin{array}{l}\text { Mean } \\
\mathrm{CO}_{2} / \mathrm{CO} \\
\text { ratio }\end{array}$ \\
\hline $\mathrm{PbO}$ & $>240$ & 20 & $\mathrm{Cs}_{2} \mathrm{CO}_{3}$ & 182 & 15 \\
\hline $\mathrm{CO}_{3} \mathrm{O}_{4}$ & 233 & 500 & $\mathrm{~K}_{2} \mathrm{CO}_{3}$ & 101 & 14 \\
\hline $\mathrm{V}_{2} \mathrm{O}_{5}$ & 203 & 6 & $\mathrm{Na}_{2} \mathrm{CO}_{3}$ & 65 & 18 \\
\hline $\mathrm{Ag}_{2} \mathrm{O}$ & 95 & 15 & $\mathrm{Li}_{2} \mathrm{CO}_{3}$ & 6 & 17 \\
\hline $\mathrm{MoO}_{3}$ & 66 & 5 & none & 0.003 & nd \\
\hline $\mathrm{CuO}$ & 27 & 6 & & & \\
\hline $\mathrm{Bi}_{2} \mathrm{O}_{3}$ & 22 & 8 & & & \\
\hline $\mathrm{MnO}_{2}$ & 21 & 150 & & & \\
\hline $\mathrm{Sb}_{2} \mathrm{O}_{3}$ & 20 & 8 & & & \\
\hline $\mathrm{CaO}$ & 16 & 7 & & & \\
\hline $\mathrm{La}_{2} \mathrm{O}_{3}$ & 13 & 8 & & & \\
\hline $\mathrm{Cr}_{2} \mathrm{O}_{3}$ & 12 & 3 & & & \\
\hline $\mathrm{Fe}_{2} \mathrm{O}_{3}$ & 7 & 6 & & & \\
\hline $\mathrm{NiO}$ & 1 & 5 & & & \\
\hline none & 0.9 & 2 & & & \\
\hline
\end{tabular}

Promotion of oxides ( $\mathrm{Mn}, \mathrm{Fe}, \mathrm{Co})$ by potassium was investigated by Jakubek et al. who showed that the promotion is due to the formation of bulk compounds between $\mathrm{K}$ and metal oxides [204]. This also allows formation of tunneled or layered structures, which enable very high potassium mobility. Another classical feature of the soot combustion is the specific reactivity of $\mathrm{NO}_{2} / \mathrm{O}_{2}$ mixtures allowing oxidation at much lower temperature than in $\mathrm{O}_{2}$ alone. This effect was studied in detail by Wasalathanthri et al. over mesoporous Mn oxides [205]. $\mathrm{NO}_{2}$ allows decreasing the ignition temperature and is particularly efficient on the less active oxides: while $\mathrm{T}_{50}$ in $\mathrm{O}_{2}$ varies between 300 and $400^{\circ} \mathrm{C}$ for the different $\mathrm{Mn}$ oxides, oxidation profiles are much closer with $\mathrm{T}_{50}$ varying from 270 to $300^{\circ} \mathrm{C}$ in $\mathrm{NO}_{2}+\mathrm{O}_{2}$ mixtures.

To-day, there is a so huge flow of publications mixtures.ver mixed oxides that it is not possible to be exhaustive. As several recent reviews were published on the subject, analysis of the literature will be restricted to the very most recent publications. Mixed oxide catalysts used in DPF are most often made of perovskites, of spinels or of cerium-based oxides (other than perovskites).

Perovskites for soot combustion. The use of perovskites for soot combustion was reviewed by Royer et al. [23], Mishra and Prasad [206] and Labhasetwar et al. [207]. $\mathrm{Co}_{3} \mathrm{O}_{4}$ being one of the most active oxide, Co-based perovskites were widely investigated. Sun et al. have synthetized core-shell Co NPs socketed on oxygendeficient layered perovskite composed of $\mathrm{Pr}_{0.5} \mathrm{Ba}_{0.5} \mathrm{MnO}_{3}$ (PBMO) partially substituted with cobalt [208]. The PBMO perovskite was impregnated with $10 \% \mathrm{Co}$ and treated in $\mathrm{H} 2$ at $500-850^{\circ} \mathrm{C}$. Part of $\mathrm{Mn}$ substitutes for Co (PBMCo) while $\mathrm{CO}^{\circ}$ nanoparticles are formed at the surface of the layered perovskite. The system is very active for soot combustion with $\mathrm{T}_{50}$ below $460^{\circ} \mathrm{C}$. PBMCo acts as $\mathrm{O}$ donor (superoxides species) which are spillovered to Co NP. During soot combustion, CoNP are covered by a layer of Co oxide, forming probably the active sites of oxidation. Lee et al. have prepared nanofibers of $\mathrm{La}_{1-x} \mathrm{Sr}_{x} \mathrm{CO}_{0.2} \mathrm{Fe}_{0.8} \mathrm{O}_{3-\delta}$ perovskite by electrospinning, which increases the high-contact area by trapping soot in the unique pore structure of the fibers [209]. Temperatures 
of soot oxidation are shifted down of $30-40^{\circ} \mathrm{C}$ with respect to a bulk perovskite of the same composition. Alkali metals being good promoters of soot oxidation, $\mathrm{K}$ promotion of $\mathrm{Mg}$-substituted $\mathrm{La}_{0.8} \mathrm{Ce}_{0.2} \mathrm{CoO}_{3}(\mathrm{LCCM})$ perovskite was investigated by Wang et al. [210] while Shao et al. focused their attention on the promotion of $\mathrm{LaCoO}_{3}$ by $\mathrm{Cs}$ [211]. 10\% $\mathrm{K}$ added to $\mathrm{Mg}-\mathrm{LCCM}$ shift down the temperature of maximal rate of combustion from 450 to $380^{\circ} \mathrm{C}[210]$. Comparatively, promotion of $\mathrm{LaCoO}_{3}$ by $\mathrm{Cs}$ seems modest and more marked in $\mathrm{NO}+\mathrm{O}_{2}$ $\left(\Delta \mathrm{T}_{50}=19^{\circ} \mathrm{C}\right)$ than in $\mathrm{O}_{2}\left(\Delta \mathrm{T}_{50}=9^{\circ} \mathrm{C}\right)$, which suggests that the alkali metal has a strong effect on NO activation [211]. In fact, Cs rather inhibits NO oxidation but significantly increases NOx adsorption. Silver can also be used as a promoter of soot oxidation. Dinamarca et al. have shown that the temperature of the maximal oxidation rate was shifted from $45^{\circ} \mathrm{C}$ for $\mathrm{LaMn}_{0.9} \mathrm{CO}_{0.1} \mathrm{O}_{3}$ to $371^{\circ} \mathrm{C}$ for $\mathrm{La}_{0.7} \mathrm{Ag}_{0.3} \mathrm{Mn}_{0.9} \mathrm{Co}_{0.1} \mathrm{O}_{3}$ perovskite [212]

Spinels and other structures. Spinel chromites were investigated for soot combustion. Wang et al. have prepared three-dimensionally ordered macroporous (3DOM) spinel-type $\mathrm{MCr}_{2} \mathrm{O}_{4}(\mathrm{M}=\mathrm{Co}, \mathrm{Ni}, \mathrm{Zn}, \mathrm{Mn}$ ) catalysts by a citrate route in the presence of polymethyl methacrylate (PMMA) microspheres [213]. After dissolution of PMMA microspheres, open structures of 3DOM spinel are formed that allows a good contact of carbon soots with the catalyst and a higher oxidation rate (Figure 6.13).
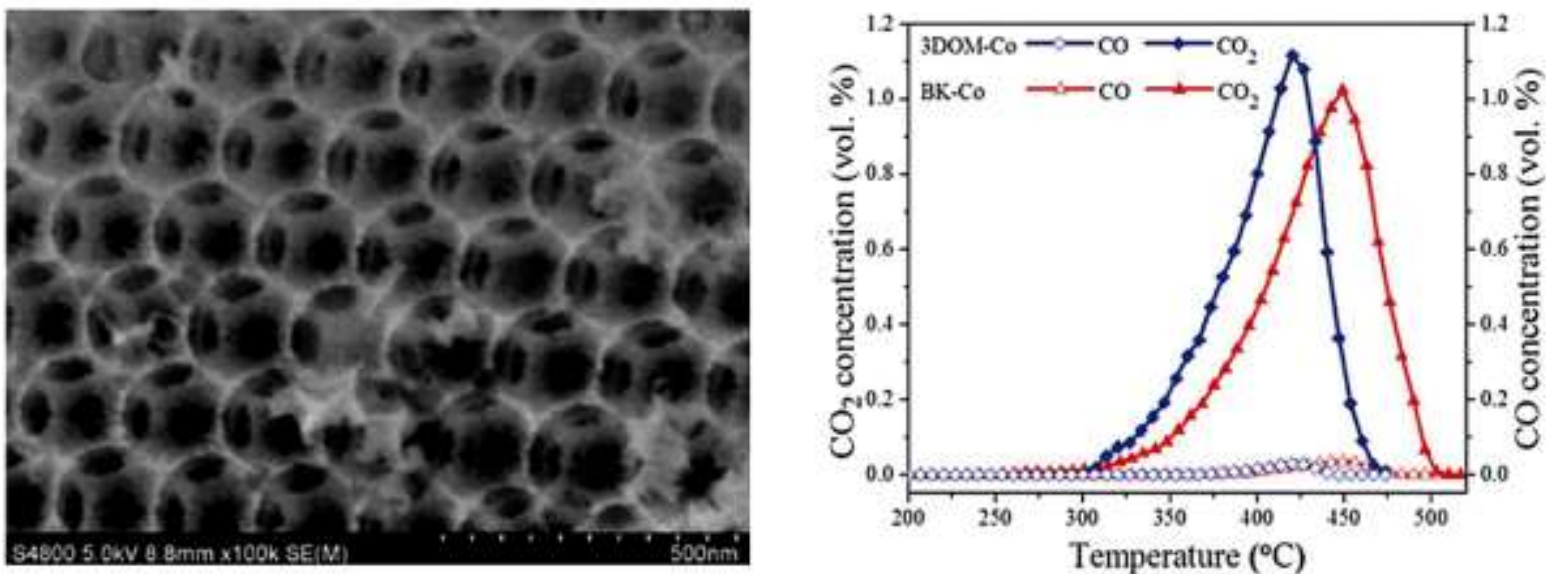

Figure 6.13. SEM image of $3 \mathrm{D}-\mathrm{CoCr}_{2} \mathrm{O}_{4}$ spinel (left) and soot oxidation on this catalyst (right). The $3 \mathrm{DOM}$ $\mathrm{CoCr}_{2} \mathrm{O}_{4}$ catalyst (3DOM-Co, $40 \mathrm{~m}^{2} \mathrm{~g}^{-1}$ ) is prepared using monodisperse polymethyl methacrylate (PMMA) microspheres with an average size of $360 \mathrm{~nm}$ as the colloidal crystal template. For the soot oxidation $\left(5 \% \mathrm{O}_{2}+2500 \mathrm{ppm} \mathrm{NO}\right)$, 10omg of catalyst is intimately mixed with $10 \mathrm{mg}$ of soot (MA10o Mitsubishi); temperature ramp of $2^{\circ} \mathrm{C} \mathrm{min}^{-1}$. Oxidation profile of BK-Co (bulk $\mathrm{CoCr}_{2} \mathrm{O}_{41} 62 \mathrm{~m}^{2} \mathrm{~g}^{-1}$ ) is given for comparison. From ref. [213].

Chromite of cobalt can also be improved by substituting a part of the cobalt by cerium. Niu et al. have shown that mesoporous $\mathrm{Ce}_{0.1} \mathrm{CO}_{0.9} \mathrm{Cr}_{2} \mathrm{O}_{4}$ spinels $\left(165 \mathrm{~m}^{2} \mathrm{~g}^{-1}\right)$ were much more active than the non-substituted $\mathrm{CoCr}_{2} \mathrm{O}_{4}$ spinel with a decrease of the oxidation temperature of soot of $59^{\circ} \mathrm{C}$ [214]. Pyrochlores are also promising catalysts for soot oxidation. Wang investigated $\mathrm{Ln}_{2} \mathrm{Sn}_{2} \mathrm{O}_{7}$ pyrochlores $(\mathrm{Ln}=\mathrm{La}, \mathrm{Nd}$ and $\mathrm{Sm}$ ) and showed that $\mathrm{La}_{2} \mathrm{Sn}_{2} \mathrm{O}_{7}$ possessed the most interesting properties [215]. However, these materials seemed not better than the perovskites and spinels reviewed above.

Ceria-based catalysts. A considerable number of studies were published on these catalysts probably because cerium species were originally used as fuel-borne catalyst, which prompted authors to consider that small amounts of cerium oxides could be very active for soot combustion. Moreover, the extraordinary redox 
properties of ceria-based oxides allowed to imagine that $O$ transfer from gaseous phase to soot could be facilitated on these materials [216]. Ceria-based catalysts for soot oxidation were reviewed by Bueno-López in 2014 [217] and by Montini et al. in 2016 [218]. Accordingly, only papers published after this date will be examined. Voskanyan et al. have prepared mesoporous ceria by utilizing colloidal $\mathrm{SiO}_{2}$ as a template [219]. The procedure is similar to the one used by Wang et al. [213] illustrated in Figure 6.7A, except that PMMA polymer microspheres are replaced by colloidal silica nanoparticles of about $20 \mathrm{~nm}$. A shift of $70^{\circ} \mathrm{C}$ on the temperature of soot oxidation was observed on the mesoporous ceria with respect to a conventional sol-gel ceria. The role of ceria morphology (nanorods, nanocubes,...) was investigated by Aneggi et al. [220] et by Zhang et al. [221]. Aneggi et al. conclude that higher activity is observed over nanocubes and nanorods as compared with polycrystalline ceria octahedral particles [220]. Thermal aging at $\mathrm{T}>500^{\circ} \mathrm{C}$ markedly affects the crystal shape by truncation of the edges and corners (Figure 6.14). Finally thermal aging tends to give materials having similar soot oxidation activity.

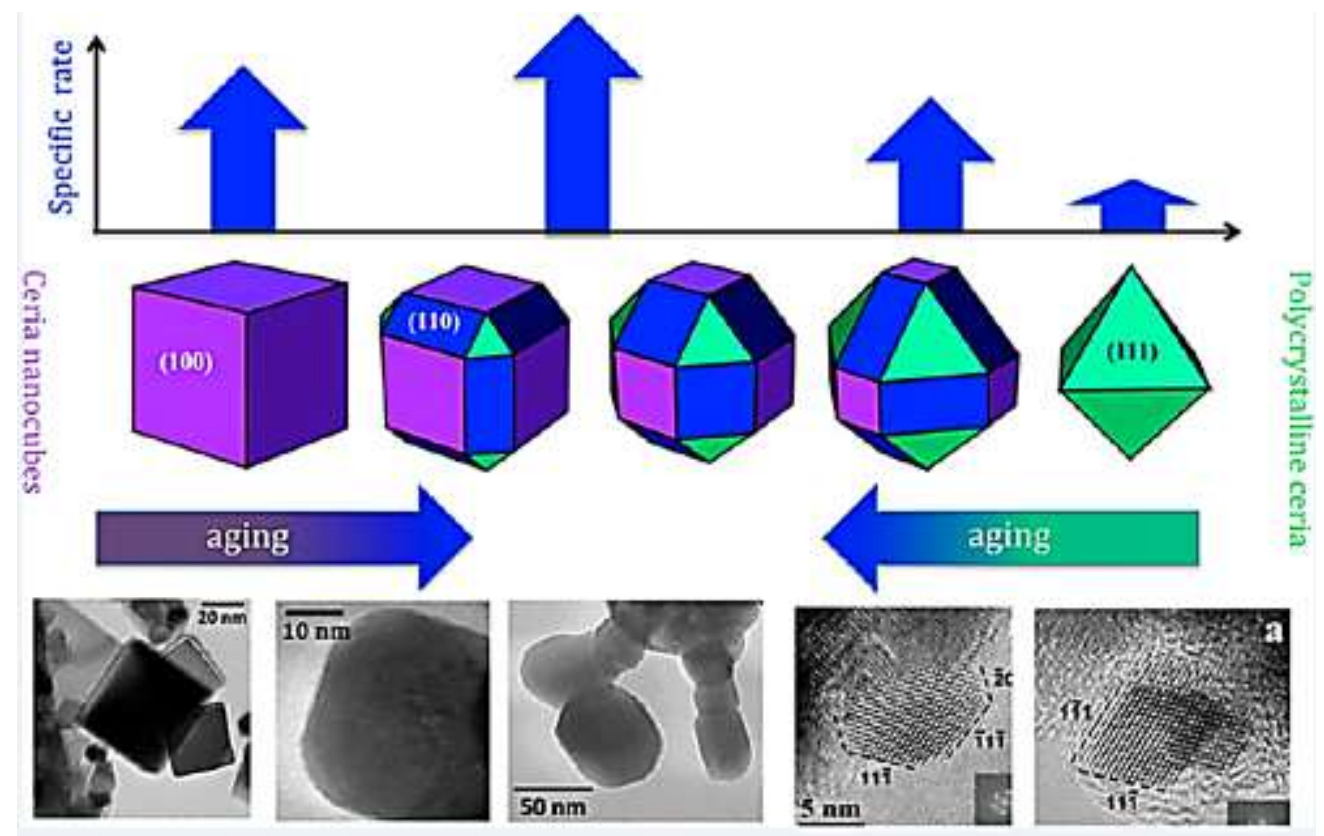

Figure 6.14 Role of crystal shape of ceria on the relative rate of soot oxidation. Nanocubes and nanorods are initially more active. But thermal aging creates edge and corners on polycrystalline particles, which tends to make them similar to cubes and rods in term of catalytic activity. From ref. [220].

Similar conclusions were reported by Zhang et al. with a very good activity of nanorods, compared to nanoparticles and nanoflakes [221]. The intimate mechanism of soot oxidation was investigated by means of ambient pressure photoemission spectroscopy [222]. It appears that carbon is consumed in two cooperative steps: (i) reaction of $\mathrm{O}_{2}$ at the ceria-soot interface forming $\mathrm{O}$ vacancies and reduced $\mathrm{Ce}$ (III) species; (ii) direct reaction of $\mathrm{O}_{2}$ on soot by active superoxides species which result from the reaction of gaseous $\mathrm{O}_{2}$ on $\mathrm{O}$ vacancies. This result is in line with the formation of $\mathrm{Ce}_{6} \mathrm{O}_{11}$ nanodomains during soot combustion [223]. There is strong indication that the contact between ceria or ceria-ziconia and soot plays a decisive role on carbon oxidation. Aneggi et al. demonstrated that a 2D layer of carbon wrapping CeZrOx particles could be oxidized at very low temperature (onset oxidation at $70-100^{\circ} \mathrm{C}$ and maximum rate between 250 and $270^{\circ} \mathrm{C}$ ) [224]. Activity 
of ceria can be improved by addition of praseodymium, $\mathrm{Ce}_{0.5} \mathrm{Pr}_{0.5} \mathrm{O}_{2}$ being more active than ceria [225] or $\mathrm{Ce}_{0.5} \mathrm{Zr}_{0.5} \mathrm{O}_{2}$ catalysts [226]. Combining $\mathrm{Pr}$ and $\mathrm{Zr}$ in $\mathrm{Ce}_{0.8} \mathrm{Zr}_{0.1} \mathrm{Pr}_{0.1}$ is also a possibility to improve activity of pure ceria [227]. Finally, addition of Fe [228] or $\mathrm{Cu}[229,230]$ can give promising performances in soot oxidation, particularly in $\mathrm{NO}+\mathrm{O}_{2}$.

\subsection{Nitrogen-containing compounds}

Nitrogen compounds, including nitrogen oxides $\left(\mathrm{NO}\right.$ and $\left.\mathrm{NO}_{2}\right)$ and nitrous oxide $\left(\mathrm{N}_{2} \mathrm{O}\right)$ are currently considered as dangerous air pollutants involved in acid rains, photochemical smog, ozone depletion, greenhouse effect and can have direct harmful effects on human health. Consequently, standards are applicable for major sources of air pollution to limit discharge of nitrogen compounds.

\subsubsection{Scope of the section}

Worldwide, the selective catalytic reduction (SCR) technology is well established as an emissions control system for stationary and mobile source. Lean NOx trap (LNT), also called NOx storage-reduction (NSR), is another deNOx after-treatment process to control NOx emissions of direct injection gasoline and Diesel engines of vehicles. The NSR (or LNT) system operates in transient conditions. It works mainly in lean condition. NOx are then oxidized on precious metals and stored on basic compounds, mainly as nitrates. Periodically, the catalyst is submitted to rich conditions for a few seconds and the previously stored NOx are reduced into $\mathrm{N}_{2}$ on the precious metals. To the opposite, the SCR system aimed to reduce NOx in continuous in an oxygen-rich environment and requires a reductant agent to convert NOx to nitrogen. To this purpose, the typical on-boarded reductant is an aqueous solution of urea. Ammonia is then obtained by two consecutive reactions: the "urea thermolysis" (Eq. 6.14) leading to $\mathrm{NH}_{3}$ and HNCO, and the "HNCO hydrolysis" (Eq. 6.15), leading to the second $\mathrm{NH}_{3}$ molecule to provide the expected amount of reductant. The deNOx reactions are then assumed to occur via the so-called $\mathrm{NH}_{3}$-SCR process.

$$
\begin{aligned}
& \left(\mathrm{NH}_{2}\right) \mathrm{CO}\left(\mathrm{NH}_{2}\right) \rightarrow \mathrm{NH}_{3}+\mathrm{HNCO} \\
& \mathrm{HNCO}+\mathrm{H}_{2} \mathrm{O} \rightarrow \mathrm{NH}_{3}+\mathrm{CO}_{2}
\end{aligned}
$$

Higher deNOx performances are obtained in both system (SCR and LNT) when the $\mathrm{NO}_{2}$ concentration to the input of deNOx technology is boosted. Usually, a Diesel Oxidation Catalyst (DOC) is placed upstream the deNOx converter to partially convert $\mathrm{NO}$ into $\mathrm{NO}_{2}$. The exhaust gas enriched with $\mathrm{NO}_{2}$ allows the onset of the $\mathrm{SCR}$ reaction by ammonia at lower temperature. It enables to achieve the fast-SCR stoichiometry. $\mathrm{NO}_{2}$ is also more appropriate for the storage step of the NSR process. As a consequence, the oxidation reaction of $\mathrm{NO}$ to $\mathrm{NO}_{2}$ remains from a great interest for the efficiency of $\mathrm{NOx}$ emissions control system. $\mathrm{NO}_{2}$ also presents a powerful oxidizing ability thereby participates to the soots combustion trapped in the Diesel particulate filter (DPF). The deNOx after-treatment technology, either SCR or LNT, also provide $\mathrm{NH}_{3}$ emissions that need to be contained to limit the ammonia slip.

At present, the $\mathrm{NH}_{3}-\mathrm{SCR}$ process is the preferred technology for $\mathrm{NOx}$ abatement in Diesel exhausts. The $\mathrm{WO}_{3}-\mathrm{V}_{2} \mathrm{O}_{5}-\mathrm{TiO}_{2}$ catalyst developed for stationary deNOx applications is now replaced by $\mathrm{Cu}$ or Fe-exchanged zeolites (mainly stabilized ferrierite, chabazite, SAPO or SSZ-13). Extensive reviews $[231,232,233]$ and 
outstanding studies, both on vanadium-based oxides $[234,235]$ or zeolite catalysts $[236,237,238]$ were devoted to this technology which is not detailed in this section mainly focused on oxidation reactions, important steps of the deNOx processes. In this respect, great efforts were made by industry and academia researchers to promote oxidation activities of $\mathrm{NO}$, urea and $\mathrm{NH}_{3}$ in the framework of Urea-SCR, $\mathrm{NH}_{3}-\mathrm{SCR}$ and LNT processes. This section is focused on reference oxide materials for these reactions.

\subsubsection{NO oxidation}

The control of soot/particulate matter $(\mathrm{PM})$ and $\mathrm{NOx}\left(\mathrm{NO}+\mathrm{NO}_{2}\right)$ emissions from Diesel vehicles is one of the most important and challenging problem since last few decades. Presently, the most effective technology to regulate PM emissions is the Diesel particulate Filter (DPF), in which the collected soot can be oxidized by $\mathrm{NO}_{2}$ (passive regeneration). The NOx selective catalytic reduction (SCR) by $\mathrm{NH}_{3}$ is worldwide well-established to control NOx emissions from stationary and mobile source urea (in this later case, urea is then used as $\mathrm{NH}_{3}$ carrier). The NOx conversion is assumed to be strongly dependant of the $\mathrm{NO}_{2}$ concentration to reach the socalled fast-SCR stoichiometry, i.e. when $\mathrm{NO}, \mathrm{NO}_{2}$ and $\mathrm{NH}_{3}$ are present in a 1:1:2 stoichiometry. NOx reduction can also be reached by the NOx storage-reduction (NSR) process. In this method, which alternates lean phase (storage) and rich phase (reduction), the adsorption step is largely enhanced when $\mathrm{NOx}$ are available as $\mathrm{NO}_{2}$.

Thus, the $\mathrm{NO}$ oxidation into $\mathrm{NO}_{2}$ remains from a great interest for the efficiency of both Diesel particulate filter and deNOx exhaust gas post-treatments. Catalysts from platinum group metals (PGM) are well-known to find practical applications for this reaction, but they have high cost and limited availability. Noble metals catalysts are also deactivated by high temperature or by poisoning due to the presence of numerous elements of the exhaust gas feed such as sulfur or alkaline metals. Consequently, great efforts were devoted to develop highly efficient noble metal-free catalysts for $\mathrm{NO}$ oxidation to $\mathrm{NO}_{2}$. Commonly, the catalyst supports are oxides such as alumina, silica, ceria (and derived oxides) and zeolites. The specific surface area and porosity, the surface properties and the interactions with active phase are also important factors that determine the activities of catalysts [239]. Considering that the $\mathrm{NO}$ oxidation into $\mathrm{NO}_{2}$ is mainly crucial for Diesel exhaust gas treatment and that the exhaust gas temperature is then quite low, the aim is to be able to oxidize $\mathrm{NO}$ to $\mathrm{NO}_{2}$ from the $150-$ $300^{\circ} \mathrm{C}$ temperature range.

The elementary steps of NO oxidation are thought to involve either Langmuir-Hinshelwood or Eley-Rideal mechanisms, which can be depicted by the following reactions (where $\square$ denotes an oxygen vacancy and $\mathrm{O} *$ an active oxygen on oxide material). The oxidation reaction (Eq. 6.16) is assumed to be rapid and equilibrated and dissociative adsorption (Eq. 6.17) is assumed to be rate limiting step [240].

$$
\begin{aligned}
& \mathrm{O}_{2}+2 \square \rightarrow 2 \mathrm{O} * \\
& \mathrm{NO}_{\text {(gas or adsorbed) }}+\mathrm{O} * \rightarrow \mathrm{NO}_{2}+\square
\end{aligned}
$$

The next parts of this section aims to report an overview of recent works published for NO oxidation over oxide based catalysts, organized by type of oxides, (ceria, cobalt, manganese, copper, perovskites, and finally zeolite microporous-based samples), considering the main active site (for instance, $\mathrm{Cu} / \mathrm{CeO}-\mathrm{ZrO}_{2}$ and $\mathrm{Cu} /$ zeolite catalysts are depicted in copper-based samples section). 
Ceria-based samples. For ceria bulk oxide, the maximum of $\mathrm{NO}$ oxidation to $\mathrm{NO}_{2}$ is observed around $450^{\circ} \mathrm{C}$, and above this temperature, the NO conversion is thermodynamically limited [241]. Consequently, great efforts were devoted to understand and improve the redox properties of noble metal-free ceria in the last years [242]. $\mathrm{Ce}_{x} \mathrm{Zr}_{1-\mathrm{x}} \mathrm{O}_{2}$ mixed oxides with different $\mathrm{Ce} / \mathrm{Zr}$ ratio were evaluated in $\mathrm{NO}$ oxidation by several authors. For instance, Lopez et al. [243] studied the NO oxidation of ceria-zirconia catalysts by catalytic tests performed in a fixed-bed reactor under a $500 \mathrm{ppm} \mathrm{NOx}+5 \% \mathrm{O}_{2}$ gas flow $\left(500 \mathrm{ml} / \mathrm{min} ; \mathrm{GHSV} 30000 \mathrm{~h}^{-1}\right.$ ). It appears that all the cerium containing catalysts accelerate the oxidation of $\mathrm{NO}$ to $\mathrm{NO}_{2}$ to the opposite of $\mathrm{ZrO}_{2}$ sample, accordingly to $[244,245]$. However, $\mathrm{Ce}_{0.76} \mathrm{Zr}_{0.24} \mathrm{O}_{2}$ and $\mathrm{CeO}_{2}$ present the same $\mathrm{NO}_{2}$ profile, with $\mathrm{NO}_{2}$ formation starting from approximately $275^{\circ} \mathrm{C}$ and a maximum $\mathrm{NO}_{2}$ level at $450^{\circ} \mathrm{C}\left(30 \%\right.$ of $\mathrm{NO}_{2}$ yield).

The addition of lanthanide cations with variable oxidation state $(+3 /+4)$, such as praseodymium, also deserves particular interest to enhance the ceria redox behavior. The corresponding $\mathrm{Ce}_{\mathrm{x}} \mathrm{Pr}_{1-\mathrm{x}} \mathrm{O}_{2-\delta}$ mixed oxides allows the oxygen exchange at a lower temperature compared with pure ceria. The kinetic and structural studies of oxygen availability of the mixed $\operatorname{Pr}_{1-x} \mathrm{M}_{x} \mathrm{O}_{y}(\mathrm{M}=\mathrm{Ce}$ or $\mathrm{Zr}$ ) oxides was studied by Sinev [246]. Addition of either $\mathrm{Ce}$ or $\mathrm{Zr}$ to pure Pr oxide affects both the total amount of oxygen that can be reversibly exchanged between oxide and gas phase and the kinetics of the redox processes. The addition of praseodymium in the ceria network increases the creation of oxygen vacancies and induces more labile oxygen species. It results that Ce promotion dramatically increases the oxygen exchange ability (per Pr atom) and lowers the temperature of exchange, while speed up the rate of $\mathrm{Pr}_{1-x} \mathrm{Ce}_{x} \mathrm{O}_{y}$ mixed oxides in oxygen exchange reaction. These results are supported by the lower binding energy values for $\mathrm{Ce}-\mathrm{O}$ bond than for $\mathrm{Pr}-\mathrm{O}$ bond, and also because the $\mathrm{Ce}^{3^{+}}$ionization energy which is $2.22 \mathrm{eV}$ lower than for $\mathrm{Pr}^{3^{+}}$.

Giménez-Mañogil et al. [247] analyzed the trends in catalytic activities toward the $\mathrm{NO}$ oxidation to $\mathrm{NO}_{2}$ of various ceria-praseodymia mixed oxides. Catalytic tests were performed in a fixed-bed reactor under a $500 \mathrm{ppm}$

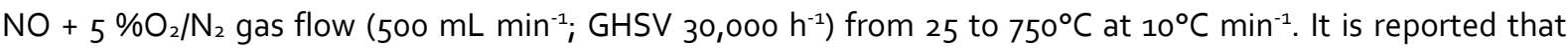
increasing the praseodymium content in $\mathrm{Ce}_{x} \mathrm{Pr}_{1-\mathrm{x}} \mathrm{O}_{2-\delta}$ formulation led to higher $\mathrm{NO}_{2}$ production. Additionally, the maximum $\mathrm{NO}_{2}$ production was shifted to lower temperatures. For instance, the ceria doping with only 20 $\mathrm{mol} \% \operatorname{Pr}\left(\mathrm{Ce}_{0.8} \mathrm{Pr}_{0.2} \mathrm{O}_{2-\delta}\right)$ led to an increase of the $\mathrm{NO}$ conversion from 24 to $39 \%$ at $375^{\circ} \mathrm{C}$. Increase $\operatorname{Pr}$ amount in $\mathrm{Ce}_{x} \mathrm{Pr}_{1-x} \mathrm{O}_{2-\delta}$ mixed oxide $\left(\mathrm{Ce}_{0.5} \mathrm{Pr}_{0.5} \mathrm{O}_{2-\delta}\right.$ and $\left.\mathrm{Ce}_{0.2} \mathrm{Pr}_{0.8} \mathrm{O}_{2-\delta}\right)$ led to a supplementary improvement of the maximum $\mathrm{NO}_{2}$ production. It also results that the BET surface area is not a determining parameter in the $\mathrm{NO}_{2}$ production. In fact, pure praseodymia presented the highest $\mathrm{NO}_{2}$ production ( $48 \%$ at $375^{\circ} \mathrm{C}$ ), therefore indicating that $\mathrm{Pr}$ based oxides are very active for the $\mathrm{NO}$ oxidation to $\mathrm{NO}_{2}$. TG-MS experiments revealed that pure ceria is not able to release $\mathrm{O}_{2}$ under inert atmosphere, but ceria-praseodymia mixed oxides and pure praseodymia presented different $\mathrm{O}_{2}$ evolution profiles. In addition, the recorded $\mathrm{CO}_{2}$ profiles show that the surface carbonates amount increases with the Pr content. These carbonates do not seem to inhibit the NO oxidation reaction. The Lewis acid character of $\mathrm{NO}$ and $\mathrm{NO}_{2}$, which tend to react with basic oxygen sites, was proposed to displace the surface carbonate species [243]. Interestingly, $\mathrm{H}_{2}$-TPR results were correlated to NO oxidation to $\mathrm{NO}_{2}$ trends. It is reported that the reduction temperature decreases together with the increase of the overall hydrogen consumption, with respect to the $\mathrm{Pr}$ amount in the $\mathrm{Ce}_{x} \operatorname{Pr}_{1-x} \mathrm{O}_{2-\delta}$ mixed oxide. 
Copper-based samples. Cerium-based oxides have been extensively studied in the framework of automotive emission control of pollutants from the exhaust gases of gasoline engines in the three-way catalysts (TWC). For instance, copper-doped ceria-zirconia mixed oxides $\left(\mathrm{Ce}_{0.8} \mathrm{Zr}_{0.2} \mathrm{O}_{2}\right)$ with different amounts of copper $(0.5,1,2,4$ and 6 wt-\%) were evaluated for $\mathrm{NO}$ oxidation to $\mathrm{NO}_{2}$ by Giménez-Mañogil et al.[248]. Characterizations revealed that copper was well-dispersed onto the ceria-zirconia support for the catalysts with low copper loading. To the opposite, CuO particles were identified by XRD and XPS in samples with 4 and 6 wt $\%$ of copper. Additionally, both specific surface area and pore volume concurrently diminished for catalysts with more than 1 wt-\% copper loading, due to the blocking of porosity. Catalysts with copper drastically decreased the reduction temperature of $\mathrm{CuO} / c e r i a-z i r c o n i a ~ s a m p l e s ~ i n ~ \mathrm{H}_{2}$-TPR experiments, due to the synergistic effect conferred by the copper-ceria interfacial interactions. The maximum of activity was found for the $4 \% \mathrm{CuO} / \mathrm{ceria}$-zirconia composition, with $54 \%$ of $\mathrm{NO}$ conversion in $\mathrm{NO}_{2}$ at $348^{\circ} \mathrm{C}$. Note that a very low loading of copper significantly increased the activity for the $\mathrm{NO}$ oxidation to $\mathrm{NO}_{2}$ with regard to the ceria-zirconia support. Similarly, Wang et al. [249] reported that the dispersion of $\mathrm{CuO}$ species on the small crystallite size of $\mathrm{Ce}_{0.8} \mathrm{Zr}_{0.2} \mathrm{O}_{2}$ support was favorable for NO adsorption. The Cu-Ce-Zr solid solution provided the sites of oxygen vacancies, leading to the formation of active oxygen to improve the oxidation activity of NO. Interestingly, ternary oxides-base samples as $\mathrm{Ba}-\mathrm{Cu}-\mathrm{Ce}$ catalysts enabled to maintain higher activity for $\mathrm{NO}$ oxidation than with $\mathrm{CuO}_{\mathrm{x}}-\mathrm{CeO}_{2}$ mixed oxides after aging. In fact, Ba restrains the sintering of $(\mathrm{Cu}, \mathrm{Ce}) \mathrm{O}_{\mathrm{x}}$, resulting in relatively more favorable redox properties and thus higher activity for NO oxidation [250].

Copper exchanged zeolites are commonly used for the selective catalytic reduction (SCR) of NOx $\left(\mathrm{NO}\right.$ and $\left.\mathrm{NO}_{2}\right)$ with $\mathrm{NH}_{3}$, especially for mobile sources. This process is strongly dependent to the $\mathrm{NO}_{2} / \mathrm{NOx}$ ratio, and it is generally admitted that $\mathrm{NO}$ is first oxidized by $\mathrm{O}_{2}$ to form some types of surface complexes on the zeolite catalysts, which subsequently react with $\mathrm{NH}_{3}$ to form $\mathrm{N}_{2}$. The comparative activities of a small-pore $\mathrm{Cu}-\mathrm{CHA}$ (chabazite) and a large-pore Cu-BEA (Beta) catalyst for the oxidation of $\mathrm{NO}$ to $\mathrm{NO}_{2}$ and the subsequent formation of surface nitrates were investigated by Chen et al.[251]. Both catalysts presented a limited NO oxidation activity with around $20 \%$ of $\mathrm{NO}$ conversion into $\mathrm{NO}_{2}$ at $500^{\circ} \mathrm{C}$. In addition, the stability of surface nitrates compounds were investigated by TPD experiments following the adsorption of $\left(\mathrm{NO}_{2}+\mathrm{NO}+\mathrm{O}_{2}\right)$. Authors reported that the poor NO oxidation activity is not due to the formation of stable surface nitrates on the catalyst. On the contrary, NO was found to reduce and decompose surface nitrates, with different pathway in regard on Cu-CHA or CU-BEA sample. Interestingly, NO oxidation is favored by Cu ion dimers over exchanged copper zeolite and increasing the copper loading beyond the saturation point of the zeolite leads to a relatively higher proportion of $\mathrm{Cu}$ ions [252]. In addition, the site requirements and mechanism of dry NO oxidation were examined on a series of Cu-SSZ-13 catalysts by Ribeiro et al. [253]. Combined experimental and computational kinetic studies revealed at least two Cu ion configurations within hydrated SSZ-13, namely hydrated isolated $\mathrm{Cu}^{2+}$ ion $\left(\mathrm{as}\left[\mathrm{Cu}\left(\mathrm{H}_{2} \mathrm{O}\right)_{6}\right]^{2+}\right.$ ) and $\mathrm{Cu}_{x} \mathrm{O}_{y}$ species (clustered $\mathrm{Cu}^{2+}$ ions $\mathrm{x} \geq 2, \mathrm{y} \geq 1$ ) for low $(\mathrm{Cu} / \mathrm{Al}$ tot $<0.2)$ and high (Cu/Al tot>0.2) copper atomic ratio, respectively. It was reported that the hydrated isolated $\mathrm{Cu}^{2+}$ ions are quantitatively converted to dehydrated isolated $\mathrm{Cu}^{2+}$ ions under $\mathrm{NO}$ oxidation conditions and do not contribute to the rate of $\mathrm{NO}$ oxidation. To the opposite, the $\mathrm{Cu}_{x} \mathrm{O}_{y}$ species remain present under $\mathrm{NO}$ oxidation conditions 
and only the $\mathrm{Cu}$ dimers $\left(\mathrm{Cu}_{2} \mathrm{O}_{y}\right)$ with local $\mathrm{Cu}-\mathrm{O}_{y}-\mathrm{Cu}$ bonds can accommodate adsorption and dissociation of $\mathrm{O}_{2}$ necessary to catalyze NO oxidation. Complementary information about zeolites are available thereafter in the Zeolite and microporous-based materials section.

$\mathrm{NO}$ oxidation can be also performed over $\mathrm{Cu}$ doped $\mathrm{LaCoO}_{3}$ perovskite oxides. Various $\mathrm{LaCo}_{1-x} \mathrm{Cu}_{x} \mathrm{O}_{3}(\mathrm{x}=0.1$, $0.2,0.3$ ), synthesized using a modified sol-gel method, were studied by Zhou et al.[254]. $\mathrm{LaCO}_{0.9} \mathrm{Cu}_{0.1} \mathrm{O}_{3}$ sample exhibited the best performance and achieved a NO conversion of $82 \%$ at $310^{\circ} \mathrm{C}$. The following sequence was proposed for the catalytic activities: $\mathrm{LaCO}_{0.9} \mathrm{CU}_{0.1} \mathrm{O}_{3}>\mathrm{LaCoO}_{3}>\mathrm{LaCo}_{0.8} \mathrm{CU}_{0.2} \mathrm{O}_{3}>\mathrm{LaCO}_{0.7} \mathrm{CU}_{0.3} \mathrm{O}_{3}$. It appeared that high copper loading was not favorable for the NO oxidation. It was showed by means of structural characterizations (XRD, BET, FTIR and TEM) that increasing the Cu doping content results in the formation of isolated $\mathrm{CuO}$ on the surface of the oxides. It was proposed that the interaction between $\mathrm{Co}$ and $\mathrm{Cu}$ promoted the conversion of $\mathrm{NO}$ to $\mathrm{NO}_{2}$. It was also advanced that $\mathrm{Cu}$ doping would facilitate the reaction by decreasing the energy of oxygen vacancy formation and the $\mathrm{NO}_{2}$ desorption barrier from nitrites species.

As expected, numerous other copper supported catalysts are able to catalyze the NO oxidation reaction. For instance, $\mathrm{Cu} / \mathrm{TiO}_{2}$ catalysts was found active for the oxidation of $\mathrm{NO}$ to $\mathrm{NO}_{2}$ in oxygen-rich atmosphere, with an optimum temperature at about $350-400^{\circ} \mathrm{C}$ for around $60 \%$ of conversion [255]. However, the specific nature of active copper species was not addressed in this study.

Cobalt-based samples. Considering their high catalytic activity for oxidation reactions, $\mathrm{Co}_{3} \mathrm{O}_{4}$ based catalysts deserve particular attention. Irfan et al. [256] compared various transition metal oxides with cobalt-supported catalysts for the NO oxidation reaction. Experiments were performed in a fixed bed quartz reactor. The powder catalysts were loaded with an aid of quartz wool and heated to the desired reaction temperature. The reaction mixture consisted of $150 \mathrm{ppm} \mathrm{NO}, 8 \% \mathrm{H}_{2} \mathrm{O}, 10 \% \mathrm{O}_{2}$ balanced in $\mathrm{N}_{2}$ for a total gas flow rate of $1500 \mathrm{cc} / \mathrm{min}$. The following activities order was reported: $\mathrm{Co}_{3} \mathrm{O}_{4} / \mathrm{SiO}_{2}>\mathrm{Pt}-\mathrm{WO}_{3} / \mathrm{TiO}_{2}>\mathrm{Pt} / \mathrm{TiO}{ }_{2}>\mathrm{Pt} / \mathrm{SiO}_{2}>\mathrm{CuO}_{x} / \mathrm{TiO}_{2}>\mathrm{CO}_{3} \mathrm{O}_{4} / \mathrm{TiO} \mathrm{O}_{2}$ $>\mathrm{MnO}_{x} / \mathrm{TiO}_{2}>\mathrm{Pt} \mathrm{V}_{2} \mathrm{O}_{5} / \mathrm{TiO}_{2} . \mathrm{TiO}_{2}$ and especially $\mathrm{SiO}_{2}$ (from low surface area) supported $\mathrm{CO}_{3} \mathrm{O}_{4}$ (20 wt-\%) exhibited high activities. A maximum of $69 \% \mathrm{NO}$ conversion was reported at $300^{\circ} \mathrm{C}$ on $\mathrm{Co}_{3} \mathrm{O}_{4} / \mathrm{SiO}_{2}\left(4 \mathrm{~m}^{2} \mathrm{~g}^{-1}\right)$ with this high space velocity condition. Note that the activities of unsupported metal oxide catalysts for $\mathrm{NO}$ oxidation were also determined. Among the oxides tested $(\mathrm{Mn}, \mathrm{Co}, \mathrm{Cu}), \mathrm{Co}_{3} \mathrm{O}_{4}\left(35 \mathrm{~m}^{2} \mathrm{~g}^{-1}\right)$ is the most active catalyst (66\% of $\mathrm{NOx}$ converted at $300^{\circ} \mathrm{C}$, compared to $59 \%$ conversion for $\mathrm{MnO}_{x}$ sample of $8 \mathrm{~m}^{2} \mathrm{~g}^{-1}$ ). Authors concluded that the more oxidizing ability towards $\mathrm{NO}$ is the major reason for better activity of Co based catalysts, compared to $\mathrm{MnO}_{x}$ and $\mathrm{CuO}_{x}$ sample.

Huang et al. [257] studied cobalt oxide supported on mesoporous silica (1119 $\left.\mathrm{m}^{2} \mathrm{~g}^{-1}\right)$ for NO oxidation, and achieved about $82 \% \mathrm{NO}$ conversion at $300^{\circ} \mathrm{C}$, which was very good activity and quite comparable to noble metal catalysts. However, the use of mesoporous silica is still not considered for practical application due to thermal stability requirements. They also observed that high temperature calcination led to rapid decrease in catalytic activity, and sintering occurs at a temperature as low as about $300^{\circ} \mathrm{C}$.

Recently, Kim et al. [258] studied NO oxidation on supported cobalt oxide synthesized by conventional wet impregnation method using various supports including $\mathrm{CeO}_{2}, \mathrm{SiO}_{2}, \mathrm{ZrO}_{2}, \mathrm{TiO}_{2}$ and $\mathrm{SiO}_{2}$. Among tested 
catalysts, they reported that $\mathrm{CO}_{3} \mathrm{O}_{4}$ supported on high surface area ceria $\left(230 \mathrm{~m}^{2} \mathrm{~g}^{-1}\right.$ ) showed the highest catalytic activity with approximately $70 \%$ conversion at about $270^{\circ} \mathrm{C}$ using a weight-to-flow ratio of 0.045 g.s. $\mathrm{mL}^{-1}$. It resulted that the catalytic activity of cobalt oxide can be substantially improved by using high surface area supports with good thermal stability. Megarajan et al. [259] synthesized ceria supported cobalt oxide by the incipient wetness impregnation method. They obtained high catalytic activity for NO oxidation at moderate temperature $\left(80 \%\right.$ of $\mathrm{NO}$ oxidized at $300^{\circ} \mathrm{C}$ for $10 \mathrm{wt} \% \mathrm{Co}$ incorporated in $\mathrm{CeO}_{2}$ sample of $\left.61 \mathrm{~m}^{2} \mathrm{~g}^{-1}\right)$. The catalytic activity in NO oxidation was even comparable with those reported with noble metal based catalysts. It could be mainly due to the high dispersion of $\mathrm{CO}_{3} \mathrm{O}_{4}$ nanoparticles on ceria support with enhanced catalyst support interaction, also associated with an improvement of the redox properties of $\mathrm{CO}_{3} \mathrm{O}_{4}$-ceria catalyst.

Manganite-based samples. $\mathrm{MnO}_{\mathrm{x}}$ is widely used in $\mathrm{NO}$ oxidation due to their high catalytic efficiency and fairly cost-effective. Effects of Mn precursors [26o] and preparation methods [261] on NO oxidation over $\mathrm{Mn} / \mathrm{TiO}_{2}$ were studied. Chen et al. [262] indicated that adding Fe on $\mathrm{MnO}_{x}$ could increase the activity for NO oxidation into $\mathrm{NO}_{2}$. This result is supported by Zhao et al. [263] that also showed that the addition of Fe $\left(\mathrm{Fe}-\mathrm{La}-\mathrm{Mn} / \mathrm{Al}{ }_{2} \mathrm{O}_{3}\right)$ increased both $\mathrm{NO}$ conversion and resistance to $\mathrm{H}_{2} \mathrm{O}$ and $\mathrm{SO}_{2}$. Consequently, FeMnOx-based catalysts were expected to perform well for NO oxidation. The effect of loading sequences on the structure and activity of $\mathrm{FeMnO}_{\times} / \mathrm{TiO}_{2}$ catalyst was studied in [264]. The better catalytic activity was obtained from one-step impregnation method. For instance, $\mathrm{Fe}_{0.15}-\mathrm{Mn}_{0.3} / \mathrm{TiO}_{2}$ exhibited the highest catalytic activity, with a maximum NO conversion of $70 \%$ at $320^{\circ} \mathrm{C}$ (space velocity of $15000 \mathrm{~h}^{-1}$ ). The excellent activity was attributed to higher surface area, lower crystalline of manganese oxides, abundant $\mathrm{Mn}^{3+}, \mathrm{Fe}^{3^{+}}$and chemisorbed oxygen species $\left(\mathrm{O}_{\alpha}\right)$ on the surface.

Perovskite-based samples. Cobalt based perovskite type catalysts are well known to exhibit good activity for NO oxidation and therefore show a potential as substitute for Pt based NO oxidation catalysts. Wen et al. [265] studied series of $\mathrm{La}_{1-x} \mathrm{Ce}_{x} \mathrm{CoO}_{3}$ perovskite oxide catalysts for nitrogen monoxide oxidation, and reported approximately $80 \%$ conversion on $\mathrm{La}_{0.8} \mathrm{Ce}_{0.2} \mathrm{CoO}_{3}$ at $300^{\circ} \mathrm{C}$ under the W/F ratio of $0.096 \mathrm{~g} .5 . \mathrm{mL}^{-1}$. Kim et al. [266] also investigated the perovskite supported honeycomb catalysts for NO oxidation using $400 \mathrm{ppm} \mathrm{NO}$ and at space velocity of $30000 \mathrm{~h}^{-1}$, and reports remarkable NO conversion of $86 \%$ at about $300^{\circ} \mathrm{C}$ on $\mathrm{La}_{0.9} \mathrm{Sr}_{0.1} \mathrm{CoO}_{3}$. Under realistic conditions, $\mathrm{La}_{1-x} \mathrm{Sr}_{x} \mathrm{CoO}_{3}$ catalysts achieved higher $\mathrm{NO}$ conversion into $\mathrm{NO}_{2}$ than a commercial platinum-based DOC catalyst, constituting a promising way for a considerably lower-cost diesel exhaust treatment system.

Zeolite and microporous-based materials. Kim et al.[267] studied three different types of acid form zeolites, namely chabazite $(\mathrm{H}-\mathrm{CHA})$, beta $(\mathrm{H}-\mathrm{BEA})$, and mordenite $(\mathrm{H}-\mathrm{MOR})$ for the $\mathrm{NO}$ oxidation reaction. The corresponding catalysts presented a very low activity, with NO conversion below $2 \%$. However, authors reported that the acid form $\mathrm{H}-\mathrm{CHA}$ showed the highest activity due to the small pore cavity, which enhances the stability of the transition complex, assumed as $\mathrm{N}_{x} \mathrm{O}_{y}$ surface species $\left(\mathrm{NO}_{2}, \mathrm{~N}_{2} \mathrm{O}_{4}, \mathrm{~N}_{2} \mathrm{O}_{3}, \ldots\right)$. Similar results were previously reported by Lobo et al. [268]. By evaluating the NO oxidation activity over microporous materials, it was shown that NO oxidation is catalyzed by chabazite zeolites in the proton $\left(\mathrm{H}^{+}\right)$, sodium $\left(\mathrm{Na}^{+}\right)$ and siliceous forms, and by microporous carbons. The catalytic properties of the samples were attributed to 
their ability to stabilize a $\left[\mathrm{N}_{2} \mathrm{O}_{4}\right]^{2+}$ transition state within the micropores through van der Waals forces. Electrostatic effects from extra-framework cations within SSZ-13 samples (a CHA zeolite type) were shown to provide additional stabilization of the transition state and further enhanced reaction rates. SSZ-13 is favored for SCR processes because of its small-pore structure that enables to resist to dealumination effect from hydrothermal aging and to avoid structure collapse. The confinement effects from the framework that accelerate the gas-phase reaction were also proposed by Artioli et al. [269] to explain the NO oxidation activity of silicalite-1 (siliceous ZSM-5) and siliceous samples of zeolite beta (BEA) and chabazite (CHA). These results stated that no specific catalytic sites were present and that NO oxidation reaction proceeds via elementary steps. The obtained NO oxidation rates are much higher (by factors of $10^{4}$ ) than homogeneous reaction rates.

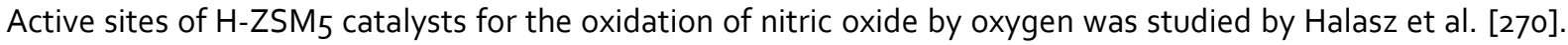
Authors concluded that Lewis acidic lattice (aluminium ions and silanol hydroxyls) are probably not the active sites in the catalytic oxidation of NO. To the contrary, the oxidation of $\mathrm{NO}$ to $\mathrm{NO}_{2}$ would be catalyzed above $200^{\circ} \mathrm{C}$ by Brønsted acidic bridging hydroxyls. Harold et al.[271] focused on the comparison of iron and copper exchanged ZSM-5 catalysts for the NO oxidation reaction. Combining comprehensive experimental and kinetic modeling studies, it was demonstrated that Fe-zeolite was more active in NO oxidation than Cu-zeolite. The presence of water in the gas mixture strongly inhibits the NO oxidation. Additionally, the instability of nitrates in the presence of $\mathrm{NO}$ was also reported and the surface reaction between adsorbed $\mathrm{O}$ atoms and gaseous $\mathrm{NO}$ was proposed as the rate determining step. It was also related that the $\mathrm{NO}_{2}$ is more strongly bound on $\mathrm{Cu}$ chabazite compared with Fe-ZSM-5.

\subsubsection{Ammonia oxidation}

The removal of ammonia from air or water is environmentally important. Currently, ammonia is removed from industrial flue gases via biological treatment by absorption, or by thermal combustion. An attractive alternative process is the selective catalytic oxidation (SCO) to nitrogen and water. Such technology may also find application in combination with the selective catalytic reduction (SCR) process, in which NOx is reduced to nitrogen using ammonia, to avoid $\mathrm{NH}_{3}$ slip. It can proceed in the following three principal ways below (Eq. 6.1820):

$$
\begin{aligned}
& 2 \mathrm{NH}_{3}+3 / 2 \mathrm{O}_{2} \rightarrow \mathrm{N}_{2}+3 \mathrm{H}_{2} \mathrm{O} \\
& 2 \mathrm{NH}_{3}+2 \mathrm{O}_{2} \rightarrow \mathrm{N}_{2} \mathrm{O}+3 \mathrm{H}_{2} \mathrm{O} \\
& 2 \mathrm{NH}_{3}+3 / 2 \mathrm{O}_{2} \rightarrow 2 \mathrm{NO}+3 \mathrm{H}_{2} \mathrm{O}
\end{aligned}
$$

With many practical catalysts, $\mathrm{N}_{2}, \mathrm{~N}_{2} \mathrm{O}$ and $\mathrm{NO}$ are formed simultaneously at $400-500^{\circ} \mathrm{C}$ in various proportions [272], but the N-compounds selectivity may be tune with appropriate materials. For instance, the main product is nitric oxide in the presence of platinum or cobalt oxide catalysts at $750-900^{\circ} \mathrm{C}$. With manganese oxide, nitrous oxide is formed at $300-400^{\circ} \mathrm{C}$. Ammonia can be oxidized into $\mathrm{N}_{2}$ over vanadium pentoxide at $500-600^{\circ} \mathrm{C}$. Overall, the oxidation of ammonia results in the formation of $\mathrm{N}_{2}$ at low temperature. $\mathrm{N}_{2} \mathrm{O}$ is observed by raising the temperature of reaction, its yield passing through a maximum. Ammonia is oxidized to a greater extent (NO) for higher temperatures. 
Mechanisms of the Langmuir-Hinshelwood type were proved to be unsuitable for the interpretation of the experimental data. It was proposed that the first step of the process involves the chemisorption of oxygen with the formation of the $\mathrm{O}_{2}{ }^{-}$anion, followed by the reaction of $\mathrm{NH}_{3}$ with surface oxygen to form adsorbed ( $\mathrm{NH}$ ) species, subsequently converted into surface nitroxyl (HNO). The final reaction products are $\mathrm{N}_{2}$ from $(\mathrm{NH})$ and (HNO) and/or $\mathrm{N}_{2} \mathrm{O}$ from two nitroxyl species.

Simple oxide-based samples. Catalytic behaviors of simple oxide for $\mathrm{NH}_{3}$ oxidation was studied by several authors. Lanthanide ( $\mathrm{La}, \mathrm{Ce}, \mathrm{Pr}$ ) oxides exhibit a low activity, while $\mathrm{Al}_{2} \mathrm{O}_{3}$ and $\mathrm{SiO}_{2}$ show activities even lower. The activity of barium peroxide tends to that of $\mathrm{Fe}_{2} \mathrm{O}_{3}$. Finally, according to II'chenko et al. [272] the activities of the single oxides decrease as follows:

$$
\begin{aligned}
& \mathrm{Co}_{3} \mathrm{O}_{4}, \mathrm{Mn}_{2} \mathrm{O}_{3}>\mathrm{Cr}_{2} \mathrm{O}_{3}>\mathrm{Fe}_{2} \mathrm{O}_{3}>\mathrm{CuO}>\mathrm{NiO}>\mathrm{V}_{2} \mathrm{O}_{5}>\mathrm{MoO}_{3}>\mathrm{ThO}_{2}>\mathrm{WO}_{3}>\mathrm{SnO}_{2}>\mathrm{ZrO}_{2}>\mathrm{ZnO} \\
& >\mathrm{Nb}_{2} \mathrm{O}_{5}>\mathrm{Bi}_{2} \mathrm{O}_{3}>\mathrm{Sb}_{2} \mathrm{O}_{4}>\mathrm{Ta}_{2} \mathrm{O}_{5}
\end{aligned}
$$

It appears that transition metal oxides such as $\mathrm{CO}_{3} \mathrm{O}_{4}, \mathrm{MnO}_{2}\left(\mathrm{Mn}_{2} \mathrm{O}_{3}\right), \mathrm{Cr}_{2} \mathrm{O}_{3}$ and $\mathrm{CuO}$ present the highest activities in the $\mathrm{NH}_{3}$ oxidation. $\mathrm{NiO}, \mathrm{Fe}_{2} \mathrm{O}_{3}$, and $\mathrm{V}_{2} \mathrm{O}_{5}$ oxides are moderately active, whereas the activities of the $\mathrm{La}_{2} \mathrm{O}_{3}, \mathrm{Pr}_{6} \mathrm{O}_{11} \mathrm{CeO}_{2}, \mathrm{TiO}_{2}, \mathrm{ZrO}_{2}, \mathrm{ThO}_{2}, \mathrm{Nb}_{2} \mathrm{O}_{5}, \mathrm{~T}_{2} \mathrm{O}_{5}, \mathrm{MoO}_{3}$ and $\mathrm{WO}_{3}$ are low. The higher selectivity regarding $\mathrm{N}_{2} \mathrm{O}$ is obtained with the most active oxides.

Complex and promoted oxide-based samples. Concerning the reaction involving the oxidation of $\mathrm{NH}_{3}$ to $\mathrm{N}_{2} \mathrm{O}$ at 200-300 ${ }^{\circ} \mathrm{C}$, it was reported that $\mathrm{MnO}_{2}$ with addition of $\mathrm{Bi}_{2} \mathrm{O}_{3}$ is extremely efficient [272]. Sazonova et al. [273] studied a wide range of various catalytic systems from ordinary oxides to multi-component supported and unsupported catalysts, including perovskites and zeolites, with a particular attention paid to vanadium supported catalysts $\left(\mathrm{V}_{2} \mathrm{O}_{5} / \mathrm{MeO}, \mathrm{MeO}=\mathrm{TiO}_{2}, \mathrm{SiO}_{2}, \mathrm{MgO}\right)$. They concluded that the most active in ammonia oxidation to molecular nitrogen are vanadium-titanium, copper-titanium and copper-substituted zeolites (ZSM5) catalysts. Promotion by $\mathrm{MoO}_{3}$ and $\mathrm{WO}_{3}$ of vanadium-titanium catalysts changed the temperature dependence of the nitrogen formation rate: at low temperatures $\left(250^{\circ} \mathrm{C}\right), \mathrm{N} 2$ formation decreased with the increase of $\mathrm{MoO}_{3}$ and $\mathrm{WO}_{3}$ content.

The selective catalytic oxidation (SCO) of ammonia to nitrogen over $\mathrm{Fe}_{2} \mathrm{O}_{3}-\mathrm{Al}_{2} \mathrm{O}_{3}, \mathrm{Fe}_{2} \mathrm{O}_{3}-\mathrm{TiO}_{2}, \mathrm{Fe}_{2} \mathrm{O}_{3}-\mathrm{ZrO}_{2}$ and $\mathrm{Fe}_{2} \mathrm{O}_{3}-\mathrm{SiO}_{2}$ was studied by $\mathrm{Yang}$ et al. [274]. The $\mathrm{Fe}_{2} \mathrm{O}_{3}-\mathrm{TiO}_{2}$ catalysts prepared from iron sulfate yielded a higher selectivity for $\mathrm{N}_{2}$ than those prepared from nitrate, with more than $92 \%$ of $\mathrm{N}_{2}$ yields at $400-450^{\circ} \mathrm{C}(\mathrm{GHSV}$ $=2.0 \times 10^{5} \mathrm{~h}^{-1}$ ). It was reported that lattice oxygen may participate in the SCO reaction. Authors assumed a twostep SCO mechanism in which $\mathrm{NH}_{3}$ is first oxidized to $\mathrm{NO}$ and then $\mathrm{NO}$ is reduced to $\mathrm{N}_{2}$ by unreacted $\mathrm{NH}_{3}$ adsorbed species through a SCR reaction pathway.

Several alumina-supported (transition) metal (Cu, Mo, V, Pt, Ir, Rh, Pd) were evaluated by Gang et al. [275] in the $\mathrm{NH}_{3}$ oxidation to nitrogen reaction. Authors showed that $\mathrm{Cu} / \mathrm{Al}_{2} \mathrm{O}_{3}$ sample presented the higher activity of transient metal supported catalysts. However, noble-metal catalysts remained more active and metalexchanged zeolite are proposed as promising materials for ammonia oxidation.

Zeolite-based samples. A screening study about ZSM-5 based sample reported promising performances of copper-substituted zeolite materials [273]. Cobalt exchanged ZSM-5 catalysts were studied by Li et al. [276] 
which confirmed that ion exchanged zeolite are more active than the corresponding $\mathrm{Al}_{2} \mathrm{O}_{3}$ supported catalysts with the same metal loading. Higher $\mathrm{N}_{2}$ selectivity was achieved with $\mathrm{Y}$ zeolite exchanged with transient metals. The oxidation of ammonia on $\mathrm{Y}$ zeolites containing $\mathrm{Mn}^{2+}, \mathrm{Fe}^{3+}, \mathrm{Co}^{2+}, \mathrm{Ni}^{2+}, \mathrm{Cu}^{2+}, \mathrm{Cr}^{3+}$ or $\mathrm{Ag}^{+}$cations was investigated and the following activity ranking was established:

$$
\mathrm{Cu}-\mathrm{Y}>\mathrm{Cr}-\mathrm{Y}>\mathrm{Ag}-\mathrm{Y}>\mathrm{CO}-\mathrm{Y}>\mathrm{Fe}-\mathrm{Y}>\mathrm{Ni}-\mathrm{Y}, \mathrm{Mn}-\mathrm{Y} \text {. }
$$

Gang et al. [275] reported that the activity of copper ion-exchanged $Y$ zeolite catalysts for ammonia oxidation was shown to be comparable to that of noble metal catalysts at low temperatures, with even much higher $\mathrm{N}_{2}$ selectivity for the zeolite catalysts.

\subsubsection{Urea oxidation}

Studies about urea reactivity are essentially devoted to $\mathrm{SCR}$ process, since $\left(\mathrm{NH}_{2}\right) \mathrm{CO}\left(\mathrm{NH}_{2}\right)$ is recognized as a safe storable ammonia precursor. $\mathrm{NH}_{3}$ is obtained by two consecutive reactions: the "urea thermolysis" (Eq.6.14) leading to $\mathrm{NH}_{3}$ and $\mathrm{HNCO}$, and the "HNCO hydrolysis" (Eq. 6.15). The overall reaction corresponds to the "direct urea hydrolysis" (Eq. 6.21).

$$
\left(\mathrm{NH}_{2}\right) \mathrm{CO}\left(\mathrm{NH}_{2}\right)+\mathrm{H}_{2} \mathrm{O} \rightarrow 2 \mathrm{NH}_{3}+\mathrm{CO}_{2}
$$

Urea thermolysis (Eq. 6.14) is endothermic and thermally assisted compared to HNCO hydrolysis (Eq. 6.14) which is exothermic. With pure urea, Koebel et al. [277] observed the thermal decomposition according to (Eq. 6.14) and reported that isocyanic acid is stable in the gas phase. However, $\mathrm{HNCO}$ is easily hydrolyzed with water vapor on many solid oxides, such as SCR catalysts (Eq 6.15) [278]. It was proposed that the rate of HNCO hydrolysis is much higher than the rate of the SCR reaction at low to medium temperatures on usual SCR catalysts. Interestingly, it was reported that both (Eq. 6.14) and (Eq. 6.15) reactions can be catalyzed by transition metal materials and then the rate determining step depends on the temperature. For instance, over anatase $\mathrm{TiO}_{2}$, Bernhard et al. [279] observed that the hydrolysis was somewhat slower than thermolysis below $150^{\circ} \mathrm{C}$, whereas the hydrolysis was faster above $160^{\circ} \mathrm{C}$. Unfortunately, during the urea decomposition process, undesired reactions can also occur. Schaber et al. [280] indicated that, at around $190^{\circ} \mathrm{C}$, cyanuric acid $\left(\mathrm{C}_{3} \mathrm{H}_{3} \mathrm{~N}_{3} \mathrm{O}_{3}\right)$, ammelide and ammeline are produced primarily from biuret, which results itself from reaction of $\mathrm{HNCO}$ with urea. All these by-products may induce catalyst surface deactivation caused by deposit formation and also lead to imbalance in the $\mathrm{NH}_{3}$-NOx stoichiometry, degrading the DeNOx efficiency.

Using an innovative experimental synthetic gas bench adjusted to powdered catalysts and allowing the use of urea or ammonia as reductant agent, the competitive reactivity of the HNCO intermediate species was recently evidenced by Seneque et al. over acidic zirconia-based catalyst $[281,282]$. The expected HNCO hydrolysis to yield ammonia can compete with other reactions and possible divergences in terms of DeNOx efficiency were evidenced depending on the nature of the reductant (i.e. $\mathrm{NH}_{3}$ or urea aqueous solution). It was demonstrated that $\mathrm{HNCO}$ appeared more reactive toward $\mathrm{O}_{2}$ than $\mathrm{NH}_{3}$. Selective catalytic oxidation (SCO) experiments showed a reductant oxidation of about $30 \%$ at $300^{\circ} \mathrm{C}$ for Urea-SCO, compared with $8 \%$ for $\mathrm{NH}_{3}-\mathrm{SCO}$. Oxidation of $\mathrm{HNCO}$ intermediate by $\mathrm{NO}_{2}$ was also evidenced, even if these oxidation reactions appeared negligible over the studied catalyst under usual SCR mixtures. 
Interestingly, this study also evidences a new "HNCO-SCR" route involving both $\mathrm{NO}$ and $\mathrm{NO}_{2}$, probably via the formation of HONO, which is commonly proposed as intermediate species in $\mathrm{NO}_{x}$ reduction mechanisms. Finally, the various competitive reactions regarding HNCO in the urea SCR process are highlighted in Scheme 6.1.

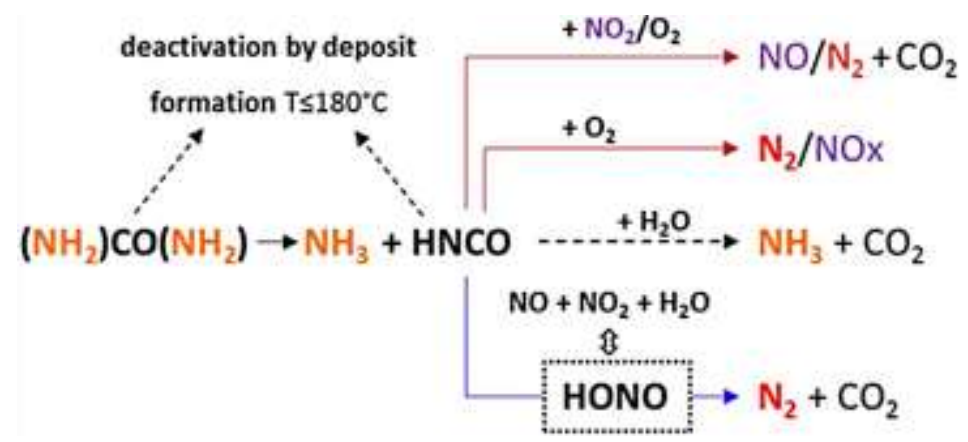

Scheme 6.1. Competitive reactivity of HNCO for Urea-SCR with shortened urea residence time. From ref. 282.

\subsubsection{NOx-trap systems (basic oxides)}

Due to the high efficiency of noble metals for both NO oxidation in lean media and stored NOx reduction during short rich incursions, catalysts developed for Lean NOx trap process essentially deal with Platinum Group Metal (PGM) materials, usually based on a mix of Pt, Pd and Rh. However, catalysts without PGM were also investigated such as transient oxide catalysts, spinel type structures, zirconia and titania functionalized oxides, or perovskite-based samples. For instance, spinel-type oxide was studied by Fino et al. for NOx removal from Diesel engine [283]. Nanostructured spinel-type oxides catalysts $\mathrm{AB}_{2} \mathrm{O}_{4}$ (where $A=\mathrm{Co}$ and $\mathrm{Mn}$, and $\mathrm{B}=\mathrm{Cr}$ and Fe), prepared by the solution combustion method and characterized by BET, XRD, SEM and TEM, were evaluated by temperature programmed oxidation/reduction (TPO/TPR) for NOx removal. The following activity classification for $\mathrm{NO}_{x}$ reduction in the $350-450^{\circ} \mathrm{C}$ temperature range was obtained: $\mathrm{CoFe}_{2} \mathrm{O}_{4}>\mathrm{CoCr}_{2} \mathrm{O}_{4}$ $>\mathrm{MnCr}_{2} \mathrm{O}_{4}$. Based on transient thermal analysis studies (TPD), authors proposed that the prevalent activity of the chromite catalysts could be explained by their higher concentration of weakly chemisorbed suprafacial oxygen, which contributed actively to the oxidation mechanism by spillover.

NOx storage and reduction pathways on zirconia and titania functionalized binary and ternary oxides $\left(\mathrm{ZrO}_{2} / \mathrm{TiO}_{2}, \mathrm{Al}_{2} \mathrm{O}_{3} / \mathrm{ZrO}_{2} / \mathrm{TiO}_{2}\right)$ as $\mathrm{NOx}$ storage and reduction (NSR) systems was also studied [284]. NOx adsorption on the $\mathrm{Al}_{2} \mathrm{O}_{3} / \mathrm{ZrO}_{2} / \mathrm{TiO}_{2}$ (AZT) system was found to be significantly greater than that of $\mathrm{ZrO}_{2} / \mathrm{TiO}_{2}$ $(Z T)$, due to specific surface area ten times higher $\left(264 \mathrm{~m}^{2} \mathrm{~g}^{-1}\right.$ for AZT material compared with $26 \mathrm{~m}^{2} \mathrm{~g}^{-1}$ for ZT system). It was reported that the thermal stability of nitrates species is higher over AZT compared with ZT, assigned to the defective structure and the presence of coordinative unsaturated sites (CUS) on the former surface. Nevertheless, Pt-functionalized counterparts facilitated the decomposition of nitrates together with an enhancement of the NOx reduction rate.

Supported YCeZrO ternary oxides using $\mathrm{LaCoO}_{3}$ perovskite as active phase were also proposed as efficient Lean NOx-trap catalysts. A series of non-platinic ceria-based oxides supported catalysts $\mathrm{LaCoO}_{3} / \mathrm{K}_{2} \mathrm{CO}_{3} / \mathrm{S}$ 
$\left(\mathrm{S}=\mathrm{CeO}_{2}, \mathrm{Ce}_{0.75} \mathrm{Zr}_{0.25} \mathrm{O}_{2}\right.$ or $\left.5 \% \mathrm{Y} / \mathrm{Ce}_{0.75} \mathrm{Zr}_{0.25} \mathrm{O}_{2}\right)$ revealed interesting behaviors [285]. It was reported that the doping of $\mathrm{Zr}$ or $\mathrm{YZr}$ into $\mathrm{CeO}_{2}$ facilitates the formation of CeZrO binary or $\mathrm{YCeZrO}$ ternary solid solutions, increasing the specific surface area and improving the redox properties of ceria. Additionally, by means of EXAFS and $\mathrm{H}_{2}$-TPR experiments it was found that $\mathrm{LaCoO}_{3}$ supported over the solid solutions exhibited higher dispersion and better reducibility than that supported on $\mathrm{CeO}_{2}$. Finally, the $\mathrm{YCeZrO}$ ternary solid solution supported catalyst containing 5 wt $\% \mathrm{~K}_{2} \mathrm{CO}_{3}$ exhibited the best performance for the NSR process at $350^{\circ} \mathrm{C}$ : a high NO-to- $\mathrm{NO}_{2}$ conversion (66.5\%) was obtained in lean condition, and a very high NOx reduction percentage $(98.2 \%)$, associated with an extremely high $\mathrm{NOx}$-to- $\mathrm{N}_{2}$ selectivity $(98.8 \%)$, was recorded in rich condition in the absence of $\mathrm{CO}_{2}$.

\subsubsection{NOx direct decomposition}

Nitrogen oxides (NOx) emitted from combustion facilities are harmful for human health and our environment. As a consequence, the $\mathrm{NOx}$ decomposition $\left(2 \mathrm{NO} \rightarrow \mathrm{N}_{2}+\mathrm{O}_{2}\right.$ ) is the most desirable but also the most challenging NOx abatement process. Therefore, the direct decomposition of NO is one of the candidate reactions for the high temperature deNOx applications. Numerous types of catalysts, such as supported noble metals $[286,287,288]$, ion-exchanged zeolites [289] and metal oxides $[290,291,292]$ are known to be possibly suitable for this purpose. The main elementary steps involved are:

$$
\begin{aligned}
& \mathrm{NO}_{\mathrm{g}} \leftrightarrow \mathrm{NO}_{\text {ads. }} \\
& \mathrm{NO}_{\text {ads. }} \rightarrow \mathrm{N} \text { ads. }+\mathrm{O}_{\text {ads. }} \\
& 2 \mathrm{~N}_{\text {ads. }} \rightarrow \mathrm{N}_{2} \\
& 2 \mathrm{O}_{\text {ads. }} \rightarrow \mathrm{O}_{2}
\end{aligned}
$$

The poisoning of catalyst by oxygen resulting from NO decomposition (and/or coexisting component) was commonly admitted as the main reason for low catalytic performances. Consequently, perovskite-type oxides, which possess oxygen-deficient sites in their structure, exhibit relatively high catalytic activity in the hightemperature region. Brownmillerite-like compounds, as $\mathrm{Sr}_{2} \mathrm{Fe}_{2} \mathrm{O}_{5}$ which has perovskite structure with randomly distributed oxygen vacancies, showed a remarkable NO decomposition activity at $700-900^{\circ} \mathrm{C}$, whereas the calcium analogue $\left(\mathrm{Ca}_{2} \mathrm{Fe}_{2} \mathrm{O}_{5}\right)$ was almost inactive even at such a high temperature as $900^{\circ} \mathrm{C}$ [293]. It was reported that $\mathrm{Ca}_{2} \mathrm{Fe}_{2} \mathrm{O}_{s}$ does not change its own crystal structure and remains in the orthorhombic brownmillerite-like structure, so-called an "ordered" oxygen deficient perovskite structure. To the opposite, an order-disorder transition was observed for $\mathrm{Sr}_{2} \mathrm{Fe}_{2} \mathrm{O}_{5}$ at $700^{\circ} \mathrm{C}$. As a result, $\mathrm{Sr}_{2} \mathrm{Fe}_{2} \mathrm{O}_{5}$ possesses a statistically disordered oxygen-deficient perovskite structure at temperatures above $700^{\circ} \mathrm{C}$, with the formation of aniondeficient perovskite phase. It implies that significant oxygen vacancies are necessary for NO decomposition. $\mathrm{Ba}_{2} \mathrm{Cu}_{3} \mathrm{O}_{7-y}$ perovskite-like compounds also exhibited interesting behaviors [294]. MgO supported $\mathrm{Y}-\mathrm{Ba}-\mathrm{Cu}-\mathrm{O}$ catalysts were studied in order to highlight the improvement of catalytic properties through a high dispersion. At $700{ }^{\circ} \mathrm{C}$, the conversion was about $35 \%$, similar to that of bulk $\mathrm{Ba}_{2} \mathrm{Cu}_{3} \mathrm{O}_{7-y}$ catalyst. When the temperature is increased up to $800^{\circ} \mathrm{C}$, the conversion reached approximately $73 \%$ for the supported catalyst, compared to $40 \%$ for the perovskite bulk compound. The following activity order was obtained at $800^{\circ} \mathrm{C}$, in which a 
commercial platinum sample was evaluated as a reference: $\mathrm{Y}-\mathrm{Ba}-\mathrm{Cu}-\mathrm{O} / \mathrm{MgO}>\mathrm{Pt} / \mathrm{Al}_{2} \mathrm{O}_{3}>\mathrm{La}_{0.85} \mathrm{Sr}_{0.15} \mathrm{CoO}_{3}$. It was advanced that (i) the decomposition of $\mathrm{NO}$ is likely to be facilitated by the redox cycle of $\mathrm{Cu}\left(\mathrm{Cu}^{2+} \leftrightarrow \mathrm{Cu}^{+}\right)$ and (ii) the NO adsorption sites are Cu ions adjacent to oxygen vacancies. The decomposition of NO required higher temperatures $\left(700\right.$ to $\left.800^{\circ} \mathrm{C}\right)$, because it implies the completion of the Cu redox cycle. The role of the copper valence in the direct decomposition of nitrogen monoxide was also advanced by Yasuda et al.[295] for $\mathrm{La}_{2 x} \mathrm{~A}_{x}^{\prime} \mathrm{CU}_{1-y} \mathrm{~B}_{\mathrm{y}}^{\prime} \mathrm{O}_{4}\left(\mathrm{~K}_{2} \mathrm{NiF}_{4}\right.$ type structure with $\left.\mathrm{A}^{\prime}=\mathrm{Sr}, \mathrm{B}^{\prime}=\mathrm{Al}, \mathrm{Zr}, \mathrm{x}=0-1.0, \mathrm{y}=0,0.2\right)$ catalysts. It was reported that the average oxidation number of copper in the catalyst samples increased from 2.00 for $\mathrm{La}_{2} \mathrm{CuO}_{4}$ up to 2.30 with $\mathrm{Sr}^{2+}$ substitution, and decreased with $\mathrm{Al}^{3^{+}}$or $\mathrm{Zr}^{4^{+}}$substitution. The highest oxidation state was observed for the $\mathrm{Sr}^{2+}$ substitution with $\mathrm{x}=0.5$. The composition became oxygen rich upon $\mathrm{Al}^{3^{+}}$and $\mathrm{Zr}^{4+}$ substitution and oxygen-deficient with $\mathrm{Sr}^{2+}$ substitution. It was observed that the catalytic activity increased with the increase of the average oxidation number of copper, resulting in the redox cycle of $\mathrm{Cu}^{2+} \leftrightarrow \mathrm{Cu}^{3+}$. $\mathrm{Note}^{2}$ that, contrary to Shimada et al. [294], the presence of $\mathrm{Cu}^{+}$is unlikely because of its instability in the octahedral site of the $\mathrm{K}_{2} \mathrm{NiF}_{4}$-type structure.

Rare earth oxides (REOs)-based catalysts from C-type cubic structure were also reported as efficient NO decomposition catalysts $[296,297,298]$. High NO decomposition activity was achieved in the presence of oxygen-deficient sites, which may increase the probability of NO adsorption. Several alkaline earth oxides, which did not include oxygen-deficient sites in the lattice, such as $\mathrm{Sr} / \mathrm{La}_{2} \mathrm{O}_{3}$ and $\mathrm{Ba} / \mathrm{MgO}$, were reported to effectively catalyze the NO decomposition reaction by Vannice et al. [299] and Lunsford et al. [300,301]. A barium-nitro phase was reported as an intermediate in the catalytic cycle. Nitro species at the surface apparently react with $\mathrm{NO}$ to form the decomposition products, $\mathrm{N}_{2}$ and $\mathrm{O}_{2}$. The catalytic performance of supported alkaline earth metal oxides for $\mathrm{NO}$ decomposition decreased following the order: $\mathrm{Ba} / \mathrm{Y}_{2} \mathrm{O}_{3}>\mathrm{Sr} / \mathrm{Y}_{2} \mathrm{O}_{3}$ $>\mathrm{Ca} / \mathrm{Y}_{2} \mathrm{O}_{3}>\mathrm{Mg} / \mathrm{Y}_{2} \mathrm{O}_{3}>\mathrm{Y}_{2} \mathrm{O}_{3}$. Finally, Ba containing metal oxide catalysts, as BaMnO-based perovskite [302], $\mathrm{Ba} / \mathrm{Ba}-\mathrm{Y}-\mathrm{O}$ [303], $\mathrm{Ba} / \mathrm{Y}_{2} \mathrm{O}_{3}$ [304] or $\mathrm{Ba}_{3} \mathrm{Y}_{3.4} \mathrm{Sc}_{0.6} \mathrm{O}_{9}$ samples [305], showed relatively high $\mathrm{NO}$ decomposition activity. Note that the additive effect of $\mathrm{Ba}$ into $\mathrm{CeO}_{2}$-based mixed oxides such as $\mathrm{CeO}_{2}-\mathrm{MnO}_{x}, \mathrm{CeO}_{2}-\mathrm{FeO}$ and rare earth oxides was also reported by Iwamoto et al. [306,307,308] and Haneda et al. [309].

The reaction mechanism of NO decomposition by Cu/zeolites highlighted the role of the Cu' coordination and its localization in zeolites on the reaction profile. The improved coordination of the $\mathrm{Cu}^{\prime}$ cation with the framework resulted in the formation of less stable reaction intermediates and surprisingly in higher apparent energies of activation [289].

\subsection{Wet air oxidation}

Wet air oxidation (WAO) is a process of elimination of aqueous pollutants by oxidation with $\mathrm{O}_{2}$ under pressure. Other oxidants can also be used: $\mathrm{H}_{2} \mathrm{O}_{2}$ in the wet peroxide oxidation (WPO) or ozone in ozonation processes. Oxide catalysts can be used but care should be taken to avoid leaching of metallic ions. Information about catalytic processes of WAO can be found in recent reviews by Arena et al. [310] and by Jing et al. [311]. WAO of dye wastewater was reviewed by Fu and Kyzas [312]. Due to its low biodegradability and high toxicity for activated sludges, phenol is often used as a model compound in WAO [313] or WPO [314,315]. $\mathrm{H}_{2} \mathrm{O}_{2}$ being a 
oxidant stronger than $\mathrm{O}_{2}$, WPO is generally carried out at low temperature with $\mathrm{Cu}$ or Fe catalysts. Figure 6.15 shows the unique role of the association of a catalyst ( $4 \% \mathrm{CuO}-\mathrm{SBA}-15$ ) with $\mathrm{H}_{2} \mathrm{O}_{2}$ in WPO of phenol.
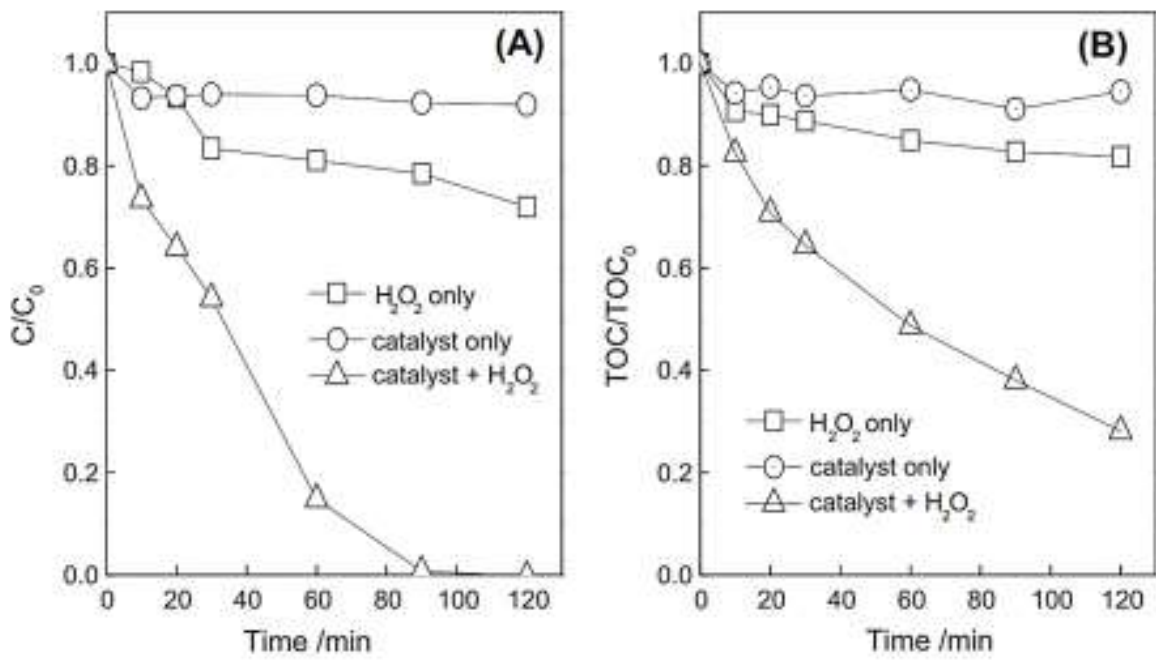

Figure 6.15 Phenol conversion and removal of TOC (total organic carbon) at $60^{\circ} \mathrm{C}$ with $\mathrm{H}_{2} \mathrm{O}_{2}$ alone, with catalyst alone and in CWPO (catalyst $+\mathrm{H}_{2} \mathrm{O}_{2}$ ). From ref. [314].

The high activity of the system $\mathrm{CuO}-\mathrm{H}_{2} \mathrm{O}_{2}$ would be due to the formation of very reactive $\mathrm{HO}_{2}{ }^{\bullet}$ and $\mathrm{OH}^{\bullet}$ radicals (eq. 6.26 and 6.27):

$$
\begin{aligned}
& \mathrm{S}-\mathrm{Cu}^{2+}+\mathrm{H}_{2} \mathrm{O}_{2} \rightarrow \mathrm{S}-\mathrm{Cu}^{1+}+\mathrm{HO}_{2}^{\cdot}+\mathrm{H}^{+} \\
& \mathrm{S}-\mathrm{Cu}^{1+}+\mathrm{H}_{2} \mathrm{O}_{2} \rightarrow \mathrm{S}-\mathrm{Cu}^{2+}+\mathrm{OH}^{\bullet}+\mathrm{OH}^{-}
\end{aligned}
$$

Phenol concentration decreases more rapidly than TOC, which means that organic intermediates are formed before total oxidation (first catechol, hydroquinone, resorcinol and then maleic, oxalic, formic and acetic acid). Cu, Mn, Fe oxides were used for CWAO processes: degradation of Acid Red over Cu-Mn/TiO 2 composites [316], oxidation of Rhodamine $\mathrm{B}$ over $\mathrm{MnO}_{2}$ [317], oxidation of paper industry wastewater over $\mathrm{Ce}_{0.4} \mathrm{Fe}_{0.6} \mathrm{O}_{2}$ [318] or $\mathrm{Ce}_{1-x} \mathrm{Cox}_{x} \mathrm{O}_{y}$ mixed oxides [319]. CWPO were mainly performed over Fe $[320,321]$ or Cu catalysts [322], the systems $\mathrm{Fe}^{2+} / \mathrm{Fe}^{3+}$ and $\mathrm{Cu}^{+} / \mathrm{Cu}^{2+}$ being best able to generate active oxygen species from $\mathrm{H}_{2} \mathrm{O}_{2}$. Coupling CWPO with photons (photo-Fenton) allows to obtain decolorization of Orange II at ambient temperature over Fesmectite [323]. Though noble metal catalysts are generally more active than oxide catalysts in CWAO, there are some exceptions to this rule. For instance, Pt catalysts are rapidly deactivated when the wastewater contains amines which form soluble complexes with noble metals. It was proven by Schmit et al. that $\beta-\mathrm{MnO}_{2} / \mathrm{CeO}$ catalysts could oxidize methylamine at $190^{\circ} \mathrm{C}$ without serious leaching of $\mathrm{Mn}$ ions (<0.1 ppm after a $24 \mathrm{~h}$ reaction) [324].

\subsection{Conclusions and perspectives}

If oxide catalysts are mainly used in selective oxidation processes, the progresses made in their synthesis allow to obtain efficient catalysts for combustion and depollution systems. Cobalt, manganese, iron and copperbased oxides can exhibit very high activity for $\mathrm{CO}, \mathrm{CH}_{4}$ and $\mathrm{VOC}$ oxidation. Mixed oxides (perovskites, spinels, hexaaluminates, ...) still show superior performances thanks to their high surface area and improved stability. 
Redox supports, especially those based on ceria, reinforce the performance of oxide catalysts in oxidation reactions by stabilizing the proper $\mathrm{M}^{\mathrm{n}+} / \mathrm{M}^{(\mathrm{n+1})+}$ balance required for a good activity. Copper or iron-exchanged zeolites are also used in DeNOx processes with zeolites stable above $900^{\circ} \mathrm{C}$. Shape-structured oxides (nanocubes, nanowires, nanobelts,...) were widely investigated in the recent years. Not only the nature of the exposed faces but also crystals defects (vacancies, intersticial atoms, shear planes,...) can have a decisive effect on the catalyst performances. In most cases, oxygen mobility is a key-factor in oxidation processes. ${ }^{18} \mathrm{O} /{ }^{16} \mathrm{O}$ exchange between the gas phase and surface or bulk $O$ species can give useful information about the mechanism of reaction. In the future, more and more sophisticated oxides (mesoporous and nanocasting, coreshell, shaped-structured,....), with a perfect control of the metal-metal and metal-oxygen interaction, should be developed for interesting applications provided that these new oxides have proven their stability at high temperature. Another way of improvement is to fractionate very stable oxides into nanoparticles of high surface area by reactive grinding. And finally, new activation processes (plasma, ultrasound, ....) may also be excellent ways of research for these materials.

\section{References}

[1] T. Exley in Principles of Natural Philosophy, Longman et al Publ. London, 1827.

[2] M. W. Roberts, Birth of the catalytic concept (1800-1900), Catal. Lett. 67 (2000) 1-4.

[3] R. K. Grasselli, Selective oxidation and ammoxidation catalysis: History of catalyst design, in Surface Properties and Catalysis by Non-Metals, Volume 105, NATO ASI Series (J. P. Bonnelle, B. Delmon \& E. Derouane, Eds), Springer,pp 273-288 (1983).

[4] S. D. Jackson, J. S. J. Hargreaves, Metal Oxide Catalysis, Wiley VCH (2009).

[5] J. C. Védrine, I. Fechete, Review: Heterogeneous partial oxidation catalysis on metal oxides, C. R. Chimie 19 (2016) 1203-1225.

[6] A. B. Lamb, W. C. Bray, J. C. W. Frazer, The removal of carbon monoxide from air, Ind. Eng. Chem. 12 (1920) 213-221.

[7] E. C. Pitzer, J. C. W. Frazer, The physical chemistry of hopcalite catalysts, J. Phys. Chem. 45 (1941) 761-776. [8] Z.-R. Tang, S. A. Kondrat, C. Dickinson, J. K. Bartley, A. F. Carley, S. H. Taylor, T. E. Davies, M. Allix, M. J. Rosseinsky, J. B. Claridge, Z. Xu, S. Romani, M. J. Crudace, G. J. Hutchings, Synthesis of high surface area $\mathrm{CuMn}_{2} \mathrm{O}_{4}$ by supercritical anti-solvent precipitation for the oxidation of $\mathrm{CO}$ at ambient temperature, Catal. Sci. Technol. 1 (2011) 740-746.

[9] T. Biemelt, K. Wegner, J. Teichert, S. Kaskel, Microemulsion flame pyrolysis for hopcalite nanoparticle synthesis: a new concept for catalyst preparation, Chem. Commun. 51, 2015, 5872-5875.

[10] Z. Jaworska-Galas, W. Mista, J. Wrzyszcz, M. Zawadzki, Thermal stability improvement of hopcalite catalyst, Catal. Lett. 24 (1994) 133-139.

${ }^{[11}$ E. C. Njagi, C.-H. Chen, H. Genuino, H. Galindo, H. Huang, S. L. Suib, Total oxidation of CO at ambient temperature using copper manganese oxide catalysts prepared by a redox method, Appl. Catal. B:

Environmental 99 (2010) 103-110.

[12] H. C. Genuino, S.Dharmarathna, E. C. Njagi, M. C. Mei, S. L. Suib, Gas-phase total oxidation of benzene, tolvene, ethylbenzene, and xylenes using shape-selective manganese oxide and copper manganese oxide catalysts, J. Phys. Chem. C 116 (2012) 12066-12078

[13] W. Tang, X. Wua, S. Li, X. Shan, G. Liu, Y. Chen, Co-nanocasting synthesis of mesoporous Cu-Mn composite oxides and their promoted catalytic activities for gaseous benzene removal, Appl. Catal. B: Environmental, 162 (2015) 110-121.

[14] X. Xie, Y. Li, Z.-Q. Liu, M. Haruta, W. Shen, Low-temperature oxidation of CO catalysed by $\mathrm{Co}_{3} \mathrm{O}_{4}$ nanorods, Nature, 458 (2009) 746-749.

[15] G. S. Parkinson, Iron oxide surfaces, Surf. Sci. Rep. 71 (2016) 272-365. 
[16] S. Royer, D. Duprez, Catalytic oxidation of carbon monoxide on transition metal oxides, ChemCatChem 3 (2011) 24-65.

[17] G. Li, L. Li, B. Wu, J. Li, Y. Yuan, J. Shi , Controlled one-step synthesis of Pt decorated octahedral Fe3 $\mathrm{O}_{4}$ and its excellent catalytic performance for $\mathrm{CO}$ oxidation, Nanoscale, 7 (2015) 17855-17860.

[18] L. Hu, Q. Peng, Y. Li, Selective Synthesis of $\mathrm{CO}_{3} \mathrm{O}_{4}$ nanocrystal with different shape and crystal plane effect on catalytic property for methane combustion, J. Am. Chem. Soc. 130 (2008) 16136-16137.

[19] G. Evans, I. V. Kozhevnikov, E. F. Kozhevnikova, J. B. Claridge, R. Vaidhyanathan, C. Dickinson, C. D. Wood, A. I. Cooper, M. J. Rosseinsky, Particle size-activity relationship for $\mathrm{CoFe}_{2} \mathrm{O}_{4}$ nanoparticle $\mathrm{CO}$ oxidation catalysts, J. Mater. Chem. 18 (2008) 5518-5523.

[20] C. Shao, X. Liu, D. Meng, Q. Xu, Y. Guo, Y. Guo, W. Zhan, L. Wang, G. Lu, Catalytic performance of Co-Fe mixed oxide for $\mathrm{NH}_{3}-\mathrm{SCR}$ reaction and the promotional role of cobalt, RSC Adv. 6 (2016) 66169-66179.

[21] K. Rida, A.López Cámara, M.A. Peña, C.L. Bolívar-Díaz, A. Martínez-Arias, Bimetallic Co-Fe and Co-Cr oxide systems supported on $\mathrm{CeO}_{2}$ : Characterization and $\mathrm{CO}$ oxidation catalytic behavior, Int. J. Hydrogen Energy 40 (2015) 11267-11278.

[22] M. A. Peña, J. L. G. Fierro, Chemical Structures and Performance of Perovskite Oxides, Chem. Rev. 101 (2001) 1981-2017.

[23] S. Royer, D. Duprez, F. Can, X. Courtois, C. Batiot-Dupeyrat, S. Laassiri, H. Alamdari, Perovskites as substitutes of noble metals for heterogeneous catalysis: dream or reality, Chem. Rev. 114 (2014) 10292-10368. [24] H. Najjar, H. Batis, Development of Mn-based perovskite materials: Chemical structure and applications, Catal. Rev.-Sci. Eng. 58 (2016) 371-438.

[25] J. A. Bennett, K. Wilson, A. F. Lee, Catalytic applications of waste derived materials, J. Mater. Chem. A 4 (2016) $3617-3637$.

[26] R. Burch, M. J. Hayes, C-H bond activation in hydrocarbon oxidation on solid catalysts, J. Mol. Cata. A: Chemicals, 100 ( 1995) 13-33.

[27] F. Diehl, J. Barbier Jr, D. Duprez, I. Guibard, G. Mabilon, Catalytic oxidation of heavy hydrocarbons over $\mathrm{Pt} / \mathrm{Al}_{2} \mathrm{O}_{3}$. Influence of the structure of the molecule on its reactivity. Appl. Catal. B: Environmental 95 (2010) 217-227.

[28] D. Duprez, Study of surface reaction mechanisms by ${ }^{16} \mathrm{O} /{ }^{18} \mathrm{O}$ and $\mathrm{H} / \mathrm{D}$ isotopic exchange, Catal. Today 112 (2006) 17-22.

[29] P. Mars, D. W. van Krevelen, Oxidations carried out by means of vanadium oxide catalysts, Chem. Eng. Sci., Special Suppl. 3 (1954) 41-57.

[30] G. K. Boreskov, V. S. Muzykantov, Investigation of oxide-type oxidation catalysts by reaction of oxygen isotopic exchange, Ann. N. Y. Acad. Sci. 213 (1973) 137-16o.

[31] W. Yang, R. Zhang, B. Chen, N. Bion, D. Duprez, L. Hou, H. Zhang, S. Royer, Design of nanocrystalline mixed oxides with improved oxygen mobility: a simple non-aqueous route to nano- $\mathrm{LaFeO}_{3}$ and the consequences on the catalytic oxidation performances, Chem. Comm. 49 (2013) 4923-4925.

[32] S. Laassiri, N. Bion, D. Duprez, H. Alamdari, S. Royer, Role of $\mathrm{M}^{\mathrm{n}+}$ cations in the redox and oxygen transfer properties of $\mathrm{BaM}_{\times} \mathrm{Al}_{12-\times} \mathrm{O}_{19-\delta}(\mathrm{M}=\mathrm{Mn}, \mathrm{Fe}, \mathrm{Co})$ nanomaterials for high temperature methane oxidation, Catal. Sci. Technol. 3 (2013) 2259-2269.

[33] S. Laassiri, N. Bion, D. Duprez, S. Royer, H. Alamdari, Clear microstructure-performance relationships in $\mathrm{Mn}$-containing perovskite and hexaaluminate compounds prepared by activated reactive synthesis, Phys. Chem. Chem. Phys. 16 (2014) 4050-4060.

[34] M. Richard, F. Can, D. Duprez, S. Gil, A. Giroir-Fendler, N. Bion, Remarkable enhancement of $\mathrm{O}_{2}$ activation on yttrium-stabilized zirconia surface in a dual catalyst bed, Angew. Chem. Int. Ed. 53 (2014) 11342-11345. [35] M. Richard, F. Can, S. Gil, A. Giroir-Fendler, D. Duprez, N. Bion, Study of lanthanum manganate and yttrium-stabilized zirconia-supported palladium dual-bed catalyst system for the total oxidation of methane :A study by ${ }^{18} \mathrm{O}_{2} /{ }^{16} \mathrm{O}_{2}$ isotopic exchange, ChemCatChem 8 (2016) $1921-1928$.

[36] C.-J. Liang, J. W. Fang, Predicting the kinetics of catalytic oxidation of multicomponent organic waste gases, Chem. Eng. Sci. 144 (2016) 101-107.

[37] M. A. Vannice, An analysis of the Mars-van Krevelen rate expression, Catal. Today, 123 (2007) 18-22.

[38] S. Keav, S. Kumar Matam, D. Ferri, A. Weidenkaff, Structured Perovskite-Based Catalysts and Their Application as Three-Way Catalytic Converters-A Review, Catalysts 4 (2014) 226-255.

[39] F. S. Toniolo, M. Schmal, Improvement of Catalytic Performance of Perovskites by Partial Substitution of Cations and Supporting on HighSurface Area Materials, in Perovskite Materials - Synthesis, Characterisation, Properties, and Applications (Likun Pan and Guang Zhu, Eds), InTech publ. Rijeka, Croatia (2016).

[40] A. Ladavos, P. Pomonis, Methane Combustion on Perovskites, in Perovskites and Related Mixed Oxides: Concepts and Applications (P. Granger, V. I. Parvulescu, S. Kaliaguine, W. Prellier, Eds) Wiley VCH Publ. (2016). 
[41] Y. Yu, T. Takei, H. Ohashi, H. He, X. Zhang, M. Haruta, Pretreatments of $\mathrm{Co}_{3} \mathrm{O}_{4}$ at moderate temperature for $\mathrm{CO}$ oxidation at $-80^{\circ} \mathrm{C}$, J. Catal. 267 (2009) 121-128.

[42] P. Broqvist, I. Panas, H. Persson, A DFT Study on CO Oxidation over $\mathrm{Co}_{3} \mathrm{O}_{4}$, J. Catal. 210 (2002) 198-206. [43] A. K. Kandalam, B. Chatterjee, S.N. Khanna, B.K. Rao, P. Jena, B.V. Reddy, Oxidation of $\mathrm{CO}$ on $\mathrm{Fe}_{2} \mathrm{O}_{3}$ model surfaces, Surf. Sci. 601 (2007) 4873-4880.

[44] S. Wagloehner, D. Reichert, D. Leon-Sorzano, P. Balle, B. Geiger, S. Kureti, Kinetic modeling of the oxidation of $\mathrm{CO}$ on $\mathrm{Fe}_{2} \mathrm{O}_{3}$ catalyst in excess of $\mathrm{O}_{2}$, J. Catal. 260 (2008) 305-314.

[45] D. Ciuparu, M. R. Lyubovsky, E. Altman, L. D. Pfefferle, A. Datye, Catalytic combustion of methane over palladium-based catalysts, Catal. Rev.-Sci. Eng. 44 (2002) 593-649.

[46] P. Gélin, M. Primet, Complete oxidation of methane at low temperature over noble metal based catalysts: a review, Appl. Catal. B: Environmental, 39 (2002) 1-37.

[47] S. Royer, C. Ayrault, C. Carnevillier, F. Epron, P. Marécot, D. Duprez, Enthalpy recovery of gases issued from $\mathrm{H}_{2}$ production processes: Activity and stability of oxide and noble metal catalysts in oxidation reaction under highly severe conditions, Catal. Today 117 (2006) 543-548.

[48] S. Pengpanich, V. Meeyoo, T. Rirksomboon, K. Bunyakiat, Catalytic oxidation of methane over $\mathrm{CeO}_{2}-\mathrm{ZrO}_{2}$ mixed oxide solid solution catalysts prepared via urea hydrolysis, Appl. Catal. A General 234 (2002) 221-233. [49] V. C. Belessi, A. K. Ladavos, G. S. Armatas and P. J. Pomonis, Kinetics of methane oxidation over La-SrCe-Fe-O mixed oxide solids, Phys. Chem. Chem. Phys. 3 (2001) 3856-3862.

[50] F. Zasada, W. Piskorz, J. Janas, J. Gryboś, P. Indyka, Z. Sojka, Reactive Oxygen Species on the (100) Facet of Cobalt Spinel Nanocatalyst and their Relevance in ${ }^{16} \mathrm{O}_{2} /{ }^{18} \mathrm{O}_{2}$ Isotopic Exchange, de $\mathrm{N}_{2} \mathrm{O}$, and $\mathrm{deCH}_{4}$ Processes. A Theoretical and Experimental Account, ACS Catal. 5 (2015) 6879-6892.

[51] C. Liu, H. Xian, Z. Jiang, L. Wang, J. Zhang, L. Zheng, Y. Tan, X. Li, Insight into the improvement effect of the Ce doping into the $\mathrm{SnO}_{2}$ catalyst for the catalytic combustion of methane, Appl. Catal. B: Environmental 176-177 (2015) 542-552.

[52] I. Popescu, Y. Wu, P. Granger, I.-C. Marcu, An in situ electrical conductivity study of LaCoFe perovskitebased catalysts in correlation with the total oxidation of methane, Appl. Catal. A: General 485 (2014) 20-27. [53] Y.-F.Y. Yao, The oxidation of hydrocarbons and $\mathrm{CO}$ over metal oxides: III. $\mathrm{Co}_{3} \mathrm{O}_{4}$, J. Catal. 33 (1974) 108122.

[54] D. H. Cunningham, T. Kobayashi, N. Kamijo, M. Haruta, Influence of dry operating conditions: observation of oscillations and low temperature $\mathrm{CO}$ oxidation over $\mathrm{Co}_{3} \mathrm{O}_{4}$ and $\mathrm{Au}_{\mathrm{C}} \mathrm{Co}_{3} \mathrm{O}_{4}$ catalysts, Catal. Lett. 25 (1994) 257-264.

[55] J. Jansson, A.E.C. Palmqvist, E. Fridell, M. Skoglundh, L. Osterlund, P. Thormahlen, V. Langer, On the catalytic activity of $\mathrm{CO}_{3} \mathrm{O}_{4}$ in low-temperature $\mathrm{CO}$ oxidation, J. Catal. 211 (2002) 387-397.

[56] Y. Zhou, Y. Li, W. Shen, Shape Engineering of Oxide Nanoparticles for Heterogeneous Catalysis, Chem. Asian J. 11 (2016) 1470-1488.

[57] L.F. Liotta, H. Wu, G. Pantaleo, A.M. Venezia, $\mathrm{Co}_{3} \mathrm{O}_{4}$ nanocrystals and $\mathrm{Co}_{3} \mathrm{O}_{4}-\mathrm{MO}$ x binary oxides for $\mathrm{CO}$, $\mathrm{CH}_{4}$ and VOC oxidation at low temperatures: a review, Catal. Sci. Technol. 3 (2013) 3085-3102.

[58] J. Pal, T. Pal, Faceted metal and metal oxide nanoparticles: design, fabrication and catalysis, Nanoscale. 7 (2015) 14159-14190.

[59] X. Xie, Y. Li, Z.-O. Liu, M. Haruta, W. Shen, Low-temperature oxidation of $\mathrm{CO}$ catalysed by $\mathrm{Co}_{3} \mathrm{O}_{4}$ nanorods, Nature. 458 (2009) 746-749.

[6o] P. Broqvist, I. Panas, H. Persson, A DFT Study on CO Oxidation over $\mathrm{Co}_{3} \mathrm{O}_{4}$, J. Catal. 210 (2002) 198-206. [61] L. Hu, K. Sun, Q. Peng, B. Xu, Y. Li, Surface active sites on $\mathrm{Co}_{3} \mathrm{O}_{4}$ nanobelt and nanocube model catalysts for CO oxidation, Nano Res. 3 (2010) 363-368.

[62] V. lablokov, R. Barbosa, G. Pollefeyt, I. Van Driessche, S. Chenakin, N. Kruse, Catalytic CO Oxidation over Well-Defined Cobalt Oxide Nanoparticles: Size-Reactivity Correlation, ACS Catal. 5 (2015) 5714-5718.

[63] Y. Yu, T. Takei, H. Ohashi, H. He, X. Zhang, M. Haruta, Pretreatments of $\mathrm{C}_{3} \mathrm{O}_{4}$ at moderate temperature for $\mathrm{CO}$ oxidation at $-80^{\circ} \mathrm{C}$, J. Catal. 267 (2009) 121-128.

[64] A. Trovarelli, P. Fornasiero, World Scientific (Firm), Catalysis by ceria and related materials, Imperial College Press; Distributed by World Scientific Pub. Co., London; Singapore, 2013.

[65] H.C. Yao, Y.F.Y. Yao, Ceria in automotive exhaust catalysts: I. Oxygen storage, J. Catal. 86 (1984) 254265.

[66] A. Trovarelli, Catalytic properties of ceria and $\mathrm{CeO}_{2}$-containing materials, Catal. Rev.-Sci. Eng. 38 (1996) 439-520.

[67] S. Bedrane, C. Descorme, D. Duprez, ${ }^{16} \mathrm{O} /{ }^{18} \mathrm{O}$ isotopic exchange: A powerful tool to investigate oxygen activation on M/Cex $\mathrm{Zr}_{1-\mathrm{x}} \mathrm{O}_{2}$ catalysts, Appl. Catal. Gen. 289 (2005) 90-96. 
[68] Y. Madier, C. Descorme, A.M. Le Govic, D. Duprez, Oxygen Mobility in $\mathrm{CeO}_{2}$ and $\mathrm{Ce}_{x} \mathrm{Zr}_{(1-x)} \mathrm{O}_{2}$ Compounds: Study by CO Transient Oxidation and ${ }^{18} \mathrm{O} /{ }^{16} \mathrm{O}$ Isotopic Exchange, J. Phys. Chem. B. 103 (1999) 10999-11006. [69] A. Galdikas, C. Descorme, D. Duprez, F. Dong, H. Shinjoh, Study of the oxygen diffusion on three-way catalysts: a kinetic model, Top. Catal. 30-31 (2004) 405-409.

[70] C. Descorme, Y. Madier, D. Duprez, Infrared Study of Oxygen Adsorption and Activation on CeriumZirconium Mixed Oxides, J. Catal. 196 (2000) 167-173.

[71] T. Montini, M. Melchionna, M. Monai, P. Fornasiero, Fundamentals and Catalytic Applications of $\mathrm{CeO}_{2}-$ Based Materials, Chem. Rev. 116 (2016) 5987-6041.

[72] Z. Wu, M. Li, S.H. Overbury, On the structure dependence of $\mathrm{CO}$ oxidation over $\mathrm{CeO}_{2}$ nanocrystals with well-defined surface planes, J. Catal. 285 (2012) 61-73.

[73] K. Wu, L.-D. Sun, C.-H. Yan, Recent Progress in Well-Controlled Synthesis of Ceria-Based Nanocatalysts towards Enhanced Catalytic Performance, Adv. Energy Mater. 6 (2016) 1600501.

[74] E. Aneggi, J. Llorca, M. Boaro, A. Trovarelli, Surface-structure sensitivity of CO oxidation over polycrystalline ceria powders, J. Catal. 234 (2005) 88-95.

[75] X. Liu, K. Zhou, L. Wang, B. Wang, Y. Li, Oxygen Vacancy Clusters Promoting Reducibility and Activity of Ceria Nanorods, J. Am. Chem. Soc. 131 (2009) 3140-3141.

[76] F. Esch, S. Fabris, L. Zhou, T. Montini, C. Africh, P. Fornasiero, G. Comelli, R. Rosei, Electron localization determines defect formation on ceria substrates, Science. 309 (2005) 752-755.

[77] Y. Gao, R. Li, S. Chen, L. Luo, T. Cao, W. Huang, Morphology-dependent interplay of reduction behaviors, oxygen vacancies and hydroxyl reactivity of $\mathrm{CeO}_{2}$ nanocrystals, Phys. Chem. Chem. Phys. 17 (2015) 3186231871.

[78] Y. Sun, Q. Liu, S. Gao, H. Cheng, F. Lei, Z. Sun, Y. Jiang, H. Su, S. Wei, Y. Xie, Pits confined in ultrathin cerium(IV) oxide for studying catalytic centers in carbon monoxide oxidation, Nat. Commun. 4 (2013) 2899. [79] Y. Sun, S. Gao, F. Lei, Y. Xie, Atomically-thin two-dimensional sheets for understanding active sites in catalysis, Chem. Soc. Rev. 44 (2015) 623-636.

[80] J. Gao, C. Jia, L. Zhang, H. Wang, Y. Yang, S.-F. Hung, Y.-Y. Hsu, B. Liu, Tuning chemical bonding of $\mathrm{MnO}_{2}$ through transition-metal doping for enhanced CO oxidation, J. Catal. 341 (2016) 82-90.

[81] S. Liang, F. Teng, G. Bulgan, R. Zong, Y. Zhu, Effect of Phase Structure of $\mathrm{MnO}_{2}$ Nanorod Catalyst on the Activity for CO Oxidation, J. Phys. Chem. C. 112 (2008) 5307-5315.

[82] E.R. Stobbe, B.A. de Boer, J.W. Geus, The reduction and oxidation behaviour of manganese oxides, Catal. Today. 47 (1999) 161-167.

[83] J. Xu, Y.-Q. Deng, Y. Luo, W. Mao, X.-J. Yang, Y.-F. Han, Operando Raman spectroscopy and kinetic study of low-temperature $\mathrm{CO}$ oxidation on an $\alpha-\mathrm{Mn}_{2} \mathrm{O}_{3}$ nanocatalyst, J. Catal. 300 (2013) 225-234.

[84] P. Venkataswamy, K.N. Rao, D. Jampaiah, B.M. Reddy, Nanostructured manganese doped ceria solid solutions for CO oxidation at lower temperatures, Appl. Catal. B Environ. 162 (2015) 122-132.

[85] K.R. Barnard, K. Foger, T.W. Turney, R.D. Williams, Lanthanum cobalt oxide oxidation catalysts derived from mixed hydroxide precursors, J. Catal. 125 (1990) 265-275.

[86] J. Shu, S. Kaliaguine, Well-dispersed perovskite-type oxidation catalysts, Appl. Catal. B Environ. 16 (1998) L303-L308.

[87] B. Levasseur, S. Kaliaguine, Effects of iron and cerium in La1-yCeyCo1-xFexO3 perovskites as catalysts for VOC oxidation, Appl. Catal. B Environ. 88 (2009) 305-314.

[88] L.A. Isupova, G.M. Alikina, S.V. Tsybulya, N.N. Boldyreva, G.N. Kryukova, I.S. Yakovleva, V.P. Isupov, V.A. Sadykov, Real structure and catalytic activity of La1-xSrxCoO3 perovskites, Int. J. Inorg. Mater. 3 (2001) 559562.

[89] K.S. Chan, J. Ma, S. Jaenicke, G.K. Chuah, J.Y. Lee, Catalytic carbon monoxide oxidation over strontium, cerium and copper-substituted lanthanum manganates and cobaltates, Appl. Catal. Gen. 107 (1994) 201-227. [90] W. Yang, R. Zhang, B. Chen, N. Bion, D. Duprez, S. Royer, Activity of perovskite-type mixed oxides for the low-temperature CO oxidation: Evidence of oxygen species participation from the solid, J. Catal. 295 (2012) $45-58$.

[91] R.W. Howarth, R. Santoro, A. Ingraffea, Methane and the greenhouse-gas footprint of natural gas from shale formations, Clim. Change. 106 (2011) 679.

[92] P. Gélin, M. Primet, Complete oxidation of methane at low temperature over noble metal based catalysts: a review, Appl. Catal. B Environ. 39 (2002) 1-37.

[93] D. Ciuparu, M.R. Lyubovsky, E. Altman, L.D. Pfefferle, A. Datye, Catalytic combustion of methane over palladium-based catalysts, Catal. Rev. 44 (2002) 593-649.

[94] J. Chen, H. Arandiyan, X. Gao, J. Li, Recent Advances in Catalysts for Methane Combustion, Catal. Surv. Asia. 19 (2015) 140-171. 
[95] L. Hu, Q. Peng, Y. Li, Selective Synthesis of $\mathrm{C}_{3} \mathrm{O}_{4}$ Nanocrystal with Different Shape and Crystal Plane Effect on Catalytic Property for Methane Combustion, J. Am. Chem. Soc. 130 (2008) 16136-16137.

[96] F. Teng, M. Chen, G. Li, Y. Teng, T. Xu, Y. Hang, W. Yao, S. Santhanagopalan, D.D. Meng, Y. Zhu, High combustion activity of $\mathrm{CH}_{4}$ and cataluminescence properties of $\mathrm{CO}$ oxidation over porous $\mathrm{C}_{3} \mathrm{O}_{4}$ nanorods, Appl. Catal. B Environ. 110 (2011) 133-140.

[97] J. Li, X. Liang, S. Xu, J. Hao, Catalytic performance of manganese cobalt oxides on methane combustion at low temperature, Appl. Catal. B Environ. 90 (2009) 307-312.

[98] H. Li, G. Lu, D. Qiao, Y. Wang, Y. Guo, Y. Guo, Catalytic Methane Combustion over $\mathrm{Co}_{3} \mathrm{O}_{4} / \mathrm{CeO}_{2}$ Composite Oxides Prepared by Modified Citrate Sol-Gel Method, Catal. Lett. 141 (2011) 452-458.

[99] Y.-F. Han, L. Chen, K. Ramesh, E. Widjaja, S. Chilukoti, I. Kesumawinata Surjami, J. Chen, Kinetic and spectroscopic study of methane combustion over $\alpha-\mathrm{Mn}_{2} \mathrm{O}_{3}$ nanocrystal catalysts, J. Catal. 253 (2008) 261268.

[100] G. Zhou, P.R. Shah, R.J. Gorte, A Study of Cerium-Manganese Mixed Oxides for Oxidation Catalysis, Catal. Lett. 120 (2008) 191-197.

[101] C. Oliva, M. Allieta, M. Scavini, C. Biffi, I. Rossetti, L. Forni, Electron Paramagnetic Resonance Analysis of La1-xMxMnO $3+\delta(M=C e, S r)$ Perovskite-Like Nanostructured Catalysts, Inorg. Chem. 51 (2012) 8433-8440.

[102] S. Royer, F. Bérubé, S. Kaliaguine, Effect of the synthesis conditions on the redox and catalytic properties in oxidation reactions of LaCo1-xFexO3, Appl. Catal. Gen. 282 (2005) 273-284.

[103] S. Royer, D. Duprez, S. Kaliaguine, Role of bulk and grain boundary oxygen mobility in the catalytic oxidation activity of LaCo1-xFexO3, J. Catal. 234 (2005) 364-375.

[104] X. Zhang, H. Li, Y. Li, W. Shen, Structural Properties and Catalytic Activity of Sr-Substituted LaFeO3 Perovskite, Chin. J. Catal. 33 (2012) 1109-1114.

[105] E. Campagnoli, A.C. Tavares, L. Fabbrini, I. Rossetti, Y.A. Dubitsky, A. Zaopo, L. Forni, $\mathrm{La1}-\mathrm{xAxC01-yFeyO} \pm \pm \delta(\mathrm{A}=\mathrm{Ce}, \mathrm{Sr})$ catalysts for the flameless combustion of methane, J. Mater. Sci. 41 (2006) 4713-4719.

[106] N. Iyi, S. Takekawa, S. Kimura, Crystal chemistry of hexaaluminates: $\beta$-alumina and magnetoplumbite structures, J. Solid State Chem. 83 (1989) 8-19.

[107] M. Tian, X.D. Wang, T. Zhang, Hexaaluminates: a review of the structure, synthesis and catalytic performance, Catal. Sci. Technol. 6 (2016) 1984-2004.

[108] M. Machida, K. Eguchi, H. Arai, Catalytic properties of BaMAl11O19- $\alpha(\mathrm{M}=\mathrm{Cr}, \mathrm{Mn}, \mathrm{Fe}, \mathrm{Co}$, and Ni) for high-temperature catalytic combustion, J. Catal. 120 (1989) 377-386.

[109] H. Huang, Y. Xu, Q. Feng, D. Y. C. Leung, Low temperature catalytic oxidation of volatile organic compounds: a review, Catal. Sci. Technol. 5 (2015) 2649-2669.

[110] Z. Zhang, Z. Jiang, W. Shangguan, Low-temperature catalysis for VOCs removal in technology and application: A state-of-the-art review, Catal. Today 264 (2016) 270-278

[111] D. Delimaris, T. loannides, $\mathrm{VOC}$ oxidation over $\mathrm{MnO}_{x}-\mathrm{CeO}_{2}$ catalysts prepared by a combustion method, Appl. Catal. B: Environmental 84 (2008) 303-312.

[112] D. Delimaris, T. loannides, VOC oxidation over $\mathrm{CuO}-\mathrm{CeO}_{2}$ catalysts prepared by a combustion method, Appl. Catal. B: Environmental 89 (2009) 295-302.

[113] C. Hu, Catalytic combustion kinetics of acetone and toluene over $\mathrm{CU}_{0.13} \mathrm{Ce}_{0.87} \mathrm{O}_{y}$ catalyst, Chem. Eng. J. 168 (2011) 1185-1192.

[114] S. A. C. Carabineiro, X. Chen, M. Konsolakis, A. C. Psarras, P. B. Tavares, J. J. M. Órfãoa, M. F. R. Pereira, J. L. Figueiredo, Catalytic oxidation of toluene on Ce-Co and La-Co mixed oxides synthesized by exotemplating and evaporation methods, Catal. Today 244 (2015) 161-171.

[115] E. Colman-Lerner, M. A. Peluso, J. Sambeth, H. Thomas, Cerium, manganese and cerium/manganese ceramic monolithic catalysts. Study of VOCs and PM removal , J. Rare Earths 34 (2016) 675-682.

[116] T. Garcia, B. Solsona, S. H. Taylor, The catalytic oxidation of hydrocarbon volatile organic compounds, in "Handbook of advanced methods and processes in oxidation catalysis" (D. Duprez, F. Cavani, Eds) Imperial College Press, London, 2014. Chapter 3, pp 51-90.

[117] M. Konsolakis, The role of Copper-Ceria interactions in catalysis science: Recent theoretical and experimental advances, Appl. Catal. B: Environmental 198 (2016) 49-66.

[118] B. Faure, P. Alphonse, Co-Mn-oxide spinel catalysts for $\mathrm{CO}$ and propane oxidation at mild temperature, Appl. Catal. B: Environmental 180 (2016) 715-725.

[119] T. Garcia, S. Agouram, J. F. Sánchez-Royo, R. Murillo, A. M. Mastral, A. Aranda, I. Vázquez, A. Dejoz, B. Solsona, Deep oxidation of volatile organic compounds using ordered cobalt oxides prepared by a nanocasting route, Appl. Catal. A: General 386 (2010) 16-27. 
[120] Z. Ren, Z.Wu, W. Song, W. Xiao, Y. Guo, J. Ding, S. L. Suib, P.-X. Gao, Low temperature propane oxidation over $\mathrm{CO}_{3} \mathrm{O}_{4}$ based nano-array catalysts: Ni dopant effect, reaction mechanism and structural stability, Appl. Catal. B: Environmental 180 (2016) 150-160.

[121] B. Solsona, T. García, R. Sanchis, M. D. Soriano, M. Moreno, E. Rodríguez-Castellón, S. Agouram, A. Dejoz, J. M. López Nieto, Total oxidation of VOCs on mesoporous iron oxide catalysts: Soft chemistry route versus hard template method, Chem. Eng. J. 290 (2016) 273-281.

[122] H. A. Almukhlifi, R. C. Burns, The effects of gold nanoparticles obtained from the thermolysis of $n$ hexanethiolate-stabilized gold nanoparticles on isobutane oxidation over metal oxide catalysts, J. Molec.

Catal. A: Chemical 411 (2016) 349-363.

[123] H. A. Almukhlifi, R. C. Burns, The complete oxidation of isobutane over $\mathrm{CeO}_{2}$ and $\mathrm{Au} / \mathrm{CeO}_{2}$, and the composite catalysts $\mathrm{MOx} / \mathrm{CeO}_{2}$ and $\mathrm{Au} / \mathrm{MOx} / \mathrm{CeO}_{2}\left(\mathrm{M}^{\mathrm{n}}=\mathrm{Mn}, \mathrm{Fe}, \mathrm{Co}\right.$ and $\left.\mathrm{Ni}\right)$ : the effects of gold nanoparticles obtained from $n$-hexanethiolate-stabilized gold nanoparticles, J. Molec. Catal. A: Chemical 415 (2016) 131-143.

[124] F.Wyrwalski, J.-M. Giraudon, J.-F. Lamonier, Synergistic Coupling of the Redox Properties of Supports and Cobalt Oxide $\mathrm{CO}_{3} \mathrm{O}_{4}$ for the Complete Oxidation of Volatile Organic Compounds, Catal. Lett. 137 (2010) 141-149.

[125] M. Assebban, Z.-Y. Tian, A. El Kasmi, N. Bahlawane, S. Harti, T. Chafik, Catalytic complete oxidation of acetylene and propene over clay versus cordierite honeycomb monoliths without and with chemical vapor deposited cobalt oxide, Chem. Eng. J. 262 (2015) 1252-1259.

[126] Z. Wang, G. Shen, J. Li, H. Liu, Q. Wang, Y. Chen, Catalytic removal of benzene over $\mathrm{CeO}_{2}-\mathrm{MnO}_{x}$ composite oxides prepared by hydrothermal method, Appl. Catal. B: Environmental 138-139 (2013) 253-259.

[127] W. Tang, X. Wua, S. Li, X. Shan, G. Liu, Y. Chen, Co-nanocasting synthesis of mesoporous Cu-Mn composite oxides and their promoted catalytic activities for gaseous benzene removal, Appl. Catal. B: Environmental 162 (2015) 110-121.

[128] S. Mo, S. Li, W. Li, J. Li, J. Chen, Y. Chen, Excellent low temperature performance for total benzene oxidation over mesoporous CoMnAl composited oxides from hydrotalcites, J. Mater. Chem. A, 4 (2016) 81138122.

[129] B. Li, Y. Chen, L. Li, J. Kan, S. Hea, B. Yang, S. Shen, S. Zhu, Reaction kinetics and mechanism of benzene combustion over the $\mathrm{NiMnO}_{3} / \mathrm{CeO}_{2} /$ Cordierite catalyst, J. Mol. Catal. A: Chemical, 415 (2016) 160-167. [130] C. Zhang, Y. Guo, Y. Guo, G. Lu, A. Boreave, L. Retailleau, A. Baylet, A. Giroir-Fendler, LaMnO 3 perovskite oxides prepared by different methods for catalytic oxidation of toluene, Appl. Catal. B: Environmental 148-149 (2014) 490-498.

[131] A. Giroir-Fendler, M. Alves-Fortunato, M. Richard, C. Wang, J. Antonio Díaz, S. Gil, C. Zhang, F. Can, N. Bion, $\mathrm{Y}$. Guo, Synthesis of oxide supported $\mathrm{LaMnO}_{3}$ perovskites to enhance yields in toluene combustion, Appl. Catal. B: Environmental 180 (2016) 29-37.

[132] Y. Wang, S. Xie, J. Deng, S. Deng, H. Wang, H. Yan, H. Dai, Morphologically Controlled Synthesis of Porous Spherical and Cubic LaMnO3 with High Activity for the Catalytic Removal of Tolvene, ACS Appl. Mater. Interfaces, 6 (2014) 17394-17401.

[133] W. Si, Y. Wang, S. Zhao, F. Hu, J. Li, A Facile Method for in Situ Preparation of the $\mathrm{MnO}_{2} / \mathrm{LaMnO}_{3}$ Catalyst for the Removal of Toluene, Environ. Sci. Technol., 50 (2016) 4572-4578.

[134] S. Behar, N.-A. Gómez-Mendoza, M.-A. Gómez-García, D. Świerczyński, F. Quignard, N. Tanchoux, Study and modelling of kinetics of the oxidation of VOC catalyzed by nanosized Cu-Mn spinels prepared via an alginate route, Appl. Catal. A: General 504 (2015) 203-210.

[135] H. Sun, Z. Liu, S. Chen, X. Quan, The role of lattice oxygen on the activity and selectivity of the OMS-2 catalyst for the total oxidation of toluene, Chem. Eng. J. 270 (2015) 58-65.

[136] D. Chlala, J.-M. Giraudon, N. Nuns, C. Lancelot, Rose-Noëlle Vannier, M. Labaki, J.-F. Lamonier, Active $\mathrm{Mn}$ species well dispersed on $\mathrm{Ca}^{2+}$ enriched apatite for total oxidation of toluene, Appl. Catal. B:

Environmental 184 (2016) 87-95.

[137] E. Genty, J. Brunet, C. Poupin, S. Casale, S. Capelle, P. Massiani, S. Siffert, R. Cousin, Co-Al mixed oxides prepared via LDH route using microwaves or ultrasound: Application for catalytic toluene total oxidation, Catalysts 5 (2015) 851-867.

[138] A. Pérez, R. Molina, S. Moreno, Enhanced VOC oxidation over Ce/CoMgAl mixed oxides using a reconstruction method with EDTA precursors, Appl. Catal. A: General 477 (2014) 109-116.

[139] S. A. C. Carabineiro, X. Chen, M. Konsolakis, A. C. Psarras, P. B. Tavares, J. J. M. Órfãoa, M. F. R. Pereira, J.L. Figueiredo, Catalytic oxidation of toluene on $\mathrm{Ce}-\mathrm{Co}$ and $\mathrm{La}-\mathrm{Co}$ mixed oxides synthesized by exotemplating and evaporation methods, Catal. Today 244 (2015) 161-171. 
[140] G. S. P. Soylu, Z. Özçelik, I. Boz, Total oxidation of toluene over metal oxides supported on a natural clinoptilolite-type zeolite, Chem. Eng. J. 162 (2010) 380-387.

[141] U. Menon, V. V. Galvita, G. B. Marin, Reaction network for the total oxidation of toluene over CuO$\mathrm{CeO}_{2} / \mathrm{Al}_{2} \mathrm{O}_{3}$, J. Catal. 283 (2011) 1-9.

[142] M. Zabihi, F. Khorasheh, J. Shayegan, Supported copper and cobalt oxides on activated carbon for simultaneous oxidation of toluene and cyclohexane in air, RSC Adv. 5 (2015) 5107-5122.

[143] L. C. Loc, N. Tri, H. T. Cuong, H. S. Thoang, Yu. A. Agafonov, N. A. Gaidaib, N. V. Nekrasov, A. L. Lapidus, Kinetics of the total oxidation of para-xylene and its mixtures with carbon monoxide over supported copper catalysts, Kinet. Catal. 55 (2014) 611-619.

[144] T. García, B. Solsona, S. H. Taylor, Naphthalene total oxidation over metal oxide catalysts, Appl. Catal. B: Environmental 66 (2006) 92-99.

[145] E. N. Ndifor, T. García, B. Solsona, S. H. Taylor, Influence of preparation conditions of nano-crystalline ceria catalysts on the total oxidation of naphthalene, a model polycyclic aromatic hydrocarbon, Appl. Catal. B: Environmental 76 (2007) 248-256.

[146] B. Puertolas, B. Solsona, S. Agouram, R. Murillo, A. M. Mastral, A. Aranda, S. H. Taylor, T. García, The catalytic performance of mesoporous cerium oxides prepared through a nanocasting route for the total oxidation of naphthalene, Appl. Catal. B: Environmental 93 (2010) 395-405.

[147] L. Torrente-Murciano, A. Gilbanka, B. Puertolas, T. García, B. Solsona, D. Chadwick, Shape-dependency activity of nanostructured $\mathrm{CeO}_{2}$ in the total oxidation of polycyclic aromatic hydrocarbons, Appl. Catal. B: Environmental 132-133 (2013) 116-122.

[148] A. Aranda, E. Aylón, B. Solsona, R. Murillo, A. M. Mastral, D. R. Sellick, S. Agouram, T. García, S. H. Taylor, High activity mesoporous copper doped cerium oxide catalysts for the total oxidation of polyaromatic hydrocarbon pollutants, Chem. Comm. 48 (2012) 4704-4706.

[149] M. Baldi, E. Finocchio, F. Milella, G. Busca, Catalytic combustion of $C_{3}$ hydrocarbons and oxygenates over $\mathrm{Mn}_{3} \mathrm{O}_{4}$, Appl. Catal. B: Environmental 16 (1998) 43-51.

[150] V. Blasin-Aubé, J. Belkouch, L. Monceaux, General study of catalytic oxidation of various VOCs over $\mathrm{La}_{0.8} \mathrm{Sr}_{0.2} \mathrm{MnO}_{3+\times}$ perovskite catalyst-influence of mixture, Appl. Catal. B: Environmental 43 (2003) 175-186.

[151] M. Assebban, A. El Kasmi, S. Harti, T. Chafik, Intrinsic catalytic properties of extruded clay honeycomb monolith toward complete oxidation of air pollutants, J. Hazard. Mater. 300 (2015) 590-597.

[152] N. Rezlescu, E. Rezlescu, P. Dorin Popa, C. Doroftei, M. Ignat, Some nanograined ferrites and perovskites for catalytic combustion of acetone at low temperature, Ceram. Intern. 41 (2015) 4430-4437.

[153] L.-Y. Lin, H. Bai, Promotional effects of manganese on the structure and activity of Ce-Al-Si based catalysts for low-temperature oxidation of acetone, Chem. Eng. J. 291 (2016) 94-105.

[154] R. Qin, J. Chen, X. Gao, X. Zhu, X. Yu, K. Cen, Catalytic oxidation of acetone over CuCeOx nanofibers prepared by an electrospinning method, RSC Adv. 4 (2014) 43874-43881.

[155] N. Bion, D. Duprez, F. Epron, Design of nanocatalysts for green hydrogen production from bioethanol, ChemSusChem, 5 (2012) 76-84.

[156] L. V. Mattos, G. Jacobs, B. H. Davis, F. B. Noronha, Production of hydrogen from ethanol: review of reaction mechanism and catalyst deactivation, Chem. Rev. 112 (2012) 4094-4123.

[157] G. Zhou, B. Gui, H. Xie, F. Yang, Y. Chen, S. Chen, X.Zheng, Influence of $\mathrm{CeO}_{2}$ morphology on the catalytic oxidation of ethanol in air, J. Ind. Eng. Chem. 20 (2014) 160-165.

[158] B. Bai, J. Li, J. Hao, 1D-MnO $2,2 \mathrm{D}-\mathrm{MnO}_{2}$ and $3 \mathrm{D}-\mathrm{MnO}_{2}$ for low-temperature oxidation of ethanol, Appl.

Catal. B: Environmental 164 (2015) 241-250.

[159] C. Almquist, M. Krekeler, L. Jiang, An investigation on the structure and catalytic activity of

cryptomelane-type manganese oxide materials prepared by different synthesis routes, Chem. Eng. J. 252

(2014) 249-262.

[160] J. Zhang, C. Zhang, H.He, Remarkable promotion effect of trace sulfation on OMS-2 nanorod catalysts for the catalytic combustion of ethanol, J. Environ. Sci. 35 (2015) 69-75.

[161] F. Kovanda, K. Jirátová, J. Ludvíková, H. Raabová, Co-Mn-Al mixed oxides on anodized aluminum supports and their use as catalysts in the total oxidation of ethanol, Appl. Catal. A: General 464-465 (2013) 181190.

[162] K. Jirátová, F. Kovanda, J. Ludvíková, J. Balabánová, J. Klempa, Total oxidation of ethanol over layered double hydroxide-related mixed oxide catalysts: Effect of cation composition, Catal. Today 277 (2016) 61-67. [163] Y.-C. Hou, M.-W. Ding, S.-K. Liu, S.-K. Wu, Y.-C. Lin, Ni-substituted LaMnO 3 perovskites for ethanol oxidation, RSC Adv. 4 (2014) 5329-5338. 
[164] Y. Hammiche-Bellal, A. Djadoun, L. Meddour-Boukhobza, A.Benadda, A. Auroux, M.-H. Berger, F. Mernache, Effect of the preparation method on the structural and catalytic properties of spinel cobalt-iron oxide, Mater. Chem. Phys. 177 (2016) 384-397.

[165] M. Motak, Ł. Kuterasiński, P. Da Costa, B. Samojeden, Catalytic activity of layered aluminosilicates for VOC oxidation in the presence of NOx, C. R. Chimie 18 (2015) 1106-1113.

[166] T. Tsoncheva, G. Issa, J. M. López Nieto, T. Blasco, P. Concepcion, M. Dimitrova, G. Atanasova, D. Kovacheva, Pore topology control of supported on mesoporous silicas copper and cerium oxide catalysts for ethyl acetate oxidation, Micropor. Mesopor. Mater. 180 (2013) 156-161.

[167] X. Chen, S. A. C. Carabineiro, S. S. T. Bastos, P. B. Tavares, J. J. M. Órfãoa, M. F. R. Pereira, J. L. Figueiredo, Catalytic oxidation of ethyl acetate on cerium-containing mixed oxides, Appl. Catal. A: General 472 (2014) 101-112

[168] T. Tsoncheva, R. Ivanova, J. Henych, N. Velinov, M. Kormunda, M. Dimitrova, D. Paneva, M. Slušná, I. Mitov, V. Štengl, Iron modified titanium-hafnium binary oxides as catalysts in total oxidation of ethyl acetate, Catal. Comm. 81 (2016) 14-19.

[169] T. Tsoncheva, G. Issa, T. Blasco, M. Dimitrova, M. Popova, S. Hernández, D. Kovacheva, G. Atanasova, J. M. López Nieto, Catalytic VOCs elimination over copper and cerium oxide modified mesoporous SBA-15 silica, Appl. Catal. A: General 453 (2013) 1-12.

[170] M. Haidy Castaño, R. Molina, S. Moreno, Catalytic oxidation of VOCs on MnMgAlOx mixed oxides obtained by auto-combustion, J. Mol. Catal. A: Chemical 398 (2015) 358-367.

[171] D. Baojuan, L. Shumin, L. Deliang, Z. Ruozhu, L. Jingge, H. Qinglan, B. Feng, Catalytic oxidation of ethyl acetate and toluene over $\mathrm{Cu}-\mathrm{Ce}-\mathrm{Zr}$ supported $\mathrm{ZSM}-5 / \mathrm{TiO}_{2}$ catalysts, RSC Adv. 6 (2016) 53852-53859.

[172] W. Tang, X.Wu, S. Li, W. Li, Y. Chen, Porous Mn-Co mixed oxide nanorod as a novel catalyst with enhanced catalytic activity for removal of VOCs, Catal. Comm. 56 (2014) 134-138.

[173] L. Bai, F. Wyrwalski, M. Safariamin, R. Bleta, J.-F. Lamonier, C. Przybylski, E. Monflier, A. Ponchel, Cyclodextrin-cobalt (II) molecule-ion pairs as precursors to active $\mathrm{CO}_{3} \mathrm{O}_{4} / \mathrm{ZrO}_{2}$ catalysts for the complete oxidation of formaldehyde: Influence of the cobalt source, J. Catal. 341 (2016) 191-204.

[174] Y. Huang, W. Fan, B. Long, H. Li, W. Qiu, F. Zhao, Y. Tong, H. Ji, Alkali-modified non-precious metal 3D$\mathrm{NiCO}_{2} \mathrm{O}_{4}$ nanosheets for efficient formaldehyde oxidation at low temperature, J. Mater. Chem. A 4 (2016) 3648-3654.

[175] P. Liu, H. He, G. Wei, X. Liang, F. Qia, F.Tan, W. Tan, J. Zhu, R. Zhu, Effect of Mn substitution on the promoted formaldehyde oxidation over spinel ferrite: Catalyst characterization, performance and reaction mechanism, Appl. Catal. B: Environmental 182 (2016) 476-484.

[176] W. Ling, Z. Huiping, Y. Ying, Z. Xinya, Total oxidation of isopropanol over manganese oxide modified ZSM-5 zeolite membrane catalysts, RSC Adv. 5 (2015) 29482-29490.

[177] L. Sivachandiran, F. Thevenet, A. Rousseau, Isopropanol removal using MnXOYpacked bed non-thermal plasma reactor: Comparison between continuous treatment and sequential sorption/regeneration, Chem.

Eng. J. 270 (2015) 327-335.

[178] G. Lafaye, J. Barbier Jr., D. Duprez, Impact of cerium-based support oxides in catalytic wet air oxidation: Conflicting role of redox and acid-base properties, Catal. Today, 253 (2015) 89-98.

[179] V. Melang Me Nze, C. Fontaine, J. Barbier Jr, Preparation and characterization of MgAlCe mixed oxides for catalytic oxidation of acetic acid (in French), CR Chimie 20 (2017) 67-77.

[180] A. Aranzabal, B. Pereda-Ayo, M. Pilar González-Marcos, J. A. González-Marcos, R. López-Fonseca, J. R. González-Velasco, State of the art in catalytic oxidation of chlorinated volatile organic compounds, Chem.

Papers 68 (2014) 1169-1186.

[181] J. R. González-Velasco, A. Aranzabal, B. Pereda-Ayo, M. Pilar González-Marcos, J. A. González-Marcos, Catalytic oxidation of volatile organic compounds: chlorinated hydrocarbons, in "Handbook of advanced methods and processes in oxidation catalysis" (D. Duprez, F. Cavani, Eds) Imperial College Press, London, 2014. Chapter 4, pp 91-131.

[182] S. Marie-Rose, M. Taralunga, X. Chaucherie, F. Nicol, E. Fiani, T. Belin, P. Magnoux, J. Mijoin, Zeolites as alternative catalysts for the oxidation of persistent organic pollutants, in "Handbook of advanced methods and processes in oxidation catalysis" (D. Duprez, F. Cavani, Eds) Imperial College Press, London, 2014. Chapter 5, pp 132-154.

[183] S.Cao, H. Wang, F. Yu, M. Shi, S. Chen, X. Weng, Y. Liu, Z. Wu, Catalyst performance and mechanism of catalytic combustion of dichloromethane $\left(\mathrm{CH}_{2} \mathrm{Cl}_{2}\right)$ over $\mathrm{Ce}$ doped $\mathrm{TiO}_{2}$, J. Colloid Interface Sci. 463 (2016) 233241.

[184] P. Yang, Z. Meng, S. Yang, Z. Shi, R. Zhou, Highly active behaviors of $\mathrm{CeO}_{2}-\mathrm{CrOx}$ mixed oxide catalysts in deep oxidation of 1,2-dichloroethane, J. Mol. Catal. A: Chemical 393 (2014) 75-83. 
[185] P. Yang, S. Zuo, Z. Shi, F. Tao, R. Zhou, Elimination of 1, 2-dichloroethane over $(\mathrm{Ce}, \mathrm{Cr})_{\times} \mathrm{O}_{2} / \mathrm{MO}_{y}$ catalysts $(\mathrm{M}=\mathrm{Ti}, \mathrm{V}, \mathrm{Nb}, \mathrm{Mo}, \mathrm{W}$ and La), Appl. Catal. B: Environmental 191 (2016) 53-61.

[186] B. de Rivas, C. Sampedro, E. V. Ramos-Fernández, R. López-Fonseca, J. Gascon, M. Makkee, J. I.

Gutiérrez-Ortiz, Influence of the synthesis route on the catalytic oxidation of 1,2-dichloroethane over $\mathrm{CeO}_{2} / \mathrm{H}$ ZSM5 catalysts, Appl. Catal. A: General 456 (2013) 96-104.

[187] S.-X. Chen, Y. Wang, A.-P. Jia, H.-H. Liu, M.-F. Luo, J.-O. Lu, Enhanced activity for catalytic oxidation of 1,2-dichloroethane over Al-substituted $\mathrm{LaMnO}_{3}$ perovskite catalysts, Appl. Surf. Sci. 307 (2014) 178-188.

[188] Z. Boukha, J. González-Prior, B.de Rivas, J. R. González-Velasco, R. López-Fonseca, J. I. Gutiérrez-Ortiz, Synthesis, characterisation and behaviour of Co/hydroxyapatite catalysts in the oxidation of 1,2-

dichloroethane, Appl. Catal. B: Environmental 190 (2016) 125-136.

[189] J. Gonzalez-Prior, J. I. Gutierrez-Ortiz, R. Lopez-Fonseca, G. Busca, E. Finocchio, B. de Rivas, Oxidation of chlorinated alkanes over $\mathrm{CO}_{3} \mathrm{O}_{4} / \mathrm{SBA}-15$ catalysts. Structural characterization and reaction mechanism, Catal. Sci. Technol. 6 (2016) 5618-5630.

[190] P. Yang, S. Yang, Z. Shi, Z. Meng, R. Zhou, Deep oxidation of chlorinated VOCs over $\mathrm{CeO}_{2}$-based transition metal mixed oxide catalysts, Appl. Catal. B: Environmental 162 (2015) 227-235.

[191] N. Blanch-Raga, A. E. Palomares, J. Martínez-Triguero, S. Valencia, Cu and Co modified beta zeolite catalysts for the trichloroethylene oxidation, Appl. Catal. B: Environmental 187 (2016) 90-97.

[192] M. T. Nguyen Dinh, J.-M. Giraudon, J.-F. Lamonier, A. Vandenbroucke, N. De Geyter, C. Leys, R. Morent, Plasma-catalysis of low TCE concentration in air using $\mathrm{LaMnO}_{3+\delta}$ as catalyst, Appl. Catal. B: Environmental 147 (2014) 904- 911

[193] A. M. Vandenbroucke, M. Mora, C. Jiménez-Sanchidrián, F.J. Romero-Salguero, N. De Geyter, C. Leys, R. Morent, TCE abatement with a plasma-catalytic combined system using $\mathrm{MnO}_{2}$ as catalyst, Appl. Catal. B:

Environmental 156-157 (2014) 94-100.

[194] B. Zapata, F. Pedraza, M. A. Valenzuela, Catalyst screening for oxidative desulfurization using hydrogen peroxide, Catal. Today, 106 (2005) 219-221.

[195] N. D. McNamara, G. T. Neumann, E. T. Masko, J. A. Urban, J. C. Hicks, Catalytic performance and stability of (V) MIL-47 and (Ti) MIL-125 in the oxidative desulfurization of heterocyclic aromatic sulfur compounds, J. Catal. 305 (2013) 217-226.

[196] L. Gao, Y. Tang, Q. Xue, Y. Liu, Y. Lu, Hydrotalcite-like compounds derived CuZnAl oxide catalysts for aerobic oxidative removal of gasoline-range organosulfur compounds, Energy Fuels, 23 (2009) 624-630.

[197] S. Ojala, S. Pitkäaho, T. Laitinen, N. Niskala Koivikko, R. Brahmi, J. Gaálová, L. Matejova, A. Kucherov, S. Päivärinta, C. Hirschmann, T. Nevanperä, M. Riihimäki, M. Pirilä, R. L. Keiski, Catalysis in VOC Abatement, Top. Catal. 54 (2011) 1224-1256.

[198] I. Barnes, J. Hjorth, N. Mihalopoulos, Dimethyl sulfide and dimethyl sulfoxide and their oxidation in the atmosphere, Chem. Rev. 106 (2006) 940-975.

[199] V. G. Devulapelli, E. Sahle-Demessie, Catalytic oxidation of dimethyl sulfide with ozone: Effects of promoter and physico-chemical properties of metal oxide catalysts, Appl. Catal. A: General 348 (2008) 86-93. [200] E. Sahle-Demessie, V. G. Devulapelli, Oxidation of methanol and total reduced sulfur compounds with ozone over $\mathrm{V}_{2} \mathrm{O}_{5} / \mathrm{TiO}_{2}$ catalyst: Effect of humidity, Appl. Catal. A: General 361 (2009) 72-80.

[201] K. Chand Soni, S. Chandra Shekar, B. Singh, T. Gopi, Catalytic activity of Fe/ZrO2 nanoparticles for dimethyl sulfide oxidation, J. Colloid Interface Sci. 446 (2015) 226-236.

[202] J. He, . Liu, L. Li, B. Wang, J. Hu, Experimental investigation of the interaction of dimethyl sulfide/ethyl mercaptan with nano-manganese dioxide, Ind. Eng. Chem. Res. 51 (2012) 15912-15917.

[203] J. P. A. Neeft, M. Makkee, J. A. Moulijn, Catalytic oxidation of carbon black - 1. Activity of catalysts and classification of oxidation profiles, Fuels 77 (1998) 11-118.

[204] T. Jakubek, W. Kaspera, P. Legutko, P. Stelmachowski, A. Kotarba, How to efficiently promote transition metal oxides by alkali towards catalytic soot oxidation, Top. Catal. 59 (2016) 1083-1089.

[205] N. D. Wasalathanthri, T. M. SantaMaria, D. A. Kriz, S. L. Dissanayake, C.-H. Kuo, S. Biswas, S. L. Suib, Mesoporous manganese oxides for NO2 assisted catalytic soot oxidation, Appl. Catal. B: Environmental 201 (2017) 543-551.

[206] A. Mishra, R. Prasad, Preparation and application of perovskite catalysts for diesel soot emissions control: An overview, Catal. Rev. 56 (2014) 57-81.

[207] N. Labhasetwar, G. Saravanan, S. K. Megarajan, N. Manwar, R. Khobragade, P. Doggali, F. Grasset, Perovskite-type catalytic materials for environmental applications, Sci. Technol. Adv. Mater. 16 (2015) 036002. [208] Y.-F. Sun, J.-H. Li, Y.-O. Zhang, B. Hua, J.-L. Luo, Bifunctional catalyst of core-shell nanoparticles socketed on oxygen-deficient layered perovskite for soot combustion: In situ observation of synergistic dual active sites, ACS Catal. 6 (2016) 2710-2714. 
[209] C. Lee, Y. Jeon, S. Hata, J.-I. Park, R. Akiyoshi, H. Saito, Y. Teraoka, Y.-G. Shul, H. Einaga, Threedimensional arrangements of perovskite-type oxide nano-fiber webs for effective soot oxidation, Appl. Catal. B: Environmental 191 (2016) 157-164. [210] L. Wang, S. Fang, N. Feng, H. Wan, G. Guan, Efficient catalytic removal of diesel soot over Mg substituted $\mathrm{K} / \mathrm{La}{ }_{0.8} \mathrm{Ce}_{0.2} \mathrm{CoO}_{3}$ perovskites with large surface areas, Chem. Eng. J. 293 (2016) 68-74. [211] W. Shao, Z. Wang, X. Zhang, L. Wang, Z. Ma, O. Li, Z. Zhang, Promotion effects of cesium on perovskite oxides for catalytic soot combustion, Catal. Lett. 146 (2016) 1397-1407.

[212] R. Dinamarca, X. Garcia, R. Jimenez, J. L. G. Fierro, G. Pecchi, Effect of A-site deficiency in $\mathrm{LaMn}_{0.9} \mathrm{Co}_{0.1} \mathrm{O}_{3}$ perovskites on their catalytic performance for soot combustion, Mater. Res. Bull. 81 (2016) 134141.

[213] J. Wang, G. Yang, L. Cheng, E. Woo Shin, Y. Men, Three-dimensionally ordered macroporous spinel type $\mathrm{MCr}_{2} \mathrm{O}_{4}(\mathrm{M}=\mathrm{Co}, \mathrm{Ni}, \mathrm{Zn}, \mathrm{Mn})$ catalysts with highly enhanced catalytic performance for soot combustion, Catal. Sci. Technol. 5 (2015) 4594-4601.

[214] X.Niu, L. Zhou, X. Hu, W. Han, Mesoporous $\mathrm{Ce}_{x} \mathrm{Co}_{1-x} \mathrm{Cr}_{2} \mathrm{O}_{4}$ spinels: synthesis, characterization and catalytic application in simultaneous removal of soot particulate and NO, RSC Adv. 5 (2015) 52595-52601.

[215] Z. Wang, H. Zhu, L. Ai, X. Liu, M. Lv, L. Wang, Z. Ma, Z. Zhang, Catalytic combustion of soot particulates over rare-earth substituted $\mathrm{Ln}_{2} \mathrm{Sn}_{2} \mathrm{O}_{7}$ pyrochlores ( $\mathrm{Ln}=\mathrm{La}$, $\mathrm{Nd}$ and $\mathrm{Sm}$ ), J. Colloid Interface Sci. 478 (2016) 209216.

[216] B. Bassou, N. Guilhaume, K. Lombaert, C. Mirodatos, D. Bianchi, Experimental microkinetic approach of the catalytic oxidation of diesel soot by ceria using temperature-programmed experiments. Part 1: Impact and evolution of the ceria/soot contacts during soot oxidation, Energy Fuels 24 (2010) 4766-4780.

[217] A. Bueno-Lopez, Diesel soot combustion ceria catalysts, Appl. Catal. B: Environmental 146 (2014) 1-11. [218] T. Montini, M. Melchionna, M. Monai, P. Fornasiero, Fundamentals and Catalytic Applications of $\mathrm{CeO}_{2}$-Based Materials, Chem. Rev. 116 (2016) 5987-6041.

[219] A. A. Voskanyan, K.-Y. Chan, C.-Y. Vanessa Li, Colloidal solution combustion synthesis: Toward mass production of a crystalline uniform mesoporous $\mathrm{CeO}_{2}$ catalyst with tunable porosity, Chem. Mater. 28 (2016) 2768-2775.

[220] E. Aneggi, D. Wiater, C. de Leitenburg, J. Llorca, A. Trovarelli, Shape-Dependent Activity of Ceria in Soot Combustion, ACS Cat. 4 (2014) 172-181.

[221] W. Zhang, X. Niu, L. Chen, F. Yuan, Y. Zhu, Soot combustion over nanostructured ceria with different morphologies, Sci. Rep. 6 (2016) 29062.

[222] L. Soler, A.Casanovas, C. Escudero, V. Pérez-Dieste, E. Aneggi, A. Trovarelli, J.Llorca, Ambient Pressure Photoemission Spectroscopy Reveals the Mechanism of Carbon Soot Oxidation in Ceria-Based Catalysts, ChemCatChem 8 (2016) 2748-2751.

[223] E. Aneggi, N. J. Divins, C. de Leitenburg, J. Llorca, A. Trovarelli, The formation of nanodomains of $\mathrm{Ce}_{6} \mathrm{O}_{11}$ in ceria catalyzed soot combustion, J. Catal. 312 (2014) 191-194.

[224] E. Aneggi, V. Rico-Perez, C. de Leitenburg, S. Maschio, L. Soler, J. Llorca, A. Trovarelli, Ceria-zirconia particles wrapped in a 2D carbon envelope : Improved low-temperature oxygen transfer and oxidation activity, Angew. Chem. Int. Ed. 54 (2015) 14040-14043.

[225] T. Andana, M. Piumetti, S. Bensaid, N. Russo, D. Fino, R. Pirone, Nanostructured ceria-praseodymia catalysts for diesel soot combustion, Appl. Catal. B: Environmental 197 (2016) 125-137.

[226] N. Guillén-Hurtado, A. García-García, A. Bueno-López, Active oxygen by Ce-Pr mixed oxide nanoparticles outperform diesel soot combustion Pt catalysts, Appl. Catal. B: Environmental 174-175 (2015) 6o-66.

[227] T. Andana, M. Piumetti, S. Bensaid, N. Russo, D. Fino, R. Pirone, CO and Soot Oxidation over Ce-Zr-Pr Oxide Catalysts, Nanoscale Res. Lett. 11 (2016) 278.

[228] H. Li, K. Li, H. Wang, X. Zhu, Y. Wei, D. Yan, X. Cheng, K. Zhai, Soot combustion over $\mathrm{Ce}_{1-x} \mathrm{Fe}_{x} \mathrm{O}_{2-\delta}$ and $\mathrm{CeO}_{2} / \mathrm{Fe}_{2} \mathrm{O}_{3}$ catalysts: Roles of solid solution and interfacial interactions in the mixed oxides, Appl. Surf. Sci. 390 (2016) 513-525.

[229] V. Rico-Pérez, E. Aneggi, A. Bueno-López, A. Trovarelli, Synergic effect of $\mathrm{Cu} / \mathrm{Ce}_{0.5} \mathrm{Pr}_{0.5} \mathrm{O}_{2-\delta}$ and $\mathrm{Ce}_{0.5} \mathrm{Pr}_{0.5} \mathrm{O}_{2-\delta}$ in soot combustion, Appl. Catal. B: Environmental 197 (2016) 95-104.

[230] A. Bueno-López, D. Lozano-Castelló, A. J. McCueb, J. A. Anderson, NOx storage and reduction over copper-based catalysts. Part 3: Simultaneous NOx and soot removal, Appl. Catal. B: Environmental 198 (2016) 266-275.

[231] J. Li, H. Chang, L. Ma, J. Hao, R. T. Yang, Low-temperature selective catalytic reduction of NOx with $\mathrm{NH}_{3}$ over metal oxide and zeolite catalysts-A review, Catal. Today 175 (2011) 147-156. 
[232] F. Gao, J. H. Kwak, J. Szanyi, C. H. F. Peden, Current understanding of Cu-exchanged chabazite molecular sieves for use as commercial diesel engine deNOx catalysts, Top. Catal. 56 (2013) 1441-1459.

[233] B. Guan, R. Zhan, H. Lin, Z. Huang, Review of state of the art technologies of selective catalytic reduction of NOx from diesel engine exhaust, Appl. Therm. Eng. 66 (2014) 395-414.

[234] P. G.W.A. Kompio, A. Brückner, F. Hipler, G. Auer, E. Löffler, W. Grünert, A new view on the relations between tungsten and vanadium in $\mathrm{V}_{2} \mathrm{O}_{5} \mathrm{AWO}_{3} / \mathrm{TiO}_{2}$ catalysts for the selective reduction of $\mathrm{NO}$ with $\mathrm{NH}_{3}, \mathrm{~J}$.

Catal. 286 (2012) 237-247.

[235] A. Marberger, D. Ferri, M. Elsener, O. Kröcher, The significance of Lewis acid sites for the selective catalytic reduction of nitric oxide on vanadium-based catalysts, Angew. Chem. Intern. Ed. 55 (2016) 1198911994 .

[236] J. Xue, X. Wang, G. Qi, J. Wang, M. Shen, W. Li, Characterization of copper species over Cu/SAPO-34 in selective catalytic reduction of NOxwith ammonia: Relationships between active Cu sites and de-NOx performance at low temperature, J. Catal. 297 (2013) 56-64.

[237] S. A. Bates, A. A. Verma, C. Paolucci, A. A. Parekh, T. Anggara, A. Yezerets, W. F. Schneider, J. T. Miller, W. N. Delgass, F. H. Ribeiro, Identification of the active Cu site in standard selective catalytic reduction with ammonia on Cu-SSZ-13, J. Catal. 312 (2014) 87-97.

[238] T. V. W. Janssens, H. Falsig, L. F. Lundegaard, P. N. R. Vennestrøm, S. B. Rasmussen, P. G. Moses, F. Giordanino, E. Borfecchia, K. A. Lomachenko, C. Lamberti, S. Bordiga, A. Godiksen, S. Mossin, P. Beato, A consistent reaction scheme for the selective catalytic reduction of nitrogen oxides with ammonia, ACS Catal. 5 (2015) $2832-2845$.

[239] J-C. Chen, G-C. Fang, S-S. Shi, Activities of different metal oxide catalysts on NO reduction and CO oxidation, Int. J. Environment and Pollution, 37 (2009) 86-96.

[240] K. Frey, D.J. Schmidt, W.F. Schneider, Implications of coverage-dependent $\mathrm{O}$ adsorption for catalytic NO oxidation on the late transition metals, Catal. Sci. Technol. 4 (2014) 4356-4365.

[241] I. Atribak, I. Such-Basáñez, A. Bueno-López, A. García- García, Comparison of the catalytic activity of $\mathrm{MO}_{2}(\mathrm{M}=\mathrm{Ti}, \mathrm{Zr}, \mathrm{Ce})$ for soot oxidation under $\mathrm{NOx} / \mathrm{O}_{2}$, J. Catal. 250 (2007) 75-84.

[242] Z. Wu, M. Li M, S.H. Overbury, On the structure dependence of $\mathrm{CO}$ oxidation over $\mathrm{CeO} 2$ nanocrystals with well-defined surface planes. J Catal 285, (2012), 61-73.

[243] I. Atribak, B. Azambre, A. Bueno López, A. García-García, Effect of NOx adsorption/desorption over ceria-zirconia catalysts on the catalytic combustion of model soot, Applied Catal. B. 92 (2009) 126-137.

[244] I. Atribak, A. Bueno López, A. García-García, Combined removal of diesel soot particulates and NOx over $\mathrm{CeO}_{2}-\mathrm{ZrO}_{2}$ mixed oxides, J. Catal. 259 (2008) 123-132.

[245] M. Adamowska, S. Muller, P. Da Costa, A. Krzton, P. Burg, Correlation between the surface properties and deNOx activity of ceria-zirconia catalysts, Appl. Catal., B: Environmental 74 (2007) 278-289.

[246] M. Yu. Sinev, G. W. Graham, L. P. Haack and M. Shelef, Kinetic and structural studies of oxygen availability of the mixed oxides $\operatorname{Pr}_{1-x} \mathrm{M}_{x} \mathrm{O}_{\mathrm{y}}(\mathrm{M}=\mathrm{Ce}$ or $\mathrm{Zr}$ ), J. Mater. Res. 11 (1996) 1960-1971.

[247], J. Gimenez-Manogil, N. Guillen-Hurtado, N, S. Fernandez-Garcia, X.W. Chen, J.J. Calvino-Gamez, A. Garcia-Garcia, Ceria-Praseodymia Mixed Oxides: Relationships Between Redox Properties and Catalytic Activities Towards NO Oxidation to $\mathrm{NO}_{2}$ and CO-PROX Reactions, Topics in Catalysis 59 (2016) 1065-1070. [248] J. Giménez-Mañogil, A. Bueno-López, A. García-García, Preparation, characterisation and testing of $\mathrm{CuO} / \mathrm{Ce}_{0.8} \mathrm{Zr}_{0.2} \mathrm{O}_{2}$ catalysts for $\mathrm{NO}$ oxidation to $\mathrm{NO}_{2}$ and mild temperature diesel soot combustion, Appl. Catal. B. 152-153 (2014) 99-107.

[249] Z. Wang, X. Sun, J.Liu, X. Li, The NO oxidation performance over $\mathrm{Cu} / \mathrm{Ce}_{0.8 \mathrm{Z}} \mathrm{Zr}_{0.2} \mathrm{O}_{2}$ catalyst, Surfaces and Interfaces 6 (2017) 103-109.

[250] F. Lin, X. Wu, D. Weng, Effect of barium loading on $\mathrm{CuO}_{x}-\mathrm{CeO}_{2}$ catalysts: NOx storage capacity, NO oxidation ability and soot oxidation activity, Catal. Today 175 (2011) 124-132.

[251] H-Y. Chen, Z. Wei, M. Kollar, F. Gao, Y. Wang, J. Szanyi, C.H.F. Peden, NO oxidation on zeolite supported Cu catalysts: Formation and reactivity of surface nitrates, Catal. Today 267 (2016) 17-27.

[252] F. Gao, E. D. Walter, M. Kollar, Y. Wang, J. Szanyi, C.H.F. Peden, Understanding ammonia selective catalytic reduction kinetics over Cu/SSZ-13 from motion of the Cu ions, J. Catal. 319 (2014) 1-14

[253] A.A.Verma, S.A. Bates, T. Anggara, C. Paolucci, A.A. Parekh, K. Kamasamudram, A. Yezerets, J.T. Miller, W.N. Delgass, W.F. Schneider, F.H. Ribeiro, NO oxidation: A probe reaction on Cu-SSZ-13, J. Catal. 312 (2014) 179-190.

[254] C. Zhou, X. Liu, C. Wu, Y. Wen, Y. Xue, R. Chen, Z. Zhang, B. Shan, H. Yin, W.G. Wang, NO oxidation catalysis on copper doped hexagonal phase $\mathrm{LaCoO}_{3}$ : a combined experimental and theoretical study,

Phys.Chem.Chem.Phys., 16 (2014) 5106-5112. 
[255] K. Shiba, H. Hinode, M. Wakihara, Catalytic oxidation of $\mathrm{NO}$ to $\mathrm{NO}_{2}$ over $\mathrm{Cr} / \mathrm{TiO}{ }_{2}$ and $\mathrm{Cu} / \mathrm{TiO} \mathrm{O}_{2}$ under oxidizing atmosphere, React. Kinet. Catal. Lett. 58 (1996) 133-137.

[256] M.F. Irfan, J.H. Goo, S.D. Kim, $\mathrm{Co}_{3} \mathrm{O}_{4}$ based catalysts for $\mathrm{NO}$ oxidation and $\mathrm{NO}_{x}$ reduction in fast $\mathrm{SCR}$ process, Appl. Catal. B: Environmental 78 (2008) 267-274.

[257] Y. Huang, D. Gao, Z. Tong, J. Zhang, H. Luo, Oxidation of NO over cobalt oxide supported on mesoporous silica J. Nat. Gas Chem. 18 (2009) 421-428.

[258] D.S. Kim, Y.H. Kim, J.E. Yie, E.D. Park, NO oxidation over supported cobalt oxide catalysts, Korean J. Chem. Eng. 27 (2010) 49-54.

[259] S.K. Megarajan, S. Rayalu, Y. Teraoka, N. Labhsetwar, High NO oxidation catalytic activity on non-noble metal based cobalt-ceria catalyst for diesel soot oxidation, J. Mol. Cat. A. 385 (2014) 112-118.

[260] E. Park, S. Chin, J. Jeong, J. Jurng, Low-temperature NO oxidation over Mn/TiO2 nanocomposite synthesized by chemical vapor condensation: effects of $\mathrm{Mn}$ precursor on the surface $\mathrm{Mn}$ species, Microporous and Mesoporous Materials 163 (2012) 96-101.

[261] Z.B. Wu, N.A. Tang, L. Xiao, Y. Liu, H.C. Wang, MnOx/TiO2 composite nanoxides synthesized by deposition-precipitation method as a superior catalyst for NO oxidation, J. Colloid Interface Sci. 352 (2010)

$143-148$

[262] Z.H. Chen, F.R. Wang, H. Li, Q. Yang, L.F. Wang, X.H. Li, Low-temperature selective catalytic reduction of $\mathrm{NO}$ x with $\mathrm{NH}_{3}$ over Fe-Mn mixed-oxide catalysts containing $\mathrm{Fe}_{3} \mathrm{Mn}_{3} \mathrm{O}_{8}$ phase, Ind. Eng. Chem. Res. 51 (2012) 202-212.

[263] W.W. Zhao, C.T. Li, P. Lu, Q.B. Wen, Y.P. Zhao, X. Zhang, C.Z. Fan, S.S. Tao, Iron, lanthanum and manganese oxides loaded on $\mathrm{Y}-\mathrm{Al}_{2} \mathrm{O}_{3}$ for selective catalytic reduction of $\mathrm{NO}$ with $\mathrm{NH}_{3}$ at low temperature, Environ. Technol. 34 (2013) 81-90.

[264] M. Zhang, C. Li, L. Qu, M. Fu, G. Zeng, C. Fan, J. Ma, F. Zhan, Catalytic oxidation of NO with Oz over $\mathrm{FeMnOx} / \mathrm{TiO}_{2}$ : Effect of iron and manganese oxides loading sequences and the catalytic mechanism study, Appl. Surf. Sci. 300 (2014) 58-65.

[265] Y. Wen, C. Zhang, H. He, Y. Yu, Y. Teraoka, Catalytic oxidation of nitrogen monoxide over $\mathrm{La}_{1-x} \mathrm{Ce}_{x} \mathrm{CoO}_{3}$ perovskites, Catal. Today 126 (2007) 400-405.

[266] C.H. Kim, G. Qi, K. Dahlberg, W. Li, Strontium-doped perovskites rival platinum catalysts for treating NOx in simulated diesel exhaust, Science 237 (2010) 1624-1627.

[267] N. Akter, L. Han, D. Huaman, Y. Kang, T. Kim, $\mathrm{NO}$ and $\mathrm{NH}_{3}$ Oxidation over zeolite materials, Materials Today: Proceedings, 3 (2016) 550-555.

[268] J.A. Loiland, R. F. Lobo, Low temperature catalytic NO oxidation over microporous materials, J Catal. 311 (2014) 412-423.

[269] N. Artioli, R.F. Lobo, E. Iglesia, Catalysis by confinement: Enthalpic stabilization of NO oxidation transition states by micropororous and mesoporous siliceous materials, J. Phys. Chem C., 117(40) (2013) 20666-20674.

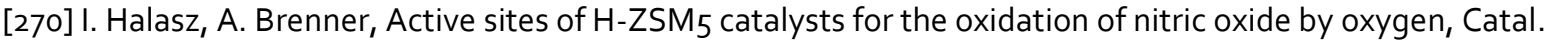
Letters, 34 (1995) 151-161.

[271] P.S. Metkar, V. Balakotaiah, M.P. Harold, Experimental and kinetic modeling study of NO oxidation: Comparison of Fe and Cu-zeolite catalysts, Catalysis Today, 184 (2012) 115-128.

[272] N.I. II'chenko, Catalytic Oxidation of Ammonia, Russ. Chem. Rev. 45 (12) (1976) 1119-1134.

[273] N.N. Sazonova, A.V. Simakov, H. Veringa, Selective catalytic oxidation of ammonia to nitrogen, React.

Kinet. Catal. Lett. 57(1) (1996) 71-79.

[274] R.Q. Long and R.T. Yang, Selective catalytic oxidation of ammonia to nitrogen over $\mathrm{Fe}_{2} \mathrm{O}_{3}-\mathrm{TiO}_{2}$

prepared with a sol-gel method, J. Catal. 207 (2002) 158-165.

[275] L. Gang, B.G. Anderson, J.V. Grondelle, R.A. van Santen, $\mathrm{NH}_{3}$ oxidation to nitrogen and water at low temperatures using supported transition metal catalysts, Catal. Today 61 (2000) 179-185.

[276] Y. Li, J.N. Armor, Selective $\mathrm{NH}_{3}$ oxidation to $\mathrm{N}_{2}$ in a wet stream, Appl. Catal. B: Environmental 13 (1997) 131-139.

[277] M. Koebel, M. Elsener, M. Kleemann, Urea-SCR: a promising technique to reduce NOx emissions from automotive diesel engines, Catal. Today 59 (2000) 335-235.

[278] M. Koebel, E.O. Strutz, Thermal and hydrolytic decomposition of urea for automotive selective catalytic reduction systems: Thermochemical and practical aspects, Ind. Eng. Chem. Res. 42 (2003) 2093-2100.

[279] A.M. Berhard, D. Peitz, M. Elsener, T. Schildhaver, O. Kröcher, Catalytic urea hydrolysis in the selective catalytic reduction of NOx: catalyst screening and kinetics on anatase $\mathrm{TiO}_{2}$ and $\mathrm{ZrO}_{2}$, Catal. Sc. Technol. 3

(2013) 942-951. 
[280] P.M. Schaber, J. Colson, S. Higgins, D. Thielen, B. Anspach, J. Braver, Thermal decomposition (pyrolysis) of urea in an open reaction vessel, Thermochim. Acta. 424 (2004) 131-142.

[281] M. Seneque, F. Can, D. Duprez, X. Courtois, Use of a $\mu$-scale synthetic gas bench for direct comparison of Urea-SCR and $\mathrm{NH}_{3}$-SCR reactions over an oxide based powdered catalyst, Catalysts 5 (2015) 1535-1553.

[282] M. Seneque, F. Can, D. Duprez, X. Courtois, NOx Selective catalytic reduction ( $\mathrm{NO}_{x}-\mathrm{SCR}$ ) by urea: Evidence of the reactivity of $\mathrm{HNCO}$, including a specific reaction pathway for NOx reduction involving $\mathrm{NO}+$ $\mathrm{NO}_{2}$, ACS Catal., 6 (7) (2016) 4064-4067.

[283] D. Fino, N. Russo, G. Saracco, V. Specchia, Removal of NOx and diesel soot over catalytic traps based on spinel-type oxides, Powder Technology, 180 (2008) 74-78.

[284] Z. Say, M. Tohumeken, E. Ozensoy, NOx storage and reduction pathways on zirconia and titania functionalized binary and ternary oxides as $\mathrm{NO}_{x}$ storage and reduction (NSR) systems, Catal. Today, 231, 2014, 135-144.

[285] R. You, Y. Zhang, D. Liu, M. Meng, L. Zheng, J. Zhang, T. Hu, YCeZrO ternary oxide solid solution supported nonplatinic lean-burn NOx trap catalysts using $\mathrm{LaCoO}_{3}$ perovskite as active phase, J. Phys. Chem. C., 118 (44) (2014) 25403-25420.

[286] F. Garin, Mechanism of NOx decomposition, Appl. Catal. A: General. 222 (2001) 183-219.

[287] A. Ogata, A. Obuchi, K. Mizuno, A. Ohi, H. Ohuchi, Active sites and redox properties of supported palladium catalysts for nitric oxide direct decomposition, J. Catal. 144 (1993) 452-459.

[288] M. Haneda, Y. Kintaichi, I. Nakamura, T. Fujitan, H. Hamada, Effect of surface structure of supported palladium catalysts on the activity for direct decomposition of nitrogen monoxide, J. Catal. 218 (2003) 405410.

[289] A. Pulido, P. Nachtigall, Correlation between catalytic activity and metal cation coordination: NO decomposition over Cu/Zeolites, ChemCatChem, 1 (2009) 449-453.

[290] M. Iwamoto, H. Hamda, Removal of nitrogen monoxide from exhaust gases through novel catalytic processes, Catal. Today, 10 (1991), 57-71.

[291] E.R.S. Winter, The catalytic decomposition of nitric oxide by metallic oxides, J. Catal., 22 (1971), 158-170. [292] G.K. Boreskov, Forms of oxygen bonds on the surface of oxidation catalysts, Discuss. Faraday Soc., 41 (1966), 263-276.

[293] S. Shin, Y. Hatakeyama, K. Ogawa, K. Shimomura, Catalytic decomposition of NO over brownmilleritelike compounds, $\mathrm{Ca}_{2} \mathrm{Fe}_{2} \mathrm{O}_{5}$ and $\mathrm{Sr}_{2} \mathrm{Fe}_{2} \mathrm{O}_{5}$, Mater. Res. Bull., 14 (1979) $133-136$.

[294] H. Shimada, S. Miyama, H. Kuroda, Decomposition of nitric oxide over Y-Ba-Cu-O mixed oxide catalysts, Chem. Lett., 17 (1988) 1797-1800.

[295] H. Yasuda, N. Mizuno, M. Misono, Role of valency of copper in the direct decomposition of nitrogen monoxide over well characterized $\mathrm{La}_{2 x} \mathrm{~A}^{\prime}{ }_{x} \mathrm{Cu}_{1-y} \mathrm{~B}_{y}^{\prime} \mathrm{O}_{41}$ J. Chem. Soc., Chem. Commun., 16 (1990) 1094-1096. [296] N. Imanaka, T. Masui, H. Masaki, Direct decomposition of nitric oxide over C-Type Cubic $\left(\mathrm{Gd}_{1-x-}\right.$ y $\left.\mathrm{Y}_{x} \mathrm{Bay}_{\mathrm{y}}\right)_{2} \mathrm{O}_{3-\mathrm{y}}$ solid solutions, Adv. Mater., 19 (2007) 3660-3663.

[297] H. Masaki, T. Masui, N. Imanaka, Direct decomposition of nitric oxide into nitrogen and oxygen over Ctype cubic $\mathrm{Y}_{2} \mathrm{O}_{3}-\mathrm{ZrO}_{2}$ solid solutions, J. Alloys Compd., 451 (2008) 406-409.

[298] N. Imanaka, T. Masui, Advances in direct NOx decomposition catalysts, Appl. Catal. A: General, 431-432 (2012) 1-8.

[299] M.A. Vannice, A.B. Walters, X. Zhang, The kinetics of NOx decomposition and NO reduction by $\mathrm{CH}_{4}$ over $\mathrm{La}_{2} \mathrm{O}_{3}$ and $\mathrm{Sr} / \mathrm{La}_{2} \mathrm{O}_{3}$, J. Catal., 159 (1996) $119-126$.

[300] S. Xie, G. Mestl, M.P. Rosynek, J.H. Lunsford, Decomposition of nitric oxide over barium oxide supported on magnesium oxide. 1. Catalytic results and in situ Raman spectroscopic evidence for a barium-nitro intermediate, J. Am. Chem. Soc., 119 (1997) 10186-10191.

[301] S. Xie, M.P. Rosynek, J.H. Lunsford, Catalytic Reactions of NO over o-7 mol\% Ba/MgO Catalysts: I. The direct decomposition of NO, J. Catal., 188 (1999) 24-31.

[302] H. Iwakuni, Y. Shinmyo, H. Yano, H. Matsumoto, T. Ishihara, Direct decomposition of $\mathrm{NO}$ into $\mathrm{N}_{2}$ and $\mathrm{O}_{2}$ on $\mathrm{BaMnO}_{3}$-based perovskite oxides, Appl. Catal. B: Environmental, 74 (2007) 299-306.

[303] K. Goto, H. Matsumoto, T. Ishihara, Direct Decomposition of NO on Ba/Ba-Y-O Catalyst, Top. Catal., 52 (2009) 1776-1780.

[304] T. Ishihara, K. Goto, Direct decomposition of $\mathrm{NO}$ over $\mathrm{BaO} / \mathrm{Y}_{2} \mathrm{O}_{3}$ catalyst, Catal. Today, 164 (2011) 484488.

[305] K. Goto, T. Ishihara, Direct decomposition of $\mathrm{NO}$ into $\mathrm{N}_{2}$ and $\mathrm{O}_{2}$ over $\mathrm{Ba}_{3} \mathrm{Y}_{3.4} \mathrm{Sc}_{0.6} \mathrm{O}_{9,}$ Appl. Catal. A: Gen., 409-410 (2011) 66-73.

[306] S. Iwamoto, R. Takahashi, M. Inove, Direct decomposition of nitric oxide over Ba catalysts supported on CeO2-based mixed oxides, Appl. Catal. B: Environmental, 70 (2007) 146-150. 
[307] W.J. Hong, S. Iwamoto, S. Hosokawa, K. Wada, H. Kanai, M. Inove, Effect of Mn content on physical properties of $\mathrm{CeO}_{x}-\mathrm{MnO}_{y}$ support and $\mathrm{BaO}-\mathrm{CeO}_{x}-\mathrm{MnO}_{y}$ catalysts for direct $\mathrm{NO}$ decomposition, J. Catal. 277 (2011) 208-216.

[308] W.J. Hong, M. Ueda, S. Iwamoto, S. Hosokawa, K. Wada, H. Kanai, H. Deguchi, M. Inoue, Effect of Fe content on physical properties of $\mathrm{BaO}-\mathrm{CeO} x-\mathrm{FeO} y$ catalysts for direct NO decomposition, Appl. Catal. B: Environmental, 106 (2011) 142-148.

[309] Y. Doi, M. Haneda, M. Ozawa, Direct decomposition of NO an Ba catalysts supported on rare earth oxides, J. Mol. Cat. A. 383-384 (2014) 70-76.

[310] F. Arena, R. Di Chio, B. Gumina, L. Spadaro, G. Trunfio, Recent advances on wet air oxidation catalysts for treatment of industrial wastewaters, Inorg. Chim. Acta 431 (2015) 101-109.

[311] G. Jing, M. Luan, T. Chen, Progress of catalytic wet air oxidation technology, Arabian J. Chem. 9 (2016) $\mathrm{S}_{1208-S_{1213}}$

[312] J. Fu, G. Z. Kyzas, Wet air oxidation for the decolorization of dye wastewater: An overview of the last two decades, Chin. J. Catal. 35 (2014) 1-7.

[313] F. Xie, L. Wang, K. Wang, D. Hua, W. Li, Preparation of $\mathrm{CuO} / \mathrm{SiO}_{2}$ hollow spheres for catalytic oxidation of phenol, Catal. Surv. Asia 20 (2016) 74-81.

[314] X. Zhong, J. Barbier Jr., D. Duprez, H. Zhang, S. Royer, Modulating the copper oxide morphology and accessibility by using micro-/mesoporous SBA-15 structures as host support: Effect on the activity for the CWPO of phenol reaction, Appl. Catal. B: Environmental 121-122 (2012) 123-134.

[315] O. P. Taran, A. B. Ayusheev, O. L. Ogorodnikova, I. P. Prosvirin, L. A. Isupova, V. N. Parmon, Perovskitelike catalysts $\mathrm{LaBO}_{3}(\mathrm{~B}=\mathrm{Cu}, \mathrm{Fe}, \mathrm{Mn}, \mathrm{Co}, \mathrm{Ni})$ for wet peroxide oxidation of phenol, Appl. Catal. B: Environmental 180 (2016) 86-93.

[316] H. Min, X. Ran, J. Fan, Y. Sun, J. Yang, W. Teng, W.-X. Zhang, G. Li, D. Zhao, Preparation of a mesoporous Cu-Mn/TiO 2 composite for the degradation of Acid Red 1, J. Mater. Chem. A 3 (2015) 7399-7405. [317] M. Das, K. G. Bhattacharyya, Oxidation of Rhodamine B in aqueous medium in ambient conditions with raw and acid-activated $\mathrm{MnO}_{2}, \mathrm{NiO}, \mathrm{ZnO}$ as catalysts, J. Mol. Catal. A: Chemical 391 (2014) 121-129.

[318] Anushree, S. Kumar, C. Sharma, Synthesis, characterization and catalytic wet air oxidation property of mesoporous $\mathrm{Ce}_{1-x} \mathrm{Fe}_{\mathrm{X}} \mathrm{O}_{2}$ mixed oxides, Mater. Chem. Phys. 155 (2015) 223-231.

[319] Anushree, S. Kumar, C. Sharma, $\mathrm{Ce}_{1-x} \mathrm{Co}_{x} \mathrm{O}_{y}$ nanocatalysts: synthesis, characterization and environmental application, Catal. Sci. Technol. 6 (2016) 2101-2111.

[320] M. Zhu, G. Diao, Synthesis of porous $\mathrm{Fe}_{3} \mathrm{O}_{4}$ nanospheres and its application for the catalytic degradation of xylenol orange, J. Phys. Chem. C, 115 (2011) 18923-18934.

[321] Z. Wan, J. Wang, Ce-Fe-reduced graphene oxide nanocomposite as an efficient catalyst for sulfamethazine degradation in aqueous solution, Environ. Sci. Pollut. Res. 23 (2016) 18542-18551.

[322] J. Han, H.-Y. Zeng, S. Xu, C.-R. Chen, X.-J. Liu, Catalytic properties of CuMgAlO catalyst and degradation mechanism in CWPO of methyl orange, Appl. Catal. A: General 527 (2016) 72-80.

[323] H. Li, Y. Li, L. Xiang, Q. Huang, J. Qiu, H. Zhang, M. V. Sivaiah, F. Baron, J. Barrault, S. Petit, S. Valange, Heterogeneous photo-Fenton decolorization of Orange II over Al-pillared Fe-smectite: Response surface approach, degradation pathway, and toxicity evaluation, J. Hazard. Mater. 287 (2015) 32-41.

[324] F. Schmit, L. Bois, F. Chassagneux, C. Descorme, Catalytic wet air oxidation of methylamine over supported manganese dioxide catalysts, Catal. Today 258 (2015) 570-575. 